\title{
Safety Comparison of Smart and Standard Channels Based on
}

\section{Sight Distance and Conflicts}

by

Constance Nagawa Sentongo

A thesis submitted to the Faculty of Graduate and Postdoctoral Affairs in partial fulfillment of the requirements for the degree of

Master of Applied Science

In

Civil Engineering

Carleton University

Ottawa, Ontario

(C) 2021

Constance Nagawa Sentongo 


\begin{abstract}
Vehicle movements through intersections can be improved by channelization, by including separate channels for the right turn movements. A standard channel provides an entrance angle greater than $90^{\circ}$, while a smart channel design is a modified right-turn channel that decreases the channelized right turn to approximately $70^{\circ}$. This study compares whether the different channel configurations have different safety performance based on conflicts and sight distance.

Vehicle interactions were manually identified using Post Encroachment Time (PET). A total of 805 interactions with PET less than or equal to 3s. were observed, involving the total movements of 58,546 right-turn and through vehicles on eight different channels.

The means of the five safety performance parameters in this study were significantly higher at standard channels than at smart channels. Ordinal logistic regression results indicated that the probability of a potential conflict having a high severity is $4.1 \%$ higher at smart channels than at standard channels
\end{abstract}




\section{Acknowledgements}

Firstly, I thank God for guiding me throughout this thesis journey and guiding me to completion.

The advice, support, and guidance from my supervisors, Dr. Yasser Hassan and Dr. Ali Kassim, is much appreciated throughout this thesis. Their timely feedback significantly enabled me to finish within the required time frame. I am very grateful to Dr. Ali Kassim, for his supervision and guidance, from collaborating with the City of Ottawa to provide the videos from which data was extracted to his continued support during the process. My sincere appreciation goes to Dr. Yasser Hassan for his encouragement and thorough in-depth feedback for each section throughout the writing process.

I truly appreciate the people that helped me before and during the data extraction process by identifying videos from the City of Ottawa that could be applied to this study, despite the limitations and reviewing the extracted data to improve measurement accuracy.

I am very grateful to my friends who have stood by me and offered help whenever I needed assistance, Sophie Mwinyi, Catherine Namugaya, Catherine Sentongo, Flavia Nshemerirwe, Daniel Kyobe and Mohannad Alyamani. I am also very grateful to everyone that gave moral support.

Finally, I extend my gratitude to my lovely parents and sister for their unconditional support and sacrifices they made to make sure that I had a conducive environment to complete this thesis successfully and the constant positive reminders whenever I was discouraged or hit a roadblock. 


\section{Table of Contents}

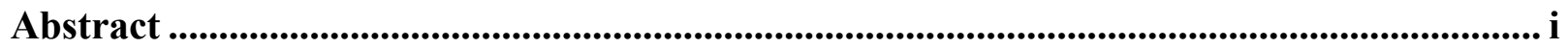

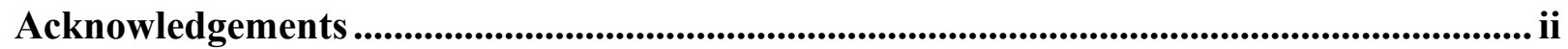

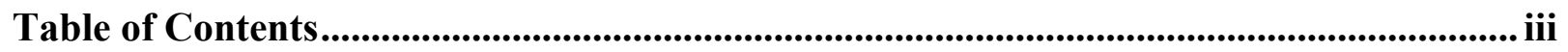

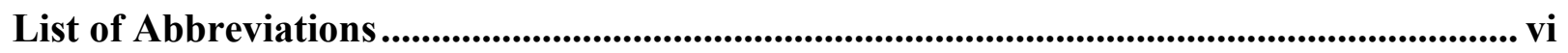

List of Tables........................................................................................................................ vii

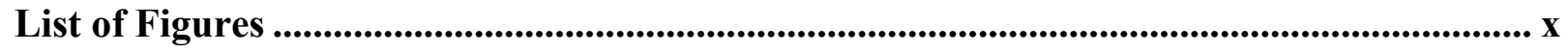

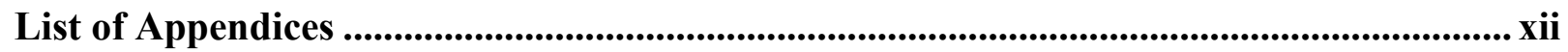

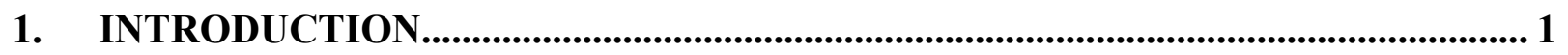

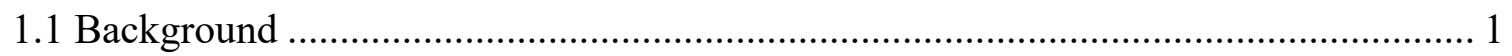

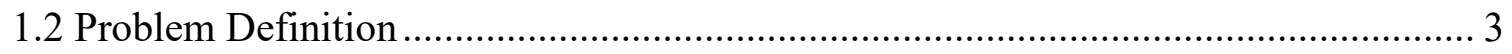

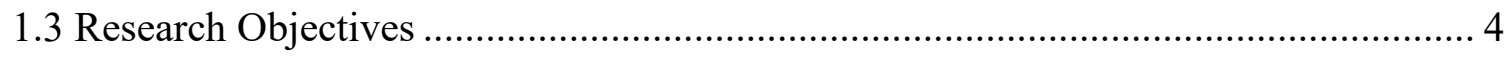

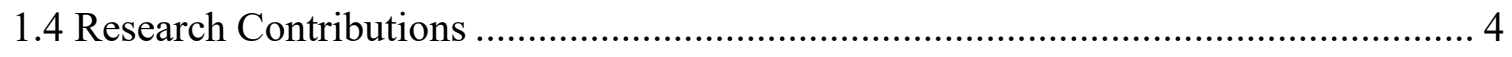

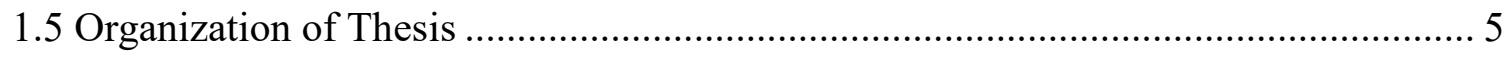

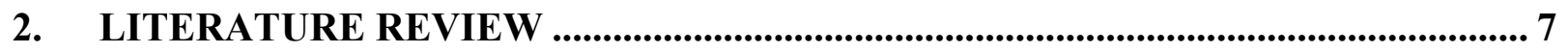

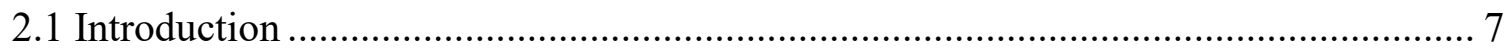

2.2 Sight Distance at a Channelized Right-turn Lane ............................................. 10

2.3 Vehicle Safety at Channelized Intersections ................................................... 14

2.3.1 Conflicts as a Surrogate Measure for Safety ............................................ 15 
2.3.2 Post Encroachment Time

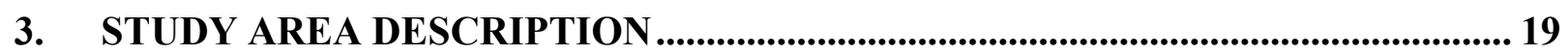

3.1 Study Area

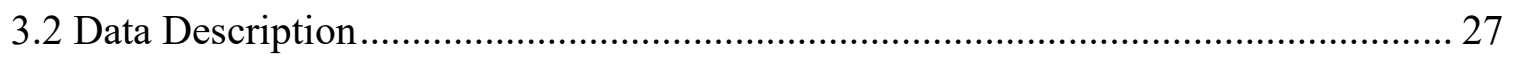

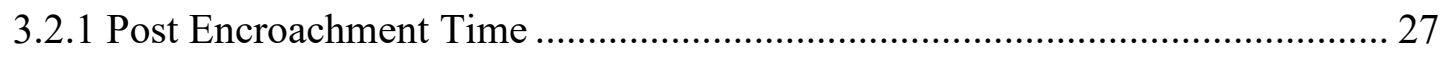

3.2.2 Intersection Sight Distance ...................................................................... 28

4. POST ENCROACHMENT TIME METHODOLOGY …................................................ 30

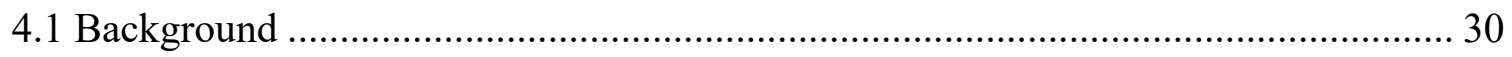

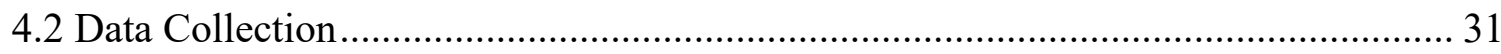

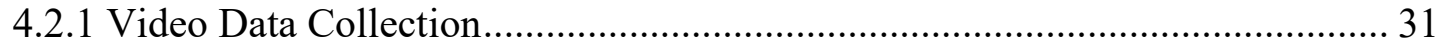

4.2.2 Method of Measuring PET ............................................................................ 32

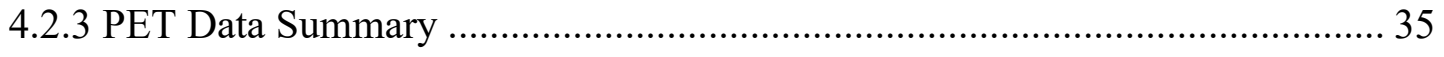

5. SIGHT DISTANCE METHODOLOGY ........................................................................ 37

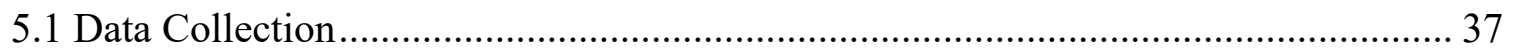

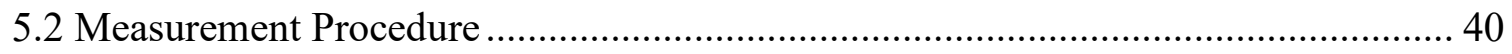

5.2.1 Sightline Distance and Right Turning Sightline Angle ................................... 40

5.2.2 Sight Distance Triangle Leg ........................................................................ 45

5.2.3 Time Headway Measurement ...................................................................... 47

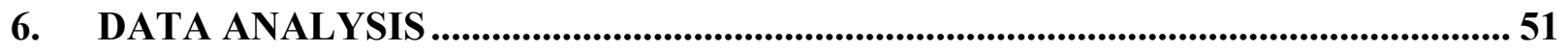

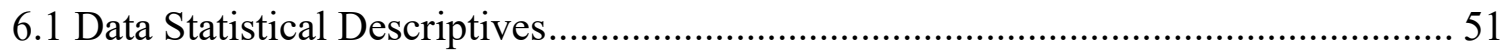




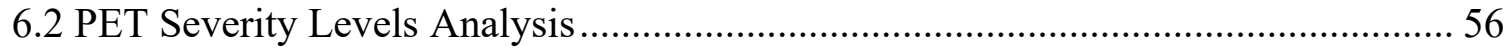

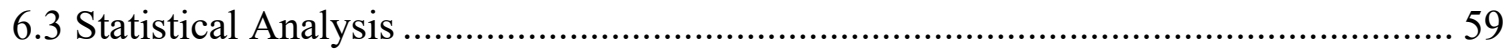

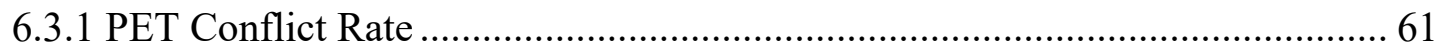

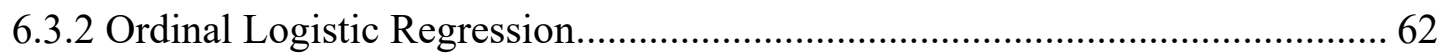

7. CONCLUSIONS AND RECOMMENDATIONS ................................................ 69

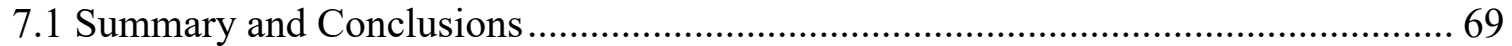

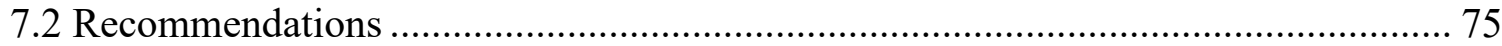

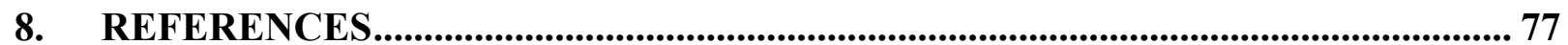




\section{List of Abbreviations}

AASHTO American Association of State Highway and Transportation

ADA Americans with Disabilities Act

AIC Akaike Information Criterion

AMFs Accident Modification Factors

ANOVA Analysis of Variance

EBR Eastbound Right-turn

FHWA Federal Highway Administration

ISD Intersection Sight Distance

MFCM Manual Frame Count Measurement Method

NBR Northbound Right- turn

PET Post Encroachment Time

TAC Transport Association of Canada

VVE Vehicle - Vehicle Event

WBR Westbound Right-turn

SBR Southbound Right-turn

SSD Stopping Sight Distance

SDTL Sight Distance Triangle Leg

SPSS Statistical Product for the Social Sciences 


\section{List of Tables}

Table 3-1: Intersections direction of travel and channel location................................................ 21

Table 3-2: Average Annual Daily Traffic at each intersection (City of Ottawa, 2020) ............... 22

Table 4-1: Day of camera set up for each intersection .............................................................. 32

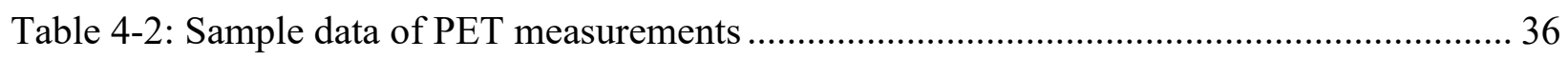

Table 4-3: Total vehicle volume observed at each intersection.................................................... 36

Table 5-1: Intersection sight distance measurements at Riverside and Brookefield ..................... 47

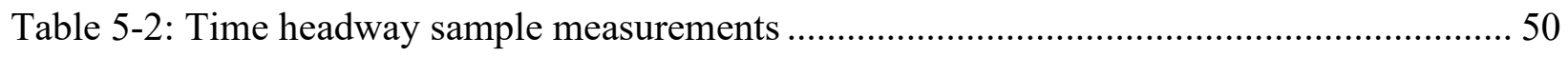

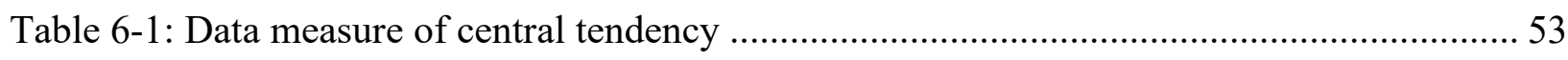

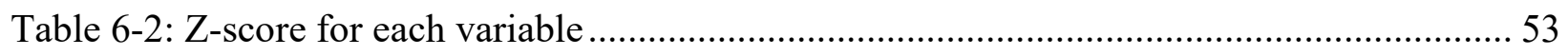

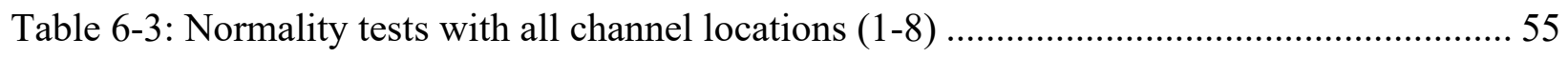

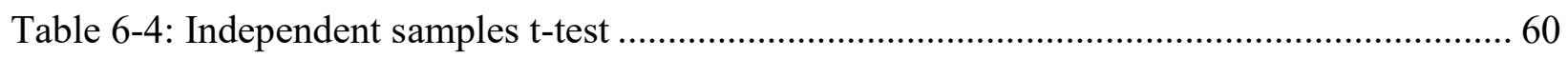

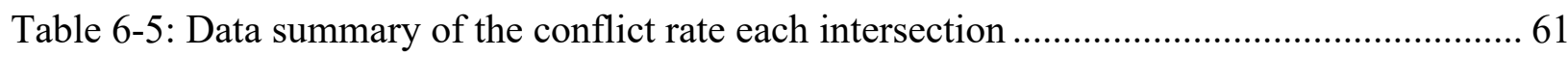

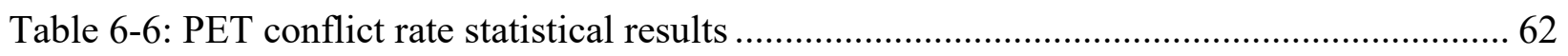

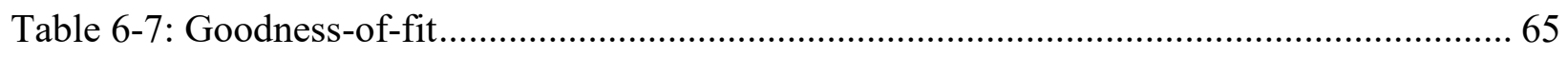

Table 6-8: Test of parallel lines to test proportional odds assumption .......................................... 66

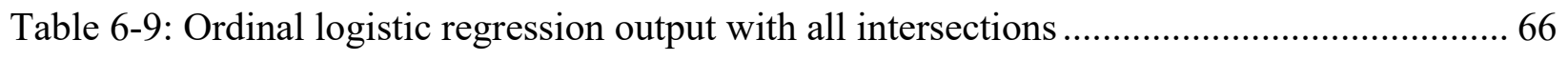

Table 6-10: Calculated probability of each severity level at a smart channel .............................. 67

Table 6-11: Calculated probability for each severity level at a standard channel ........................6 68

Table B-1: Data descriptives at all standard channel locations .................................................. 86

Table B-2: Data descriptives for all smart channel locations ....................................................... 87

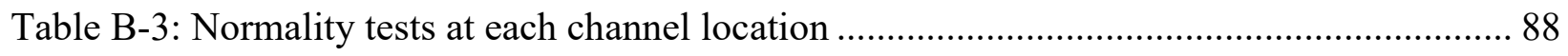

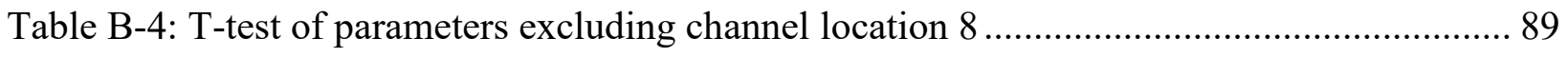


Table B-5: T-test of parameters excluding channel location 7 ................................................... 90

Table B-6: ANOVA with all channel locations included .......................................................... 92

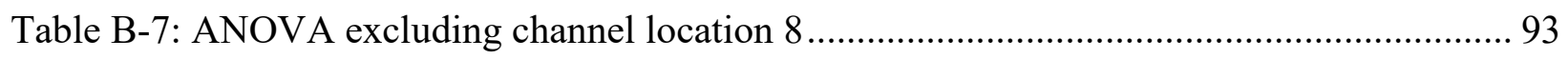

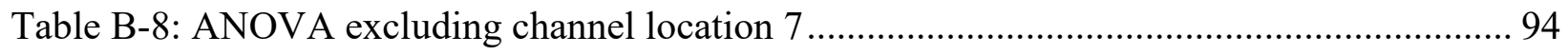

Table C-1: PET descriptives for each smart channel intersection ............................................... 96

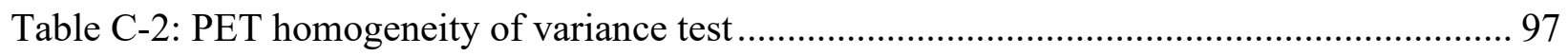

Table C-3: PET test of between subjects effects for each channel type ...................................... 98

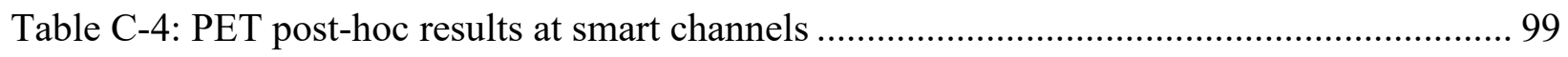

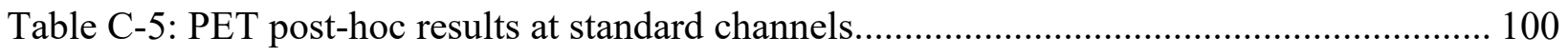

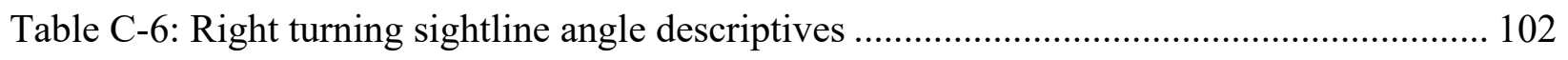

Table C-7: Right turning sightline angle homogeneity of variance test ..................................... 102

Table C-8: Right turning sightline angle tests of between subjects......................................... 103

Table C-9: Right turning sightline angle post-hoc tests. a) standard channels ,b) smart channels 105

Table C-10: Sightline distance descriptives for each channel type ………………................... 107

Table C-11: Sightline distance homogeneity of variance test .................................................. 107

Table C-12: Sightline distance tests of between subjects effects .............................................. 108

Table C-13: Sightline distance post-hoc tests. a) standard channels, b) smart channels ............ 110

Table C-14: SDTL descriptive statistics at each channel location ........................................... 112

Table C-15: SDTL homogeneity of variance tests …………................................................. 113

Table C-16: SDTL Tests of between subjects effects at smart and standard channels............... 113

Table C-17: SDTL post-hoc results a) standard channel, b) smart channels ............................... 115

Table C-18: Time headway descriptives at intersections at smart and standard channels ......... 117

Table C-19: Time headway homogeneity of variance test at smart and standard channels ....... 118 
Table C-20: Test of between subjects effects results at smart and standard channels.............. 118

Table C-21: Time headway post-hoc results at a) standard, b) smart................................. 120 


\section{List of Figures}

Figure 2-1: Geometric realignment for smart channels (Autey et al., 2012) ............................ 9

Figure 2-2: Line of sight envelope curve (Liu et al., 2010) ................................................ 12

Figure 2-3: Conflict movement scenarios between motor vehicles and cyclists at a signalized intersection. (a) right-turn motor vehicle vs cyclists. (b) Through motor vehicle versus left-turning cyclists. (c) Left-turning motor vehicle versus through cyclists (Kassim et al., 2014) .............. 18

Figure 3-1: Location of study intersections (Google Earth 2020) ......................................... 21

Figure 3-2: View of monitoring camera at smart channels.............................................. 23

Figure 3-3: View of monitoring cameras at standard channels ......................................... 23

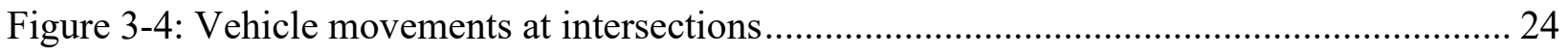

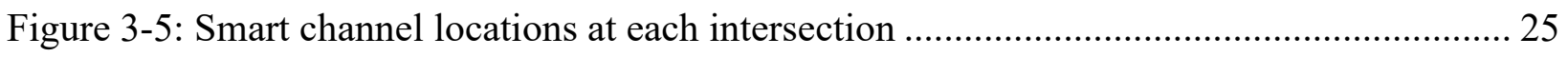

Figure 3-6: Standard channel locations at each intersection............................................ 26

Figure 4-1: Right-turn and through vehicle interaction schematic drawing ........................... 33

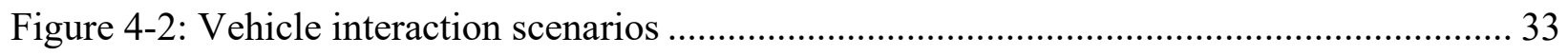

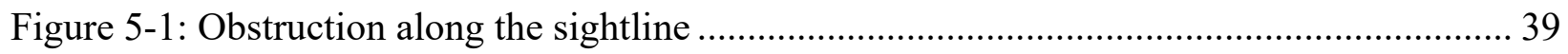

Figure 5-2: Point of clear visibility for right-turn vehicle ............................................... 40

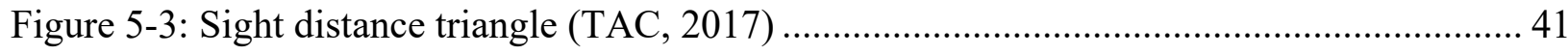

Figure 5-4: Image showing lane centerlines and scale bar ........................................... 42

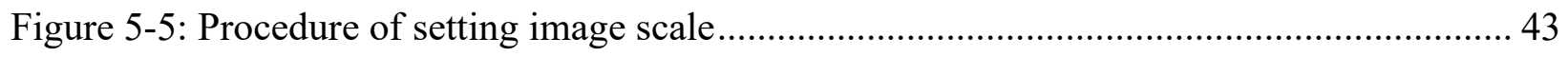

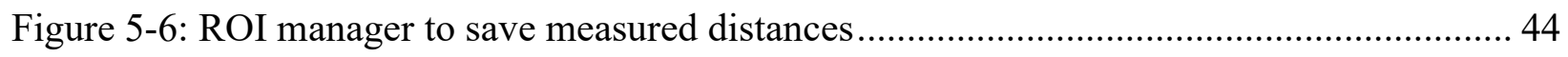

Figure 5-7: Right turning sightline angle measurement ................................................ 45

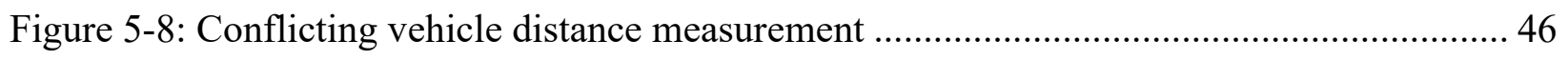

Figure 5-9: First position of approaching conflicting through vehicle ................................. 48 
Figure 5-10: Second position of approaching conflicting through vehicle.

Figure 6-1: Frequency data distribution at smart and standard channels................................ 54

Figure 6-2: Conflict count with all intersections included.............................................. 56

Figure 6-3: Conflict count at each severity level excluding channel location 8 ...................... 57

Figure 6-4: Conflict count at each severity level excluding channel location 7 ...................... 57

Figure 6-5: Percentage of potential conflict count at each standard channel intersection ........... 58

Figure 6-6: Percentage of potential conflict count at each smart channel intersection ............... 59

Figure A-1: Sight distance measurements at smart channels. a) Baseline and Clyde, b) Greenbank and Strandherd, c) Riverside and Heron, d) Strandherd and Longfields ................................ 83

Figure A-2: Sight distance measurements at standard channels. e) Fisher and Meadowlands, f) Riverside and Brookefield, g) Baseline and Woodroffe (EBR and WBR)............................. 85 


\section{List of Appendices}

Appendix A. Sight Distance Measurements Mapped Using ImageJ ....................................... 82

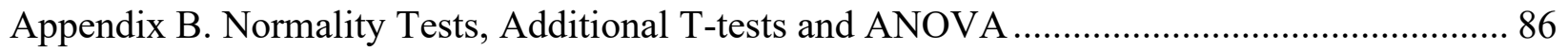

Appendix C. Games-Howell Post-Hoc Test ................................................................. 95

Appendix D. Ordinal Logistic Regression ............................................................... 121 


\section{INTRODUCTION}

\subsection{Background}

The safety and operations at signalized intersections are affected by turning movements; therefore, providing exclusive right-turn lanes at these intersections has become popular in many upgrade projects and newly constructed intersections (Roefaro, 2011). Exclusive right-turn lanes increase efficiency by reducing vehicle delays, commonly at intersections with high right-turn traffic volume (Autey et al., 2012). Right-turn lanes are also used to increase intersection capacity by separating through traffic from right-turning traffic and reducing vehicular delays (Potts et al., 2005).

The standard channel design requires a wide angle where drivers have to look over their shoulders while identifying a gap in oncoming traffic, whereas the smart channel design slows down vehicles in the vicinity of the crosswalk while providing an appropriate angle for sight distance when turning right (Gemar et al., 2015). In an attempt to reduce the crossing distance for pedestrians to shorten distance exposure and reduce pedestrians' likelihood of conflicting with vehicles, a new design termed "smart channels" was proposed by Potts et al. (2005) as an alternative design. The smart channel design is more pedestrian-friendly and supports improved traffic operations (City of Ottawa, 2009). Implementing "smart channels" is commonly advocated for safer pedestrian crossing, however, the benefits extend to vehicle-vehicle interactions because the smart channel reduces the channelized right-turn angle to $70^{\circ}$. This entrance angle affords drivers a better view of the traffic stream they are about to merge into (Autey et al., 2012). According to the Transportation Association of Canada's (TAC) guidelines, the new design 
conforms to these guidelines as drivers should not have to turn their heads more than $150^{\circ}$ to check approaching traffic (TAC, 2017).

A pilot study was successfully done in Ottawa in 2009 whose desired objectives of the smart channel design were to reduce the workload of the driver by reducing the angle of entry and shoulder check, reduce viewing angle, improve the visibility of pedestrians, and to reduce turn speed for consistency with yield conditions that may need a full stop (City of Ottawa, 2009).

For the safe operation of roadways, intersection sight distance is a significant control. However, sight distance at intersections presents a complex issue as it requires a detailed analysis. Several conditions impact the intersection sight distance, and these vary on different highways, by rural vs urban, volume levels, speed, and expectations (Layton, 2012). Both urban and rural setting studies have shown that the collision rate at most intersections generally decreases when sight obstructions are removed and sight distance increased (TAC, 2017). A roadway design with adequate sight distance enables vehicles to travel efficiently and safely to perform necessary driving manoeuvres. The sight distance for approaching vehicles should be considered when designing a channelized right-turn lane and should provide sufficient visibility for various users, clear of obstructions (Montana Department Of Transportation, 2016).

Traffic signal-controlled intersections are thought by some not to require intersection sight distance provision, reasoning that conflicting traffic movements cannot co-occur. Therefore, full sight distance at the intersection is not needed (Michigan Department of Transportation, 2015). However, signalized intersections have various operational possibilities, and intersection sight distance is needed for the following reasons: motorist signal violations, malfunction of traffic signals, flasher mode of signal operations and permitted right-turn on-red (Michigan Department of Transportation, 2015). In addition, if right-turn on red is not allowed, these other reasons will 
still hold at intersections with no channelized right turn lane. At a channelized signalized intersection, the yield control criterion for providing sufficient intersection sight distance is used for the channelized right turn (TAC, 2017).

Road safety analysis has profited from reliable analysis methods that utilize observable traffic events that do not involve crashes due to crash data limitations. These are referred to as noncrash events or surrogate measures. The theory behind using surrogate measures to study road safety assumes a relationship between severity and the frequency of different traffic events (De Ceunynck, 2017). Surrogate safety measures are the most widely used for identifying future threats, such as rear-end collisions. Although surrogate safety measures focus on quantifying traffic events' danger in a meaningful way, observing behavioural aspects of non-crash events may contain a significant amount of useful information needed to investigate underlying processes (De Ceunynck, 2017). An objective proximity indicator has been recommended as a surrogate measure for traffic interaction analysis. Post Encroachment Time (PET), among the different proximity indicators within the literature, offers a simple way to measure proximity generally between two road users (or between two vehicles in this study) without the need for extrapolation of road users' future speed or positions (Kassim et al., 2014). Post- Encroachment Time (PET) can be defined as the time difference between the moment the first vehicle leaves the area of potential collision and the moment the second vehicle arrives at this area while possessing the right of way (Allen et al., 1978).

\subsection{Problem Definition}

Sufficient sight distance for drivers at yield controlled approaches to an intersection was recognized as one of the most critical factors contributing to overall safety (AASHTO, 2011). A 
$5 \%$ crash reduction per quadrant ( $20 \%$ for the four quadrants) can result from improved sight distance (Kennaugh, 2010). According to Kennaugh (2010), step 3 of the crash mitigation process at intersections involves characterizing the field conditions, which requires traffic data studies that include: traffic volume, traffic conflict study, spot speed and evaluating sight distance. Hardly any studies have evaluated how right-turn lane configurations at intersections influence sight distance and conflicts at intersections. This study focussed on investigating from a safety perspective whether the different channel configurations, smart and standard channels, may reflect a safety issue based on conflicts and sight distance.

The dependence on reported collision data alone for analysis of traffic safety would introduce plenty of shortcomings. The shortcomings would arise because collisions are relatively rare events, and safety evaluation requires observations over a long time to monitor stable patterns (Laureshyn et al., 2010). Collisions are also usually underreported depending on the severity level and road user involved, hence a constraint to utilizing collision data. Road users' pre-collision behaviour is usually not reported and does not provide complete information about the collision process (Laureshyn et al., 2010).

\subsection{Research Objectives}

This study's primary study objective was to compare whether different configurations, i.e., standard and smart channels at channelized signalized intersections, have different safety performances based on conflicts and sight distance.

\subsection{Research Contributions}

The contributions below were achieved in this thesis. 
1. This study focussed on comparing whether different configurations, i.e., standard and smart channels have different safety performances based on conflicts and sight distance using statistical analysis.

2. The channel configuration effect was estimated on sight distance triangle leg, PET measurements, sightline distance, time headway, and right turning sightline angle using statistical analysis.

3. The channel configuration effect on conflict rate at intersections was estimated using statistical analysis

4. The study estimated the probability of PET at any severity level using ordinal logistic regression.

A total of 805 interactions with PET less than or equal to 3s. were observed, out of observations involving the movements of 44,048 through vehicles and 14,498 right-turn vehicles on eight different channels: 109 interactions within proximity level PET(0,1]s., 493 within PET proximity level $(1,2] \mathrm{s}$. and 203 within the PET proximity level $(2,3] \mathrm{s}$.

\subsection{Organization of Thesis}

This thesis consists of seven chapters. Chapter One presents the introduction. Studies related to the safety evaluation of channelized signalized intersections are presented in Chapter Two. Furthermore, Chapter Two presents the importance of having sufficient sight distance at right-turn channelized intersections and the need for using conflicts as a surrogate measure of safety. The study area is described in Chapter Three with a description of the channels considered for study. The chapter includes a description of the data collected at each channel. Chapter Four presents the methodology used to measure Post Encroachment Time (PET). Sight distance 
methodology is presented in Chapter Five. Chapter Six presents the data's descriptive statistics, statistical analysis comparing performance parameters at smart and standard channels and estimating a conflicts' probability at any severity level given the performance parameters studied. Conclusions and recommendations of this study are suggested and highlighted in Chapter Seven. 


\section{LITERATURE REVIEW}

\subsection{Introduction}

The American Association of State Highway and Transportation AASHTO (2011) defines channelization as the separation of traffic movements using pavement markings and islands (Gemar et al., 2015). Adverse operational and safety effects could result from a significant volume of right-turn vehicles at intersections; therefore, channelized right-turn lanes are commonly implemented at intersections with high right-turn traffic volume to improve safety and reduce vehicle delay (Autey et al., 2012). The new design known as "smart channels" decreases the channelized right-turn angle to approximately $70^{\circ}$. The design was meant to be more pedestrianfriendly while improving traffic operations (Autey et al., 2012). The alternative right-turn design was recently proposed to improve further channelized right-turn lanes safety for drivers (Sayed et al., 2013). This design provides drivers with a better view of the traffic stream they are about to merge with while also allowing for safer pedestrian crossing (Sayed et al., 2013). Right-turn slip lanes are often installed by transportation planners because to name a few, they allow for the control of the angles at which vehicles merge, diverge, or cross controls prohibited turns and control vehicle speeds (Gemar et al., 2015). In the past, right-turn lanes accommodated high turning speeds, coupled with pedestrians' low visibility, and therefore, unsafe pedestrian crossings (Gemar et al., 2015). The Urban smart channel design adopted slow speeds and a 55-70 angle between merging vehicle flows, allowing pedestrians' good visibility (Gemar et al., 2015). However, on some skewed intersections, the key geometric principle of achieving the $70^{\circ}$ skew is not always feasible (Suderman et al., 2015). Although right-turn slip lanes are expected to reduce rear-end collisions involving right-turn and through vehicles on the same approach, the speed 
differential between the two is reduced, therefore, rear-end and sideswipe crashes on the crossing approach may increase due to merging traffic (Gemar et al., 2015).

Gemar et al.(2015) compared intersection approaches safety of right-turn lanes, shared through/right turn lanes and conventional right-turn lanes. It was found that the estimated number of crashes for rear-end and sideswipe were not significantly affected by the type of right turn approach but concluded that sideswipe crashes increase when the right-turn movement is given an exclusive lane.

The City of Winnipeg has had great success in utilizing the "smart channel" design for most intersections. It has proven to increase yield to pedestrians and reduce vehicle speed compared to the standard compound curve (Suderman et al., 2015). Compared to traditional compound curvature, smart channels help reduce the amount required by drivers to turn their heads to clearly see oncoming traffic, mostly at skewed intersections. The design guidance is in Figure $2-1$. 


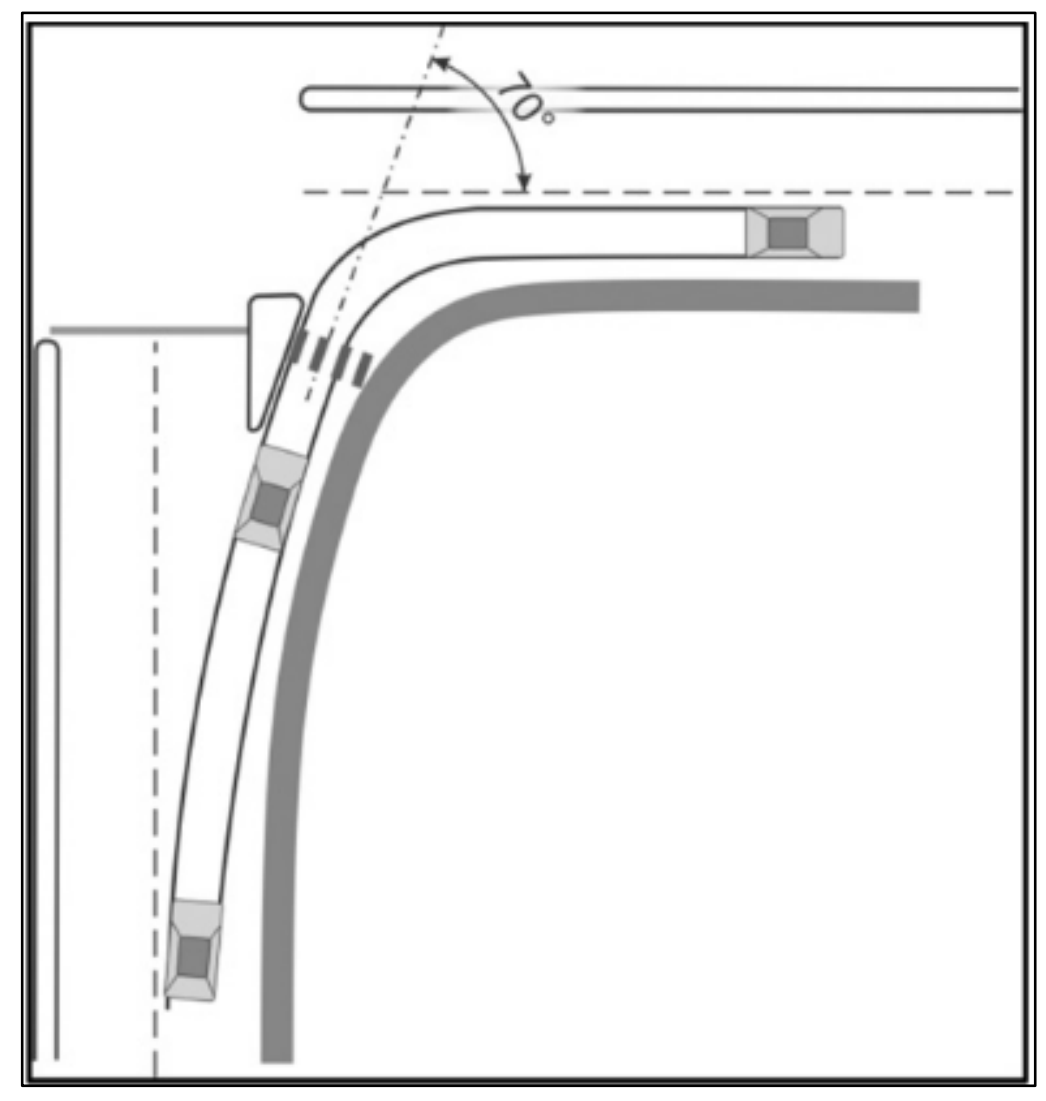

Figure 2-1: Geometric realignment for smart channels (Autey et al., 2012)

The City of Ottawa has adopted the smart channel design as a measure of improving road safety. The difficulty for older drivers turning their heads at skewed (non-90) angles to view intersection traffic and potential conflicts to smoothly merge with adjacent lane traffic is recognized by the US Federal Highway Administration (FHWA) (Autey et al., 2012). Furthermore, promoting sharper angle entry into the cross street improves pedestrian visibility while decreasing the extent to which drivers approaching have to turn their heads while looking out for oncoming traffic (Autey et al., 2012).

Florida Department of Transportation (FDOT) right-turn lane design proposed another way of narrowing the turning path using pavement markings. The markings expand the channelizing 
island using chevron pattern markings. Regardless of the many benefits associated with this retrofitting treatment, there are drawbacks to implementing this design. Although the initial cost may be low, long term costs might be incurred because of having to maintain additional pavement markings. Secondly, motorists who prefer to execute a higher speed may not follow the delineated path and encroach on the markings, making the treatment ineffective, and higher costs would be incurred to modify the curb radius to inhibit this behaviour (Gemar et al., 2015).

Comparing the Ottawa design to the Florida DOT design, The Texas Department of Transportation (TxDOT) attendees (input obtained from focus group meetings with additional TxDOT personnel) seemed to prefer the former as this configuration appeared to require less rightof-way. The Ottawa design was more suitable for elderly drivers with vision and neck concerns than the Florida DOT design, which encouraged non-compliance with the pedestrian crossing location because of the availability of extra perceived refuge in the island's painted area. Nonetheless, the Ottawa design's concern was with space availability and if the entrance to the right-turn slip lane would be blocked by vehicles waiting at the signal. TxDOT participants suggested the deceleration lane as a potential remedy to the latter.

Accordingly, it was proposed to modify the Ottawa design to comply with the Americans with Disabilities Act (ADA) requirements and checking with the AASHTO Green Book for the minimum island size recommended. Therefore, it is an easily implementable solution as it is a relatively low cost since this retrofitting remedy only requires stripping (Gemar et al., 2015).

\subsection{Sight Distance at a Channelized Right-turn Lane}

Intersections need to be designed to provide sufficient sight distance to enable drivers to control and safely operate their vehicles. Sight distance is a critical factor in designing intersections 
and is based upon speed (Kennaugh, 2010). If there are no potentially conflicting vehicles on the major road, a driver approaching a yield sign can enter the major road without stopping. It is vital to note that the sight distance needed by a driver on a yield-controlled approach should be greater than that for a stop-controlled approach (Kennaugh, 2010).

Initially, intersection sight distance was presented as a function of perception reaction time and vehicle speed by AASHTO (1984). Later, the new criterion in AASHTO (2001) based intersection sight distance on the gap-acceptance concept, derived from the drivers' observed behaviour when entering an intersection. Intersection sight distance should then be provided to enable drivers to identify that critical gap (Harwood et al., 1996). This sight distance can be guaranteed using the line of safety envelope curve (Liu et al., 2010). A driver about to enter the intersection, safety-related factors are the primary concern, with drivers looking inside the intersection's landscape to obtain information. The line of safety envelope curve allows drivers to judge the road situation while in a continuous moving process. As the driver obtains road information, their line of sight constantly tangents to the inside landscape, forming a continuous sight distance. Therefore, sufficient sight distance may improve intersection traffic efficiency, enabling vehicles to pass safely by the maximum speed (Liu et al., 2010). Figure 2-2 illustrates the line-of-sight envelope curve, which also applies to right-turning vehicles on the minor road and approaching through vehicles on the major roadway. 


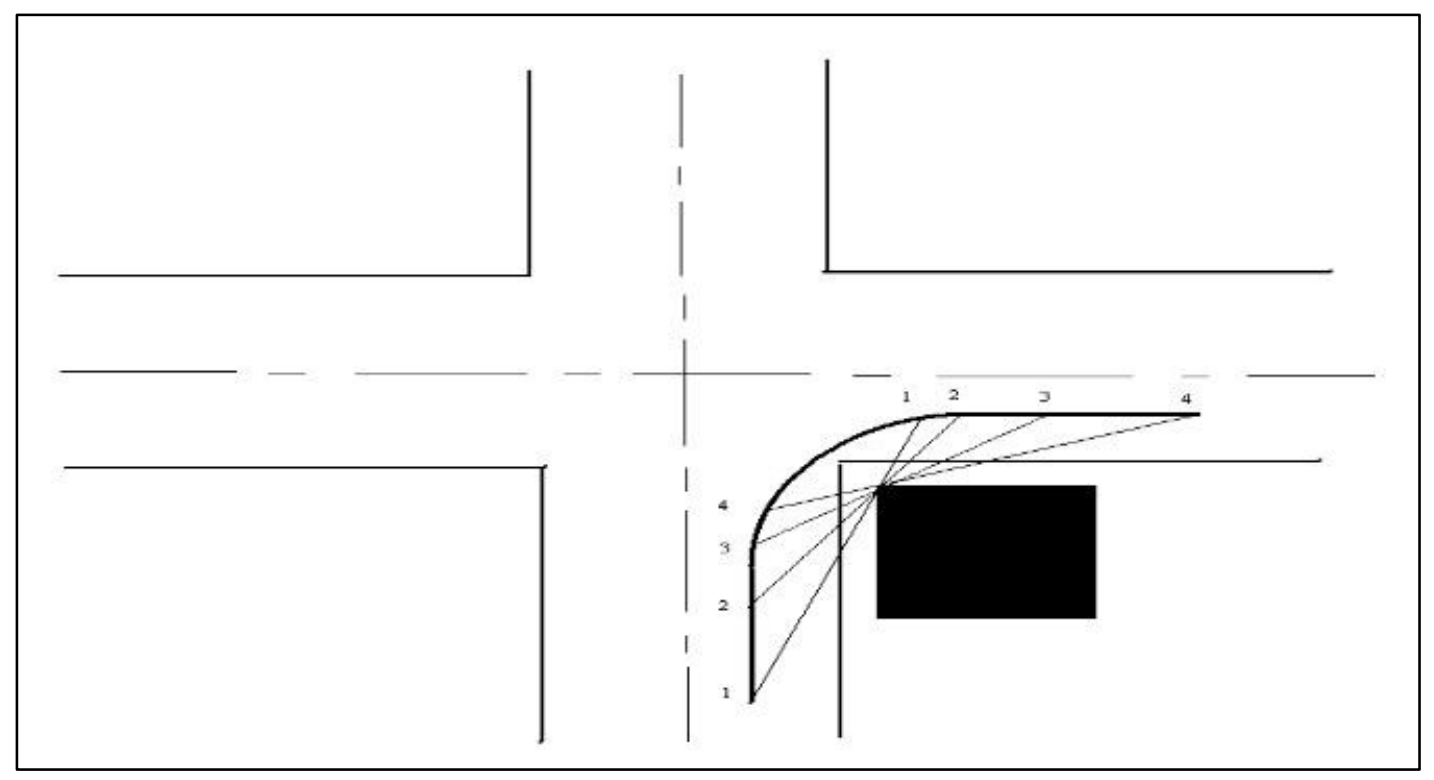

Figure 2-2: Line of sight envelope curve (Liu et al., 2010)

Adequate sight distances are achieved by designing nonlimiting horizontal and vertical alignment, avoiding sight distance obstructions in quadrants of intersections and inside horizontal curves. This distance has been defined as a function of operating speeds (Glennon, 2004). It is critical to know the safety benefits of expected sight distance for any proposed changes to the existing alignment. Equally valuable are the safety benefits of low-cost alternative improvements such as roadside obstruction removal to improve sight distance(Glennon, 2004).

A few studies have addressed the role of intersection sight distance in producing accidents; (David and Norman, 1975; Wu, 1973; Mitchell, 1973; Moore and Humphries, 1975). However, only two of them provide a form of relationship between intersection sight distance and accidents. Wu (1973) analyzed the relationship between accident rate and a term he used as 'clear vision right-of-way' at 192 intersections, the study concluded that intersections with poor visibility had significantly higher injuries and total accident rates. Nevertheless, depending on varied right-ofway widths, conclusions might be misleading in both the explicit and poor vision categories. 
David and Norman (1975) studied the relationship between accident rate and other traffic and intersection features. The intersections included were 558 in number that had 4,372 accidents over three years. The study concluded significant accident differences between "clear" and "obstructed" intersections for different restriction levels. However, many indicator variables that could significantly affect accident rates, such as speed limits and turning lane presence were not accounted for, possibly making a misleading sight distance conclusion (Glennon, 2004). Despite the unclear safety effectiveness of improved intersection sight distance, low-cost treatments, including removing minor obstructions on the inside of horizontal curves, are solutions to be considered (Glennon, 2004).

Harwood et al. (2003) research involved a panel of safety researchers that developed Accident Modification Factors (AMFs) for specific traffic control features and geometric design. The latter developed estimates of the safety effectiveness of right-turn lanes. The panel did not find any well-designed before-after-studies on the accident reduction effectiveness of right-turn lanes. After reviewing the available studies, it was estimated that the presence of a right-turn lane and one approach to a rural stop-controlled intersection reduced intersection-related accidents by $5 \%$, and a right-turn lane on both major approaches reduces the latter by $10 \%$.

At signalized intersections, drivers without right-of-way require intersection sight distance (ISD) to perceive and react to conflicting vehicles. Sight distance horizontally and vertically must also be maintained to enable drivers to have an adequate line-of-sight as they approach the intersection (FHWA, 2013). Vehicle speed and sight distance are closely related to traffic safety, and Liu et al. (2010) found a close correlation between intersection sight distance and vehicle velocity. 
In highway geometric design, sight distance is a vital safety element. The ISD existing approach is deterministic and significantly relies on extreme values of the component design variables such as friction coefficient, design speed and perception-reaction time (Easa, 2000). The distance the driver had, free from obstruction to view an approaching vehicle before a manoeuvre that resulted in a conflict was made, is described as the sightline distance in AASHTO (2018) used in the design of ISD. AASHTO (2018) discusses six different cases for ISD that can be used to determine the required sight distance.

The basis for calculating sight distance traditionally at intersections has relied upon the sight distance triangle's notion (Harwood et al., 1996). Channelized right-turn sightlines should be clear of obstructions and need to provide sufficient visibility for vehicles. The driver may either stop or continue through the intersection with a turning manoeuvre at channelized intersections; this is known as a "yield decision" (Harwood et al., 1996).

Considering that channels are yield controlled, to accommodate right-turns without stopping, the length of the leg of the approach sight distance triangle along the minor road should be $25 \mathrm{~m}$. The assumption is based on the observation that drivers turning right without stopping will slow to a turning speed of $16 \mathrm{~km} / \mathrm{h}$ [10mph] (AASHTO, 2018).

\subsection{Vehicle Safety at Channelized Intersections}

An evaluation at three intersections in Penticton, British Columbia, was done to evaluate right-turn lanes' conversion to smart channels by (Autey et al., 2012). A before and after analysis of the safety impact was done using automated detection and analysis of traffic conflicts with computer vision techniques. The results showed that the conversion of standard channels to smart channels could lead to a considerable reduction in both conflict frequency and severity. The 
average conflict severity reduced by $41 \%$, while the total average hourly conflict reduced by $51 \%$. Automated video-based conflict analysis significantly facilitates the traffic conflict data collection and overcomes the reliability and repeatability issues commonly associated with manual traffic conflict observations (Autey, 2010).

Road safety assessment can be based on either collision data or surrogate measures of safety. Road traffic safety is traditionally based on road collision statistics as the primary data source (Chin and Quek, 1997). An alternative approach is based on surrogate safety measures when analyzing road safety, usually due to the inherent collision data limitation.

\subsubsection{Conflicts as a Surrogate Measure for Safety}

Traffic conflicts are usually defined as an 'observable' case where two or more road users approach each other in space and time to the extent that a collision is likely to happen if their movements remain unchanged (Zheng et al., 2014). Techniques for road safety analysis that rely on data other than collisions are termed as surrogate safety measures. The emergence of traffic conflicts in road safety studies ignited a debate about their validity as descriptors of hazardous road conditions and caused hesitation in adopting traffic conflict programs in the absence of a strong correlation with accidents (Brown, 1993). There are still some disputes on what traffic conflicts are, despite decades of conceptual development and widespread application (Zheng et al., 2014). There is no clear relationship between geometric design standards and safety because the relationship between surrogates and safety is often counter-intuitive or uncertain. Therefore, sight distance as a substitute for safety is measured by crash frequency and severity (Hauer, 2000). Clarity is needed about what 'road safety' means to avoid sterile disagreement. For example, if two highway design alternatives connecting $\mathrm{A}$ and $\mathrm{B}$, accommodating the same traffic, the highway design likely to have fewer and less severe crashes is considered the safer one. Therefore, 
the road's safety is determined by the frequency and severity of crashes expected to happen on that road. In that case, road safety is always a situation of degree, either safer or less safe (Hauer, 2000).

Surrogate measures target at developing safety indicators related to safety but not based on observing collisions. Accidents are rare and complex events, and therefore, their statistics are difficult to use in predicting failure in the crash environment (Brown, 1994). The accuracy with which road safety can be estimated depends on the precision with which the probability of accident occurrence can be estimated (Brown, 1994). Reported accident statistics provide no satisfactory causal link between road user risk and elements on the road that present hazardous conditions. The latter has led to the development of traffic conflict observation techniques intending to reduce the uncertainty in estimating road user safety while producing a human factor measure. The human factor measure would provide a symptomatic diagnosis of hazardous road elements (Brown, 1994). Studies point out that a continuum of all traffic events is presented as conflicts and collisions being some extreme manifestation of the process of generating all traffic events.

Traffic conflict indicators as an alternative to safety analysis were used to quantify road user's degree of proximity, and in some cases, identify traffic conflicts, namely, Post Encroachment Time (PET) and Time- to- Collision (TTC). Time-to-Collision is defined as " the time that remains until a collision between two vehicles would have occurred, if the collision's course and speed difference are maintained" (Hayward, 1972). In vehicle-vehicle conflicts context, TTC represents the time elapsed from the current moment until both vehicles reach a level of proximity that the former's safety is compromised if movements of either vehicle remain unchanged. Post- Encroachment Time (PET) can be defined as the time difference between the moment the first vehicle leaves and the area of potential collision and the moment the second vehicle arrives at this area while possessing the right of way (Allen et al., 1978). 
Based on the literature, Post Encroachment Time (PET) provides a simple way to measure proximity without the need for extrapolation of future speeds or positions of road users. PET can objectively measure road users' proximity to a collision where a collision was not observed (Kassim et al., 2014).

\subsubsection{Post Encroachment Time}

A threshold needs to be selected when counting the number of conflicts to determine the observations with PET values below an identified threshold and is used solely to identify events for analysis (Kassim et al., 2014). In studies where the surrogate measure magnitude and collision frequency were not consistent, PET was used successfully to account for collision record limitations (Peesapati et al., 2018).

Regarding safety estimation at a site, many surrogate measures have a significant advantage of not requiring historical crash data directly (Peesapati et al., 2018). However, the exact relationship between PET and crashes is still an ongoing research area. Peesapati et al. (2018) studied the use of PET to estimate crashes between opposing through vehicles and left-turning vehicles for its ability to predict opposing left-turn crashes. The model combining traffic volume characteristics and PET had better prediction power than PET alone (Peesapati et al., 2018). Furthermore, it was determined that PET could be capturing the impact of other intersection characteristics on safety as other intersection characteristics inclusions. These may include grade, sight distance or other parameters that result in only marginal impacts on predictive capacity without the justification of the increased model complexity (Peesapati et al., 2018).

Huang and $\mathrm{Wu}(2003)$ and Kassim et al. (2014) measured the proximity between cyclists and motor vehicles at signalized intersections in Beijing, China and Ottawa, Canada, respectively. 
The conflict movement scenarios observed in Kassim et.al. (2014) study are illustrated in Figure 2-3. The method used for these studies can also be applied to motor vehicle-vehicle interactions. Two-time durations were measured to identify a conflict in either scenario using the image sequences of the traffic events involving the road users mentioned above. The time lag that both authors used to measure road user proximity fits the PET description. Huang and $\mathrm{Wu}$ (2003) study with the camera frame rate of 25 frames/second found the average time lag as $2.93 \mathrm{~s}$. and a minimum of 0.52 s., while Kassim et al. (2014) study that had a camera frame rate of approximately 30 frames/second, with a precision of 0.033 s., found the average time lag as 1.77 s. and a minimum of $0.07 \mathrm{~s}$. The latter study also examined automated methods of measuring PET compared to the Manual Frame Count Method (MFCM) and found that both methods' PET methods had a high correlation of determination. The average absolute difference between the methods was $0.12 \mathrm{~s}$. The Automated Method (AM) decreased the processing time by $67 \%$. Therefore, the proposed AM can practically support large-scale data collection for investigating the PET counts and collisions relationship.

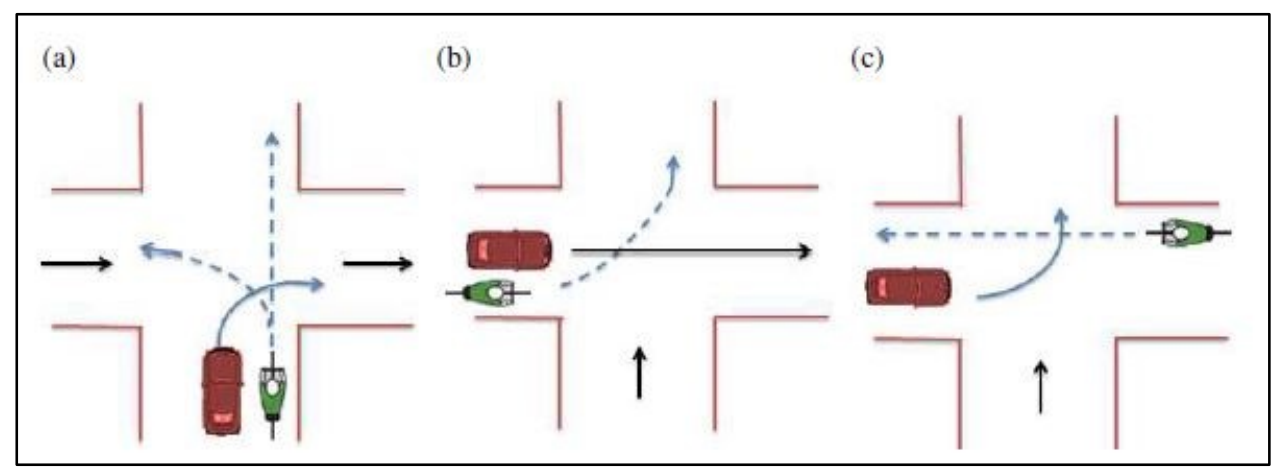

Figure 2-3: Conflict movement scenarios between motor vehicles and cyclists at a signalized intersection. (a) right-turn motor vehicle vs cyclists. (b) Through motor vehicle versus left-turning cyclists. (c) Left-turning motor vehicle versus through cyclists (Kassim et al., 2014) 


\section{STUDY AREA DESCRIPTION}

This chapter presents the study area and describes the procedure followed to obtain all the necessary data required for analysis in this study. A description of the selected study area introduces the chapter. It then presents the data requirements for analysis that guided the data collection process.

\subsection{Study Area}

The area selected in this study is in Ottawa City, the capital of Canada, located in Southeastern Ontario. Ottawa is the country's fourth-largest city. The population in Ottawa in 2020 was estimated at $1,393,086$, with a $1.08 \%$ annual change since 2015 . The population density is 317 per square kilometre (820/square miles). The city's total surface area is $2,778.13$ kilometres (1,072.9 square miles) (City of Ottawa, 2020). There are several right-turn channelized islands implemented at intersections within the City of Ottawa. These are common at wide intersections with high-speed right-turns and large corner radii. The addition of a channelized island can help reduce the speed at which right-turns are made (Autey et al., 2012). There are two right-turn lane designs implemented at intersections: the conventional standard channel design and the improved right-turn lane design. The latter is also known as the City's "urban smart channel." The urban smart channel as a countermeasure is only appropriate at locations where a channelized right-turn lane is already installed (City of Ottawa, 2010). The improved right-turn lane design provides allround good visibility and reduces speed, whereas a standard right-turn lane design promotes high speed with low visibility, and the drivers' attention and head is turned away from crossing pedestrians (City of Ottawa, 2010). 
The intersections used in this study were chosen based on data availability from the City of Ottawa. The videos used were from previously positioned cameras by the City of Ottawa to collect volume data at intersections within the city. Therefore, the camera location at the intersections and orientation favoured vehicle count studies. Nonetheless, one of the city's engineers assisted in looking through a vast number of videos within the City of Ottawa's database for three weeks to identify channels with a camera location and orientation that could be utilized for this specific study. The intersections chosen for this study were those that had a view of vehicles downstream of the right-turn channels and through vehicle movements. Figure 3-1 shows an overview of the study area with all eight-channel locations at the seven intersections chosen for this study. The channels consist of four smart channels and four standard channels. Smart channel locations include Strandherd and Longfields, Baseline and Clyde, Riverside and Heron, Greenbank and Strandherd. Standard channel locations include Baseline and Woodroffe, with two channels considered for study at this intersection, eastbound right and westbound right, Fisher and Meadowlands, and Riverside and Brookefields. 


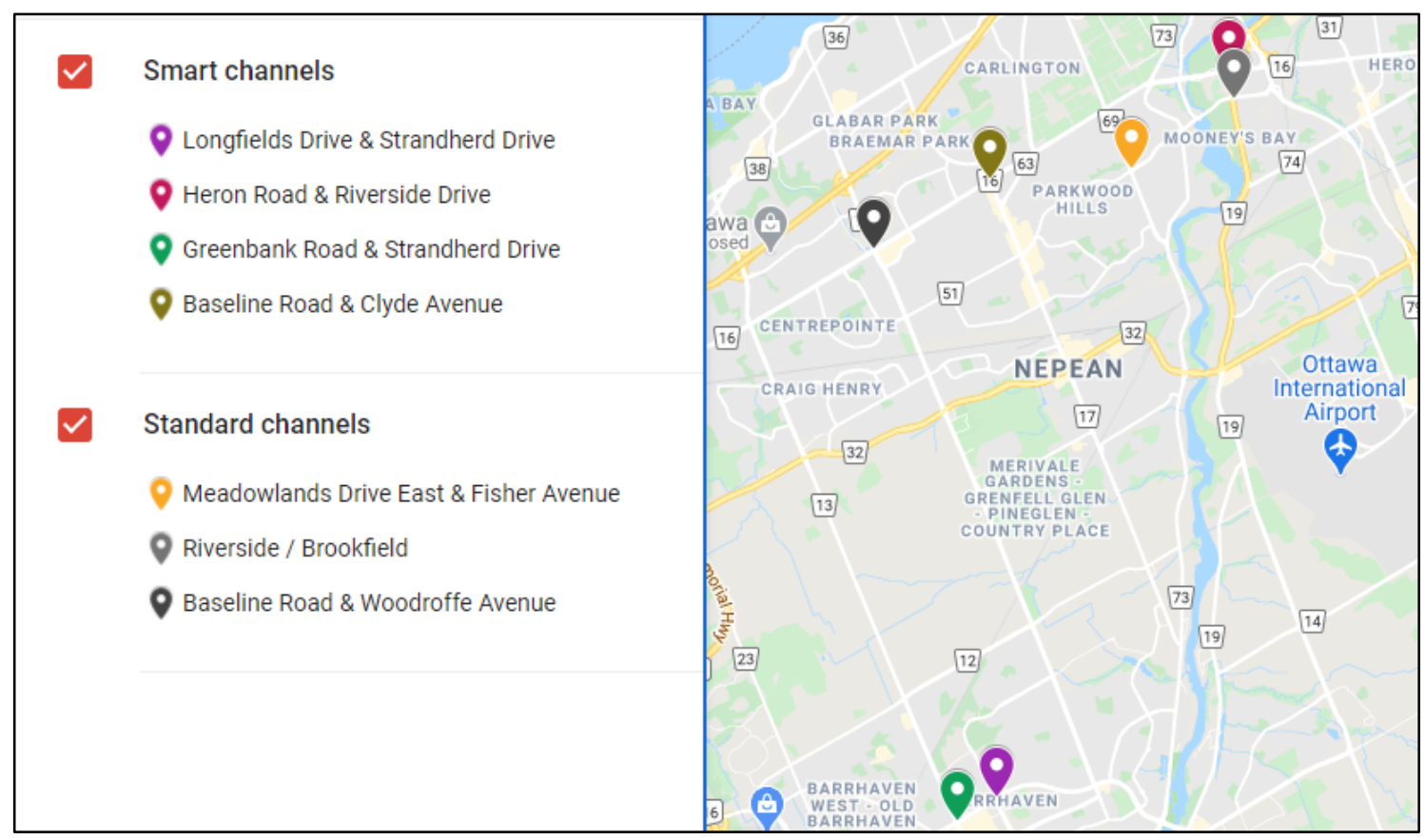

Figure 3-1: Location of study intersections (Google Earth 2020)

A summary of the eight channels is shown in Table 3-1, including the approach and movement direction using the four cardinal directions. i.e., a southbound-right-turn direction represents vehicle movements from the northern direction, turning right towards the West.

Table 3-1: Intersections direction of travel and channel location

\begin{tabular}{|c|c|c|c|}
\hline Type of Channel & 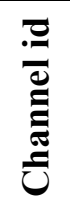 & Intersection name & Direction \\
\hline \multirow{4}{*}{ Standard Channel } & 1 & Fisher and Meadowlands & EBR \\
\hline & 2 & Baseline and Woodroffe & EBR \\
\hline & 3 & Baseline and Woodroffe & WBR \\
\hline & 4 & Riverside and Brookefield & SBR \\
\hline \multirow{4}{*}{ Smart Channel } & 5 & Baseline and Clyde & EBR \\
\hline & 6 & Greenbank and Strandherd & SBR \\
\hline & 7 & Riverside and Heron & SBR \\
\hline & 8 & Strandherd and Longfield & EBR \\
\hline
\end{tabular}

*SBR-Southbound Right, EBR- Eastbound Right, WBR-Westbound Right 
The City of Ottawa provided the Average Annual Daily Traffic (AADT) for the intersections used in this study and are presented in Table 3-2, for right-turn AADT, through AADT and total AADT, including the year the data was obtained.

Table 3-2: Average Annual Daily Traffic at each intersection (City of Ottawa, 2020)

\begin{tabular}{|c|c|c|c|c|c|c|}
\hline $\begin{array}{l}\text { Type of } \\
\text { Channel }\end{array}$ & 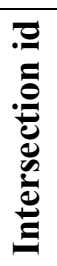 & Intersection name & $\begin{array}{c}\text { Year } \\
\text { collected }\end{array}$ & $\begin{array}{l}\text { Right } \\
\text { AADT }\end{array}$ & $\begin{array}{c}\text { Through } \\
\text { AADT }\end{array}$ & $\begin{array}{l}\text { Total } \\
\text { AADT }\end{array}$ \\
\hline \multirow{4}{*}{$\begin{array}{l}\text { Standard } \\
\text { Channel }\end{array}$} & 1 & Fisher and Meadowlands & 2019 & 784 & 6811 & 29991 \\
\hline & 2 & Baseline and Woodroffe & 2016 & 595 & 2907 & 21328 \\
\hline & 3 & Baseline and Woodroffe & 2016 & 1157 & 4901 & 21328 \\
\hline & 4 & Riverside and Brookefield & 2020 & 2667 & 322 & 52501 \\
\hline \multirow{4}{*}{$\begin{array}{c}\text { Smart } \\
\text { Channel }\end{array}$} & 5 & Baseline and Clyde & 2014 & 2848 & 7770 & 58060 \\
\hline & 6 & Greenbank and Strandherd & 2014 & 801 & 1144 & 15827 \\
\hline & 7 & Riverside and Heron & 2019 & 6526 & 13279 & 77596 \\
\hline & 8 & Strandherd and Longfield & 2016 & 1331 & 2713 & 42525 \\
\hline
\end{tabular}

The City uses Miovision cameras, commonly set up for one day to collect vehicle volume, usually between 6:45 am-6:45 pm. The monitoring cameras' views of each channel location chosen for study are shown in Figure 3-2 and Figure 3-3. 


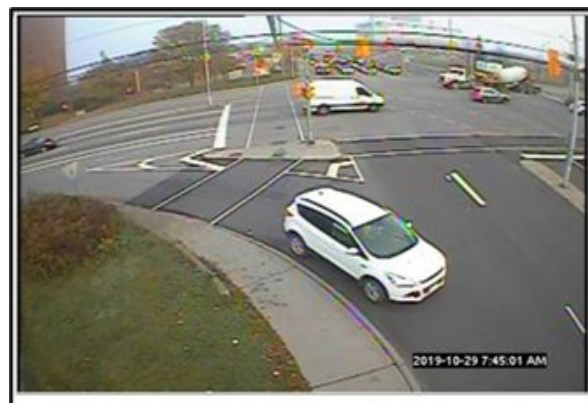

Baseline \& Clyde-SBR

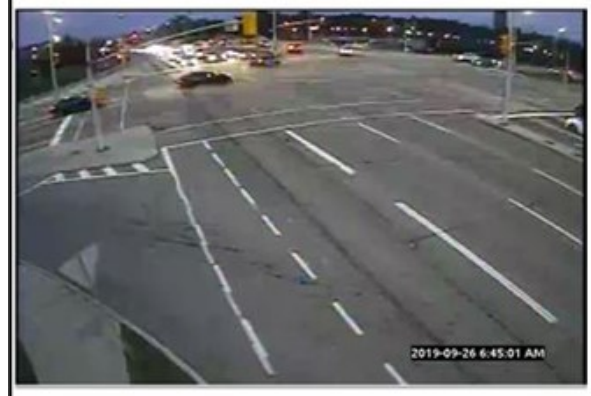

Riverside \& Heron- WBR

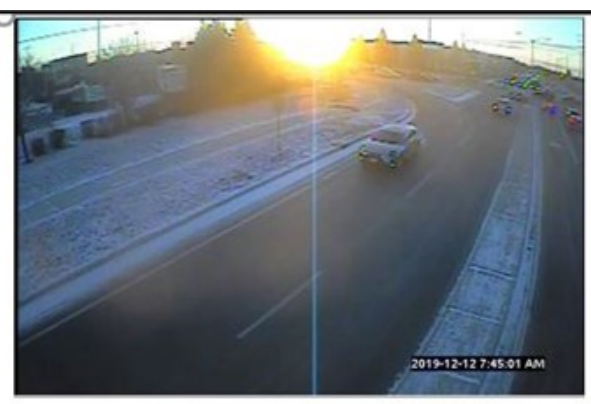

Greenbank \& Strandherd- WBR

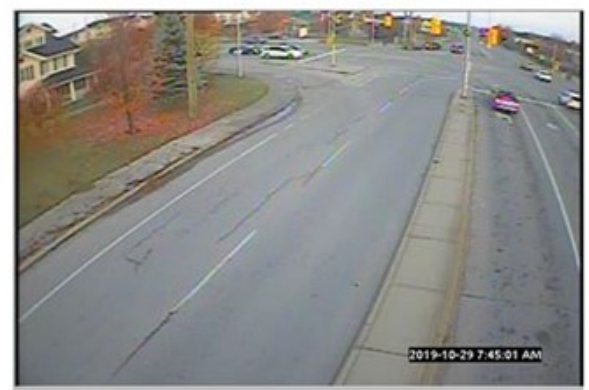

Strandherd \& Longfield- SBR

Figure 3-2: View of monitoring camera at smart channels

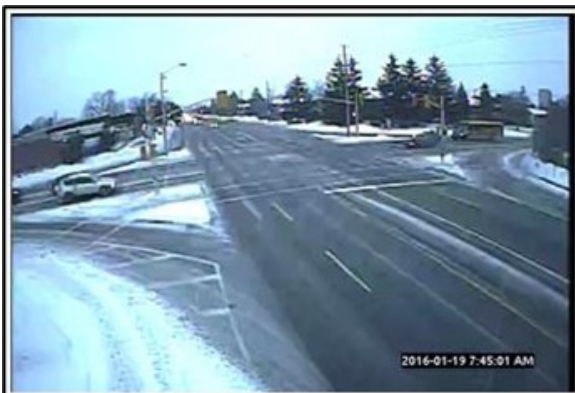

Fisher \& Meadowlands - SBR

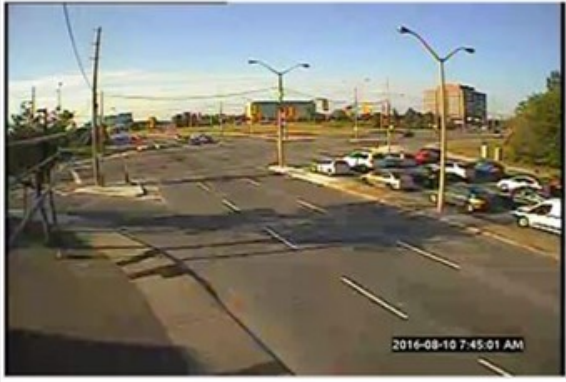

Baseline \& Woodroffe - WBR

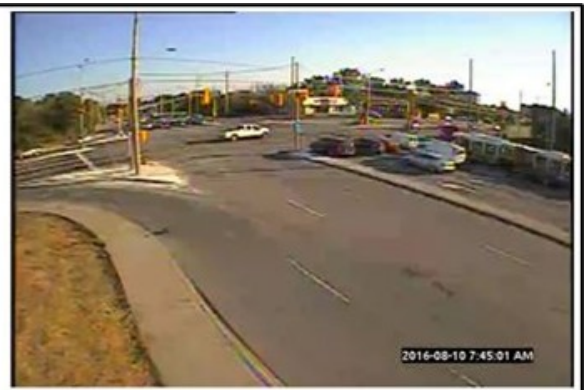

Baseline \& Woodroffe - EBR

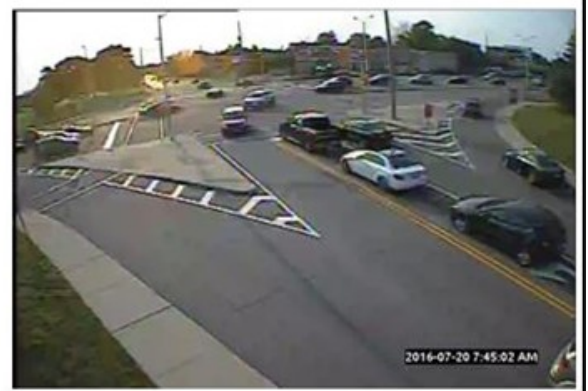

Riverside \& Brookefield- WBR

Figure 3-3: View of monitoring cameras at standard channels 
The vehicle movements analyzed in this study are right-turn movements through the channel and the through vehicle movements through the intersection. An example is shown in Figure 3-4 at Riverside and Brookefield.

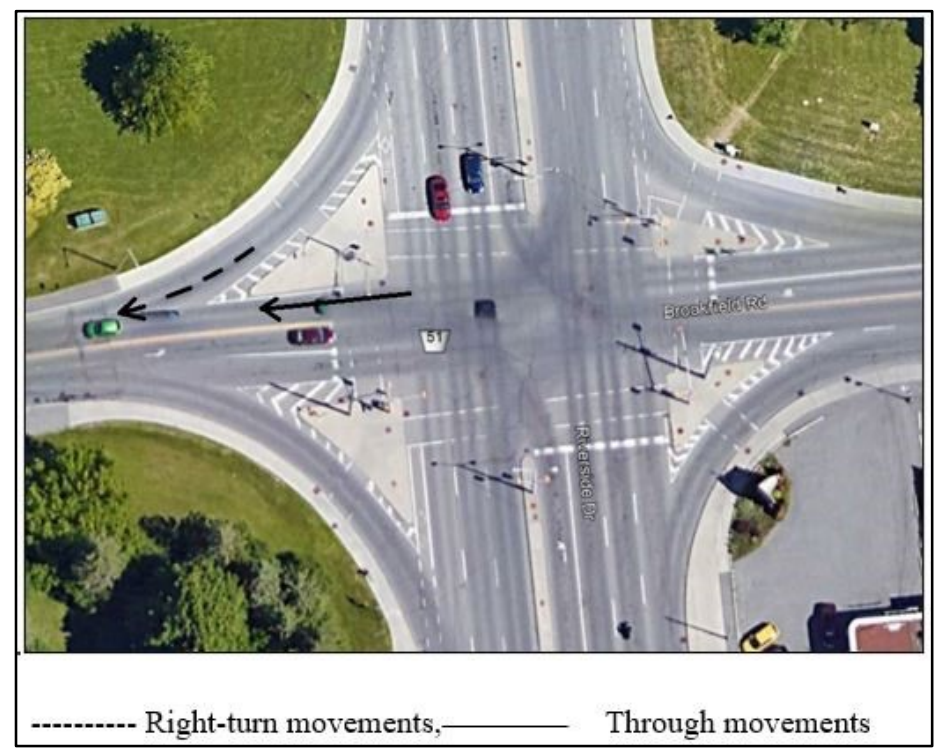

Figure 3-4: Vehicle movements at intersections

Figure 3-5 illustrates the smart channel location at each intersection used in this study. Intersection A is a four-leg intersection at Heron and Riverside Dr., with three smart channels and one standard channel. The channel with the southbound right-turn direction of travel was selected for the study. The through vehicles are in the eastbound direction. The channel's right-turn lane has a shared lane downstream that crosses a cyclist lane and bus lane, making this intersection different from the rest of the intersections chosen. Intersection B is at Strandherd and Longfields; it is a four-leg intersection with three smart channels. The movement direction for the smart channel selected is eastbound right-turn, crossing a cyclist lane before merging into a shared lane downstream. The movement of the through vehicles is in the southbound direction. Strandherd and Longfields intersection lane orientation on the through lane is different compared to other 
intersections. There is only one lane upstream and two lanes downstream, which indicates no direct link between the right-turn and through vehicles at this channel. Intersection $\mathrm{C}$ is at Greenbank and Strandherd, a four-leg intersection with three channels, two standard channels and one smart channel. The smart channel vehicle movement is westbound right-turn free-flow with a shared lane downstream that crosses a cyclist lane. The through vehicles travel in the northbound direction. Intersection D is a smart channel at Baseline and Clyde, a four-leg intersection with an eastbound right-turn movement direction that consists of a shared lane with an island upstream and a shared lane downstream.

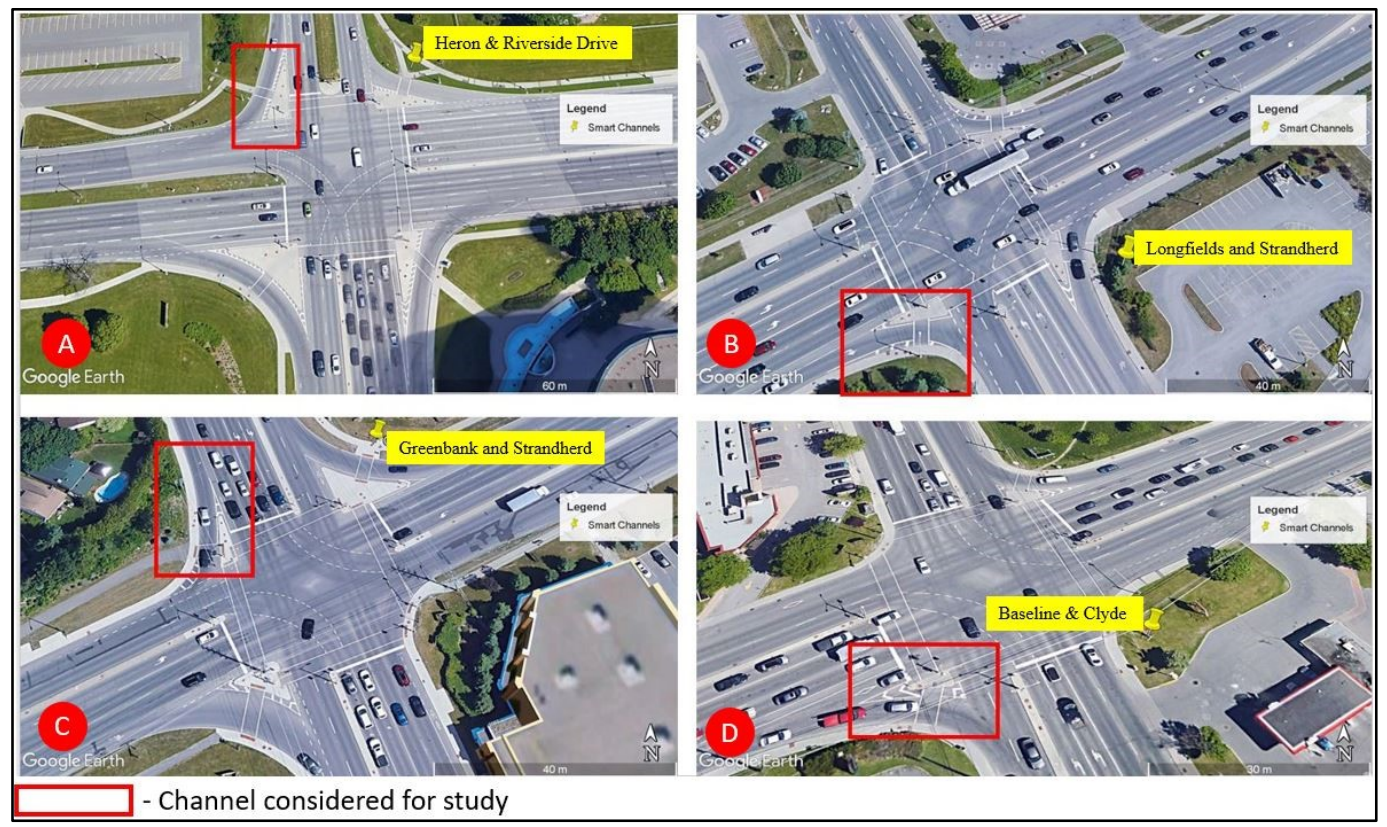

Figure 3-5: Smart channel locations at each intersection

Figure 3-6 illustrates the location of the standard channels used in this study. Intersection E is at Brookefield and Riverside, a four-leg intersection with four channels, all standard channels. The channel considered is a standard channel with movement direction southbound right-turn. The channel has a shared lane upstream and a shared lane downstream. Intersection $\mathrm{F}$ is at Baseline 
and Woodroffe, a four-leg intersection with four standard channels. The two channels considered for this study are those with movement direction: eastbound right-turn and westbound right-turn, both with an island and shared lane downstream. Intersection $G$ is at Meadowlands and Fisher, a four-leg intersection with four standard channels. The channel considered for the study is the eastbound right-turn direction. It consists of a shared lane with an island upstream and a shared lane downstream.

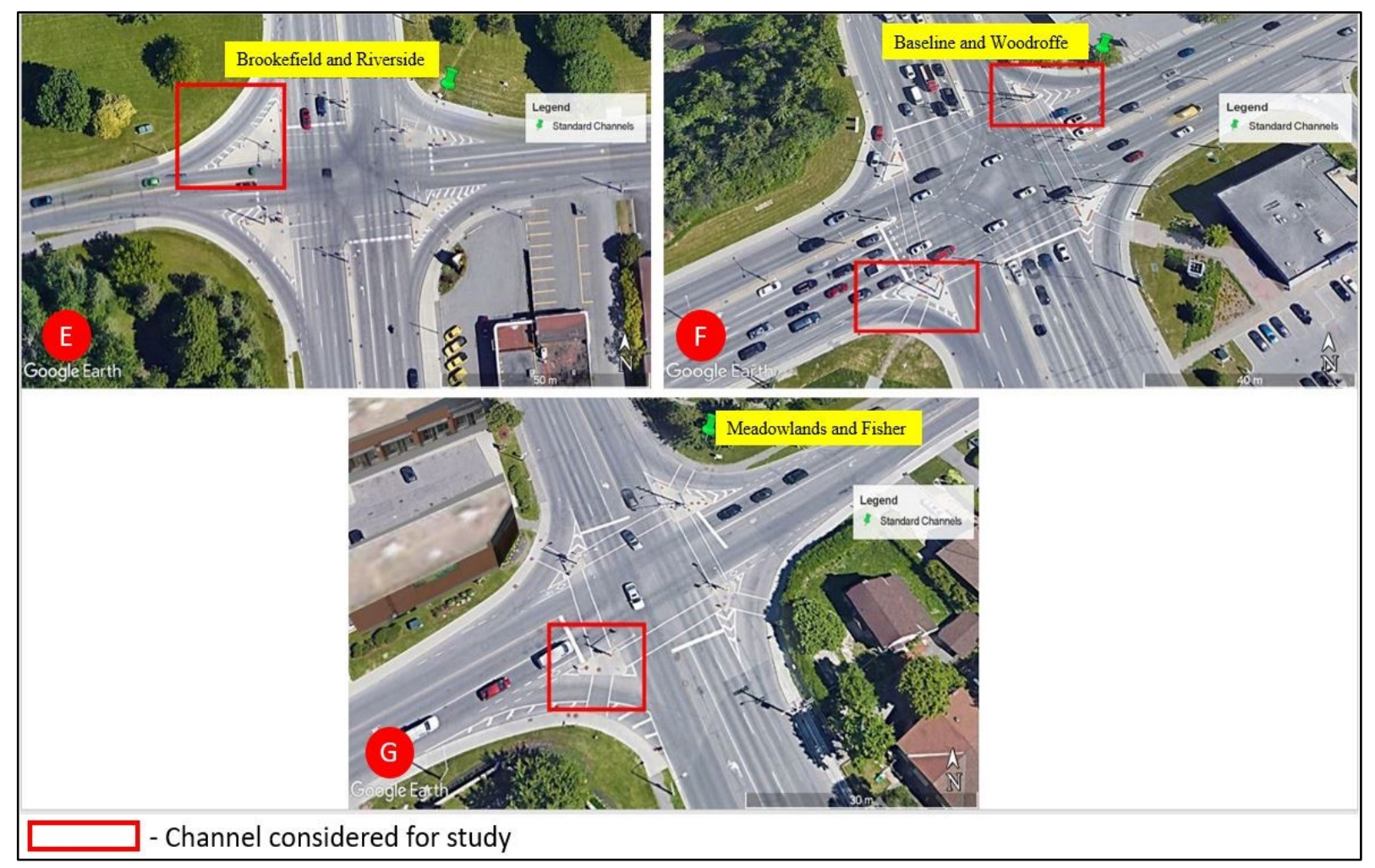

Figure 3-6: Standard channel locations at each intersection

The different lane orientations and vehicle traffic flow at Strandherd and Longfields and Heron and Riverside require that the data is analyzed accounting for these intersections to determine whether they significantly affect the data. 


\subsection{Data Description}

The data used in this study was from eight-channel locations in the City of Ottawa at seven intersections. The data collected focussed on observing drivers and identifying potential conflicts based on the PET threshold $(0,3]$ s., of vehicle interactions between right-turn and through vehicle manoeuvres at a signalized channelized intersection at four standard and four Smart channels. This section describes each variable obtained at each channel location. Thereafter, a detailed description of how these variables were measured is presented in Chapter 4 and Chapter 5. Performance parameters have been defined in this chapter, as observed at the intersections for each interaction. There are five performance parameters used in this study.

1. Post encroachment time involving very close proximity between motor vehicles.

2. Intersection sight distance (using time headway as the measure).

3. Right turning sightline angle.

4. Sight distance triangle leg on the through road.

5. Sightline distance

\subsubsection{Post Encroachment Time}

The PET definition for this study is the time difference between when the rear part of the motor vehicle leaves (or the front part arrives at) the area of a potential collision and when the front part of another motor vehicle arrives at (or the rear part departs from) this area (Kassim et al., 2014). The motor vehicle part may include any one of the vehicle's four corners. The count events were based on a threshold selection, i.e., count of interactions. The PET measurements counted were less than or equal to 3 s. i.e. traffic conflicts were registered if the conflict measure values are less than the predetermined threshold (Sayed et al., 2013). PET is analyzed in two ways 
as shown in Chapter Four, as PET measurements at each channel configuration within the threshold $(0,3] \mathrm{s}$., and PET categorized into three proximity levels: PET $(0,1] \mathrm{s}$., count of interactions between 0 and 1 , not including 0 , including 1 , PET $(1,2]$ s., a count of interactions between 1 and 2, not including 1, including 2, and PET (2,3]s., count of interactions between 2 and 3 , not including 2 , including 3 . PET $(0,1]$ s. reflects a potential conflict with a high severity level/proximity level, PET $(1,2]$ s. reflects a potential conflict with a medium severity level and PET $(2,3]$ s. reflects a potential conflict with a low severity level.

\subsubsection{Intersection Sight Distance}

In design, intersection sight distance (ISD) required at an intersection is based on the traffic control, approach speed, road width, and the design vehicle. In this study, intersection sight distance is studied for each interaction event between right-turn vehicles and through vehicles using time headway as a measure of ISD, sight distance triangle leg (SDTL), sightline distance, right turning sightline angle as visibility parameters.

The sight distance triangle leg (SDTL) is the distance on the through road at the point the through vehicle is first observed by the right turning vehicle. The SDTL distance was calculated using the sight distance triangle by obtaining the sightline distance and decision point distance for each interaction. Sightline distance was measured as the line of sight from the right turning driver's location to the conflicting through vehicles' location. The sightline distance was estimated at the moment when a driver had an unobstructed view of the conflicting through vehicle.

The right turning sightline angle is estimated as the angle the driver needed to turn his head to view the approaching vehicles before a potential conflict was observed. The right turning sightline angle was measured from the line tangential to the right-turn channel's centerline to the 
sightline. The literature mentions that smart channels have a better safety performance because of the smaller entrance angle, making it easier for drivers to manoeuvre during a right-turn. The smaller the angle, the easier a driver making a right-turn can view the conflicting through vehicles. Regardless of unrestricted view to see a vehicle at standard channels, one might have to turn back close to $150^{\circ}$, which is very difficult for some drivers such as older drivers and inexperienced drivers. Therefore, smart channels help make the driving task simpler, hence better performance in terms of safety based on literature.

Time headway used in this study is defined as the time difference between two successive locations of the through vehicle for each interaction event when the through vehicle crosses a given point along the through lane at an intersection. The two successive locations are identified at the moment the right-turn vehicle had an unobstructed view of the conflicting through vehicle and the potential conflict point downstream. i.e., based on the time of arrival to the conflict point for a through vehicle. Time headway was used as the measure of ISD using the frame count method in Virtualdub, a video processing utility for Windows. 


\section{POST ENCROACHMENT TIME METHODOLOGY}

\subsection{Background}

Many authors have ventured to identify or apply surrogate safety measures to prevail over the frequent lack of sufficient crash data. Some include; post encroachment time (Allen et al., 1978); and time-to-collision (Minderhoud and Bovy, 2001). An objective indicator is used to characterize the interaction between motor vehicles known as; Post- Encroachment Time (PET), which provides a simple way to measure proximity without the need for extrapolation or predicting future positions of vehicles. In a situation where a collision was not observed, PET can be used to measure vehicles' proximity (Tarko et al., 2009).

The PET definition for this study is the time difference between when the rear part of the motor vehicle leaves (or the front part arrives at) the area of a potential collision and when the front part of another motor vehicle arrives at (or the rear part departs from) this area (Kassim et al., 2014). Right-turn and through movements between vehicles will be considered for this study. The interactions between these vehicles were also referred to as potential conflicts.

This chapter describes a manual method used to measure PET between vehicles using a video analysis technique suggested by Kassim et al. (2014). The chapter is divided into three sections: data collection, PET measurement method, and PET sample data summary. 


\subsection{Data Collection}

PET data collection between motor vehicles involved using videos provided by the City of Ottawa to monitor right-turn motor vehicle movements and through motor vehicle movements to identify interaction events at all eight channels.

\subsubsection{Video Data Collection}

The videos from which data was extracted had a frame width of 720 pixels and a frame height of 480 pixels. The videos provided by the City of Ottawa used for this study had video footage between 6:45 am - 6:45 pm, a total of 12 hours on the day the camera was set up to observe the movements at each channel per intersection considered. This time window was used to obtain all observations used in this study. Table 4-1 details the day, month and year; the video data was created in the City of Ottawa's database. Table 4-2 gives a sample summary of the PET data collected. Each video was one hour long. In total, 96 videos were viewed, equivalent to 96 hours of viewing. A total of 58,546 vehicles were observed in this study, involving the movements of 44,048 through vehicles and 14,498 right-turn vehicles. These observations were done over four months, covering all eight channels. Table 4-3 summarizes the total vehicle volume observed at each intersection for right-turn vehicles and through vehicles. 
Table 4-1: Day of camera set up for each intersection

\begin{tabular}{|c|c|c|c|c|c|}
\hline $\begin{array}{l}\text { Type of } \\
\text { Channel }\end{array}$ & 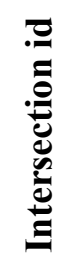 & Intersection name & $\begin{array}{c}\text { Day } \\
\text { Collected }\end{array}$ & Month & Year \\
\hline \multirow{4}{*}{$\begin{array}{c}\text { Standard } \\
\text { Channel }\end{array}$} & 1 & Fisher \& Meadowlands & Tuesday & November & 2019 \\
\hline & 2 & Baseline \& Woodroffe & Wednesday & October & 2019 \\
\hline & 3 & Baseline \& Woodroffe & Wednesday & October & 2019 \\
\hline & 4 & Riverside \& Brookefield & Wednesday & October & 2019 \\
\hline \multirow{4}{*}{$\begin{array}{l}\text { Smart } \\
\text { Channel }\end{array}$} & 5 & Baseline and Clyde & Tuesday & November & 2019 \\
\hline & 6 & Greenbank \& Strandherd & Thursday & May & 2020 \\
\hline & 7 & Riverside \& Heron & Thursday & April & 2020 \\
\hline & 8 & Strandherd \& Longfield & Tuesday & November & 2019 \\
\hline
\end{tabular}

\subsubsection{Method of Measuring PET}

The method used for this study was the Manual Frame Count Measurement (MFCM) suggested by Kassim et al. (2014), a method to identify motor vehicles' behaviour while manoeuvring the signalized intersections to determine the PET. The videos were observed manually to identify interactions. Interactions involving vehicles turning right at the channel and conflicting through vehicles were the focus of this study. The potential area of conflict is illustrated in Figure 4-1. A right-turn interaction occurred when a motor vehicle made a right-turn through either a smart or standard channel and crossing the conflicting through motor vehicles' path. 


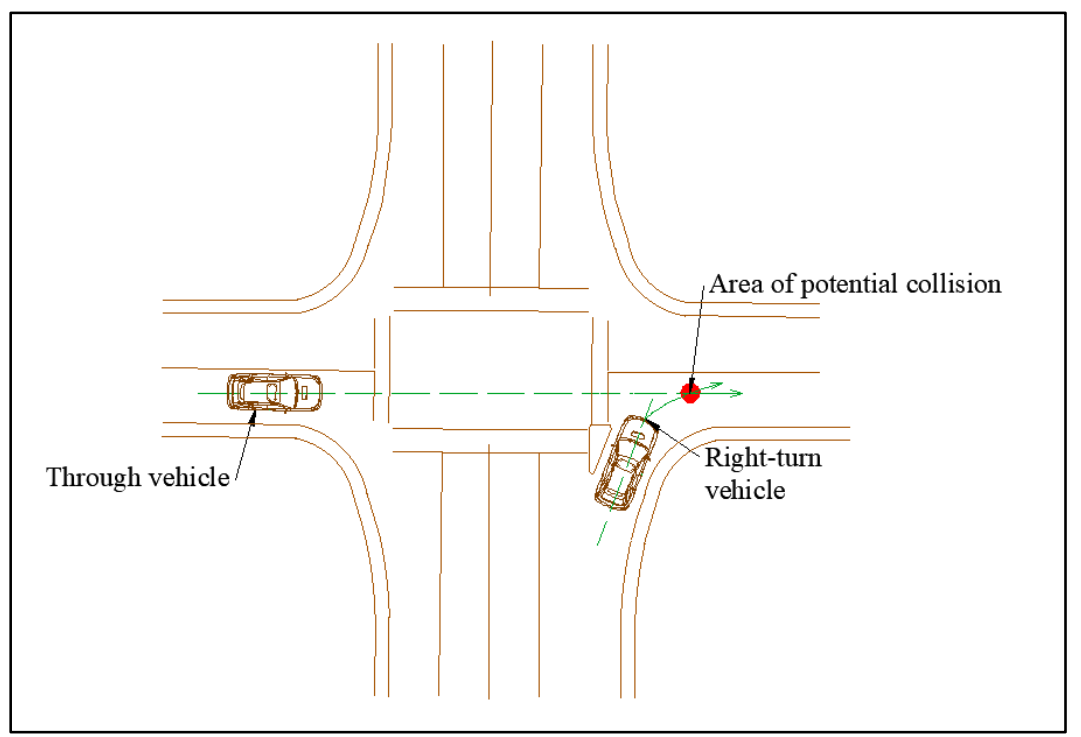

Figure 4-1: Right-turn and through vehicle interaction schematic drawing

Furthermore, two scenarios were observed with this interaction type depending on whether the vehicle turning right or through vehicle arrives first at the possible collision area, as seen in Figure 4-2.

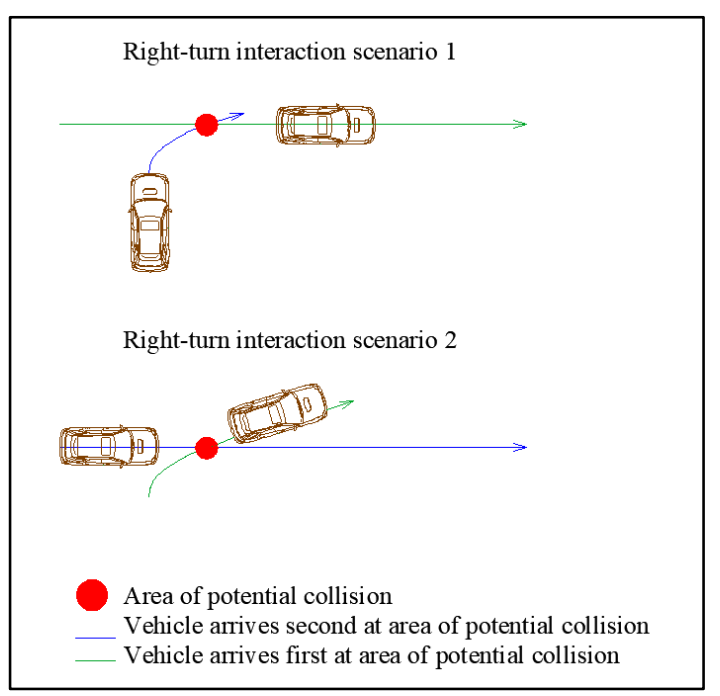

Figure 4-2: Vehicle interaction scenarios 
Using the Manual Frame Count Method (MFCM) suggested by Kassim et al. (2014), the point where the two paths of the motor vehicles intersect is known as the area of potential collision according to each scenario seen in Figure 4-2. This point of intersection was visually identified while running the video in Virtualdub. Once the intersection point was identified, a pointing device was placed on the computer screen to mark this location. The accuracy of identifying the intersection point is a function of the observer's accuracy (in this case, author of thesis). The events identified in this study were reviewed and verified by a former graduate student, and events with a frame difference of more than two had to be revisited for review by the thesis author.

For each interaction event, two frame counts were recorded corresponding to the interacting motor vehicle's arrival. The first frame was noted and recorded when the rear end of the right-turn vehicle (or through vehicle) leaves an area of potential collision and the second frame was noted and recorded when the front of the through vehicle (or right-turn vehicle) arrives at the area of potential collision. Thereafter, the frame count difference divided by the camera frame rate (approximately 30 frames/second) was used to obtain the PET for each event.

A threshold of PET $(0,3] \mathrm{s}$. was selected to count the number of interaction events. The use of PET threshold is attributed to research done by (Hyden and Linderholm, 1984). Very long PET values may not be relevant to safety and could be related more to regular non-hazardous events. A PET of $3 \mathrm{~s}$. as a critical threshold was used in many studies for PET between vehicles and cyclists (Kassim et al., 2014) (which used thresholds of 1 and 2 and 3s.), between motor vehicles (Sayed et al., 2008), between motor vehicles and pedestrians (Lord, 1996). In this study, a PET threshold of 3s. was used to identify interaction events between vehicles based on the study by Gettman et al. (2008), who analyzed various surrogate safety measures using four simulation models for different intersections. In the studies done by Gettman et al. (2008) and Kassim et al. (2014), 
interactions' proximity levels were classified into three proximity thresholds $(0,1],(1,2]$, and $(2,3] \mathrm{s}$.

\subsubsection{PET Data Summary}

An objective conflict indicator known as; Post Encroachment Time (PET) was used in this study to characterize interactions between motor vehicles at a channelized signalized intersection for both smart and standard channels. The chapter describes a manual video analysis technique used to measure PET between motor vehicles. The method used is the Manual Frame Count Method (MFCM) suggested by Kassim et al. (2014) to record PET measurements for each interaction event from the videos for all eight channels, four smart channels and four standard channels in the City of Ottawa, Ontario.

A total of 805 interactions with PET less than or equal to 3s. were observed, out of observations involving the movements of 44,048 through vehicles and 14,498 right-turn vehicles on eight different channels. A sample data of the first nineteen PET measurements at Baseline and Clyde are presented in Table 4-2. A PET threshold of 3s. was used to characterize hazardous events, as discussed in Section 4.2.2. 
Table 4-2: Sample data of PET measurements

\begin{tabular}{|l|l|r|r|r|}
\hline Intersection & Time & Video & events & PET \\
\hline Baseline \& Clyde & $6: 45 \mathrm{am}-7: 45 \mathrm{am}$ & 1 & 1 & 1.37 \\
\hline Baseline \& Clyde & $6: 45 \mathrm{am}-7: 45 \mathrm{am}$ & 1 & 2 & 2.50 \\
\hline Baseline \& Clyde & $6: 45 \mathrm{am}-7: 45 \mathrm{am}$ & 1 & 3 & 1.94 \\
\hline Baseline \& Clyde & $7: 45 \mathrm{am}-8: 45 \mathrm{am}$ & 2 & 1 & 1.20 \\
\hline Baseline \& Clyde & $7: 45 \mathrm{am}-8: 45 \mathrm{am}$ & 2 & 2 & 2.40 \\
\hline Baseline \& Clyde & $7: 45 \mathrm{am}-8: 45 \mathrm{am}$ & 2 & 3 & 1.47 \\
\hline Baseline \& Clyde & $7: 45 \mathrm{am}-8: 45 \mathrm{am}$ & 2 & 4 & 0.83 \\
\hline Baseline \& Clyde & $7: 45 \mathrm{am}-8: 45 \mathrm{am}$ & 2 & 5 & 2.00 \\
\hline Baseline \& Clyde & $7: 45 \mathrm{am}-8: 45 \mathrm{am}$ & 2 & 6 & 2.80 \\
\hline Baseline \& Clyde & $7: 45 \mathrm{am}-8: 45 \mathrm{am}$ & 2 & 7 & 1.27 \\
\hline Baseline \& Clyde & $7: 45 \mathrm{am}-8: 45 \mathrm{am}$ & 2 & 8 & 1.63 \\
\hline Baseline \& Clyde & $7: 45 \mathrm{am}-8: 45 \mathrm{am}$ & 2 & 9 & 1.60 \\
\hline Baseline \& Clyde & $7: 45 \mathrm{am}-8: 45 \mathrm{am}$ & 2 & 10 & 2.20 \\
\hline Baseline \& Clyde & $7: 45 \mathrm{am}-8: 45 \mathrm{am}$ & 2 & 11 & 1.63 \\
\hline Baseline \& Clyde & $7: 45 \mathrm{am}-8: 45 \mathrm{am}$ & 2 & 12 & 2.37 \\
\hline Baseline \& Clyde & $7: 45 \mathrm{am}-8: 45 \mathrm{am}$ & 2 & 13 & 1.37 \\
\hline Baseline \& Clyde & $7: 45 \mathrm{am}-8: 45 \mathrm{am}$ & 2 & 14 & 2.30 \\
\hline Baseline \& Clyde & $7: 45 \mathrm{am}-8: 45 \mathrm{am}$ & 2 & 15 & 2.50 \\
\hline Baseline \& Clyde & $7: 45 \mathrm{am}-8: 45 \mathrm{am}$ & 2 & 16 & 1.10 \\
\hline
\end{tabular}

Table 4-3: Total vehicle volume observed at each intersection

\begin{tabular}{|c|c|c|c|c|c|c|}
\hline $\begin{array}{l}\text { Type of } \\
\text { Channel }\end{array}$ & 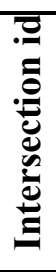 & Intersection name & Direction & 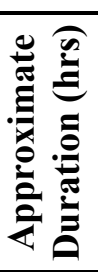 & $\begin{array}{l}\text { Total } \\
\text { vehicle } \\
\text { volume } \\
\text { (right) }\end{array}$ & $\begin{array}{l}\text { Total } \\
\text { vehicle } \\
\text { volume } \\
\text { (through } \\
\text { volume) }\end{array}$ \\
\hline \multirow{4}{*}{$\begin{array}{l}\text { Standard } \\
\text { Channel }\end{array}$} & 1 & Fisher and Meadowlands & EBR & 12 & 417 & 4549 \\
\hline & 2 & Baseline and Woodroffe & EBR & 12 & 1001 & 5857 \\
\hline & 3 & Baseline and Woodroffe & WBR & 12 & 2748 & 8475 \\
\hline & 4 & $\begin{array}{l}\text { Riverside and } \\
\text { Brookefield }\end{array}$ & SBR & 12 & 2490 & 1138 \\
\hline \multirow{4}{*}{$\begin{array}{c}\text { Smart } \\
\text { Channel }\end{array}$} & 5 & Baseline and Clyde & EBR & 12 & 2553 & 6725 \\
\hline & 6 & $\begin{array}{l}\text { Greenbank and } \\
\text { Strandherd }\end{array}$ & SBR & 12 & 2869 & 5033 \\
\hline & 7 & Riverside and Heron & SBR & 12 & 840 & 9883 \\
\hline & 8 & Strandherd and Longfield & EBR & 12 & 1580 & 2388 \\
\hline
\end{tabular}

*SBR-Southbound-right, EBR-Eastbound-right, WBR-Westbound-Right 


\section{SIGHT DISTANCE METHODOLOGY}

This chapter presents the method used to measure the sight distance at the intersections used in this study, using a manual technique. This chapter is organized into two main sections, the data collection and the measurement procedures. The subsections include a brief recap on the study sites' description, the video data collection process, followed by a detailed description of the methodologies used to measure time headway (as the measure of ISD), sightline distance, right turning sightline angle, SDTL as parameters of visibility. The distance between the through vehicles' location when first seen by a right turning vehicle to its location at the potential conflict area could not be measured directly from the video in Virtualdub, hence using time headway as a measure of ISD. Besides, time headway is a more relevant safety measure compared to distance as it is a better indication of driver response to safety-critical events.

\subsection{Data Collection}

Manual techniques were utilized to measure the sightline distance, right turning sightline angles, SDTL and time headway for each event at the eight channels when a conflict was observed on the intersecting lane. As explained in Section 3.1, the study uses seven, four-leg signalized intersections within Ottawa, Ontario, comprising of four smart channels and four standard channels. A map showing the location of the intersections is shown in Figure 3-1. The view of the intersections as viewed from the monitoring cameras, previously positioned by the City of Ottawa, is shown in Figure 3-2 and Figure 3-3 for smart and standard channels, respectively.

According to AASHTO (2011) policy, motor vehicle drivers approaching an intersection at-grade should have an unobstructed view of the whole intersection to avoid collisions by 
permitting control of the vehicle. One of the smart channel functionalities is to reduce turning speed in consistency with yield conditions that may require a stop (City of Ottawa, 2009).

During turning manoeuvres, sight distance is usually measured from the height of the turning vehicle driver's eye (also known as an observer) to the top of the approaching conflicting through vehicle (also known as an object). In some cases, the driver cannot clearly detect the approaching vehicles' presence until part of the vehicle is visible because of an obstruction within its sight distance triangle (TAC, 2017).

The channel shown in Figure 5-1 is at Strandherd and Longfields. During data extraction from the videos, the right-turn vehicle (marked 1) was the observer, illustrated in Figure 5-1, the conflicting through vehicle (marked 3) as the object, and the adjacent through vehicle obstructing the observer's sightline (marked 2) as the obstructor. Figure 5-1 is an example of a scenario where the observer could not clearly see the approaching conflicting through vehicle until the right-turn vehicle was just about to merge into the intersecting lane. In some cases, the vehicle in the adjacent through lane to the right-turn lane waiting to go through the intersection, restricted the right-turn driver's view of the approaching conflicting through vehicles. The obstruction extent depends on the adjacent through vehicles' lanes alignment and the vehicle's size and position in the adjacent through lanes. 


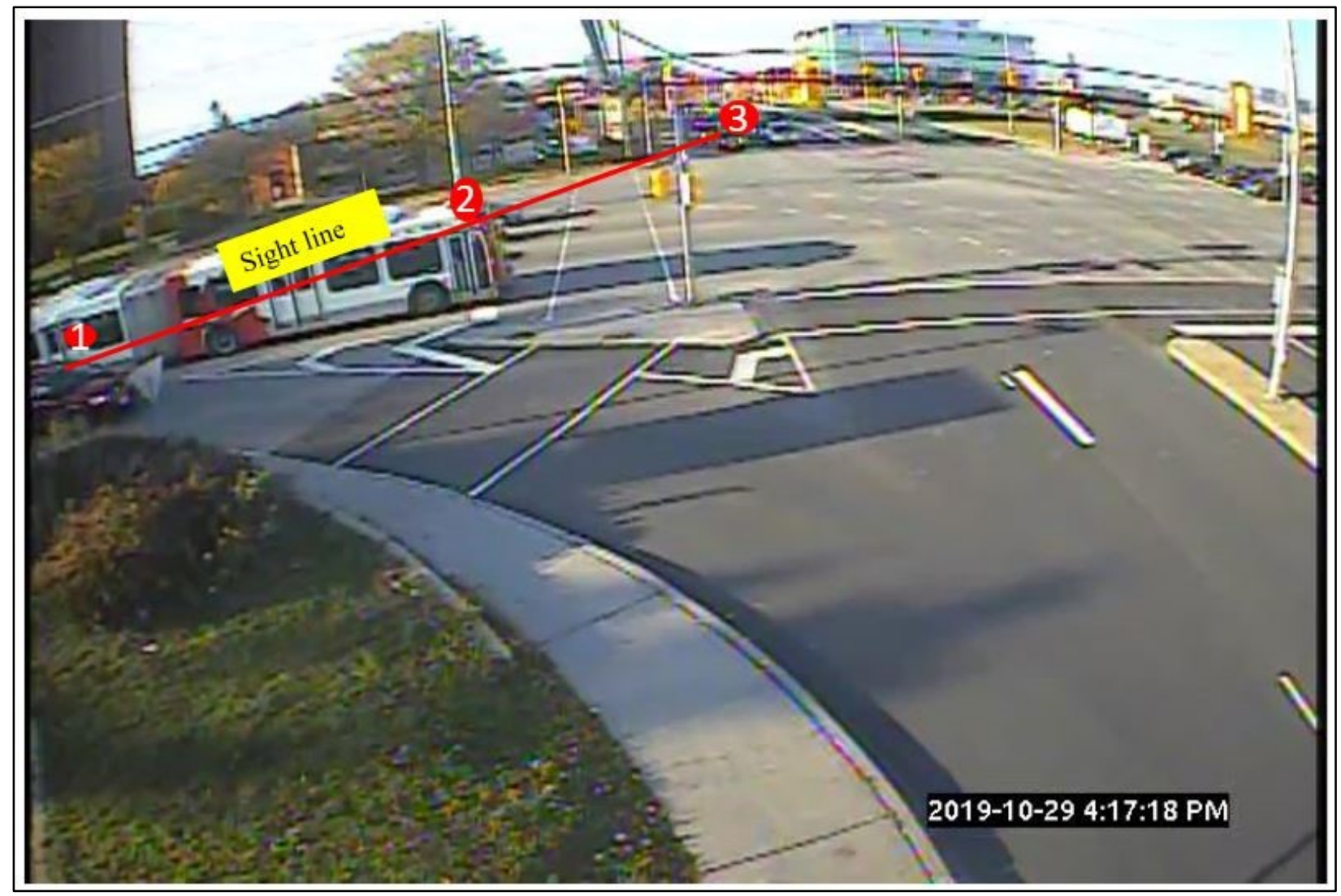

Figure 5-1: Obstruction along the sightline

The new positions 1 and 2 in Figure 5-2 for each conflict observation were identified at the point when the right-turn vehicle could see the approaching conflicting through vehicle on the intersecting lane. These positions are free from obstructions and enable drivers to obtain the information they need to decide whether to stop or merge with oncoming traffic safely. The position of the right-turn vehicle for this scenario is further downstream of the right-turn lane compared to that in Figure 5-1. A conflict was observed depending on the conflicting through vehicle's speed, time headway and whether sight distance was sufficient or not. Sufficient sight distance is necessary such that the right-turn vehicles can avoid conflicts with the conflicting through vehicles approaching from the left. 


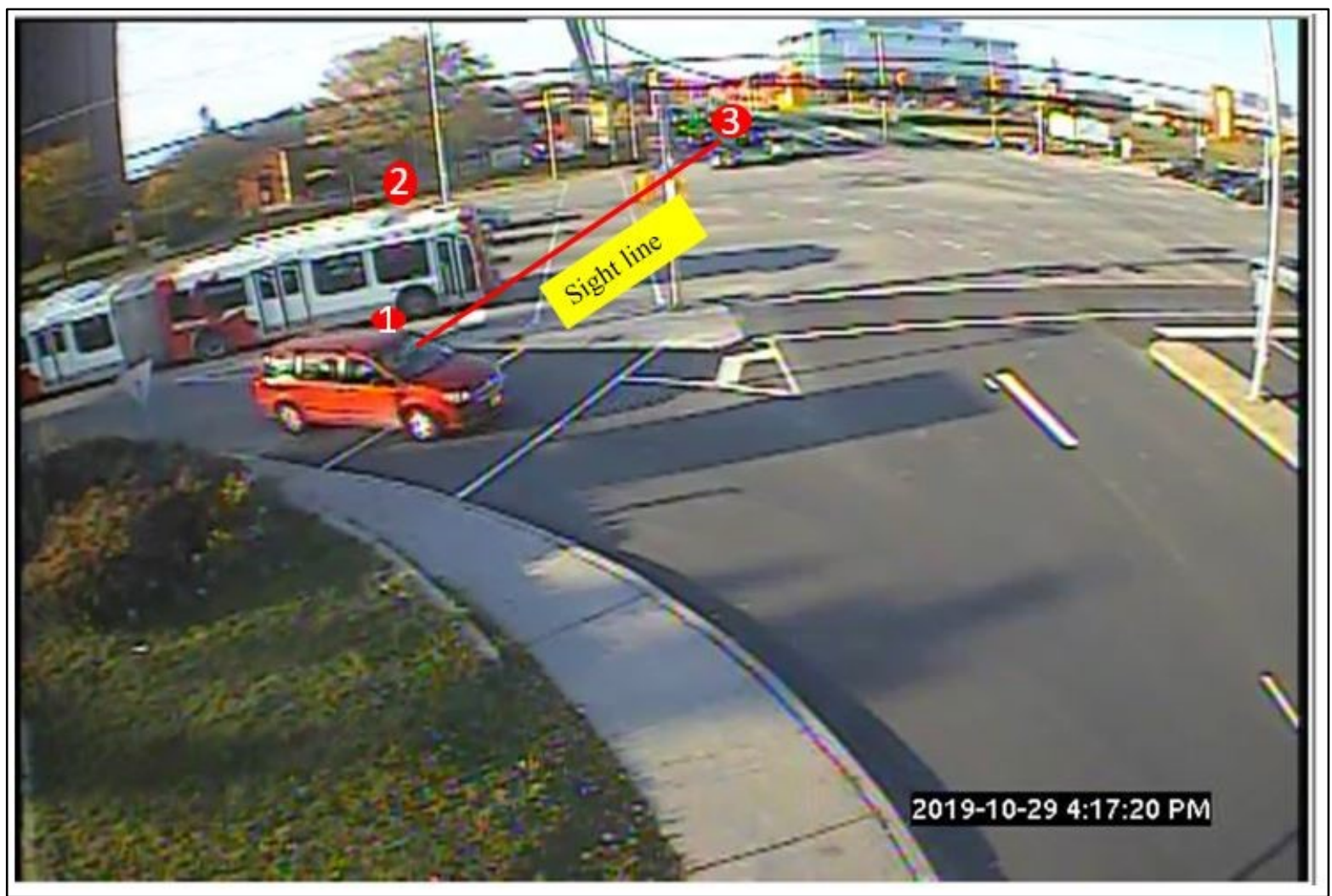

Figure 5-2: Point of clear visibility for right-turn vehicle

\subsection{Measurement Procedure}

\subsubsection{Sightline Distance and Right Turning Sightline Angle}

Firstly, the sight distance triangle concept described in (TAC, 2017) was used to obtain the sightline distance for each conflict observed, see sightline in Figure 5-3. The sightline's starting point depends on the position of the right-turn vehicle along the channel. The right-turn vehicle's position is estimated at the point a right-turn driver first sees the approaching conflicting through vehicle from the left (vehicle position B), to the location of the conflicting through vehicle along the through lane's centerline (vehicle position A on the right) that was free from obstruction. 


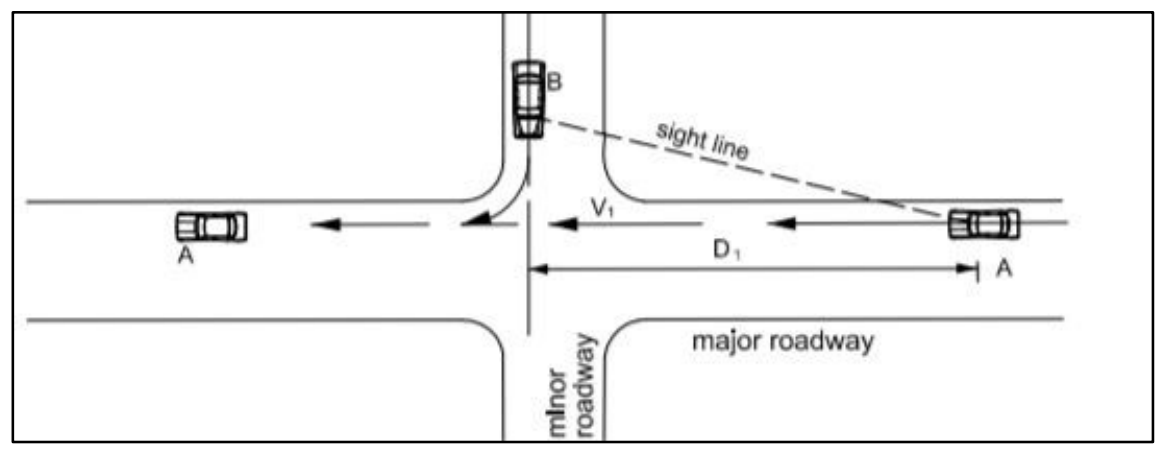

Figure 5-3: Sight distance triangle (TAC, 2017)

Measuring the sightline distance directly from the image captured from Virtualdub was a challenge, as the camera angle and position were not specific to a conflict study. The videos used were provided by the City of Ottawa, with camera positions specific to vehicle counts study. Therefore, the image captured for sightline distance measurements would have required perspective correction using the Homography Matrix to obtain accurate sightline distance measurements. An alternative approach was used, where the location of the right-turn vehicle relative to the conflicting through vehicle from the left was identified, one that had a clear view (free from obstructions). Identifying position 1 (decision point location) and 3 (conflicting vehicle location) for each case was done visually using Virtualdub illustrated in Figure 5-2.

Thereafter, an aerial view of each intersection was obtained from Google Earth. The aerial view image was imported into AutoCAD to draw each lane's centerline on both the right-turn lane and conflicting through lane. Finally, the aerial view was imported into ImageJ (a Java-based image processing program) to measure the sightline distances between vehicles using the vehicle positions identified in Virtualdub for each interaction event. 
The image imported into ImageJ software program consists of a scale bar, shown in Figure 5-4 as an example at Riverside and Brookefield. The scale bar was used to scale the image before measurements were done. The straight-line tool, shown in Figure 5-5, was used to draw a straight line along the scale bar's length. Under the Analyze drop-down menu, the set scale option was selected, and the pop-up window was displayed with the line distance in pixels. The known distance of $40 \mathrm{~m}$ shown on the scale bar is input into the known distance section along with its unit of length (m). Pressing the okay button set the scale.

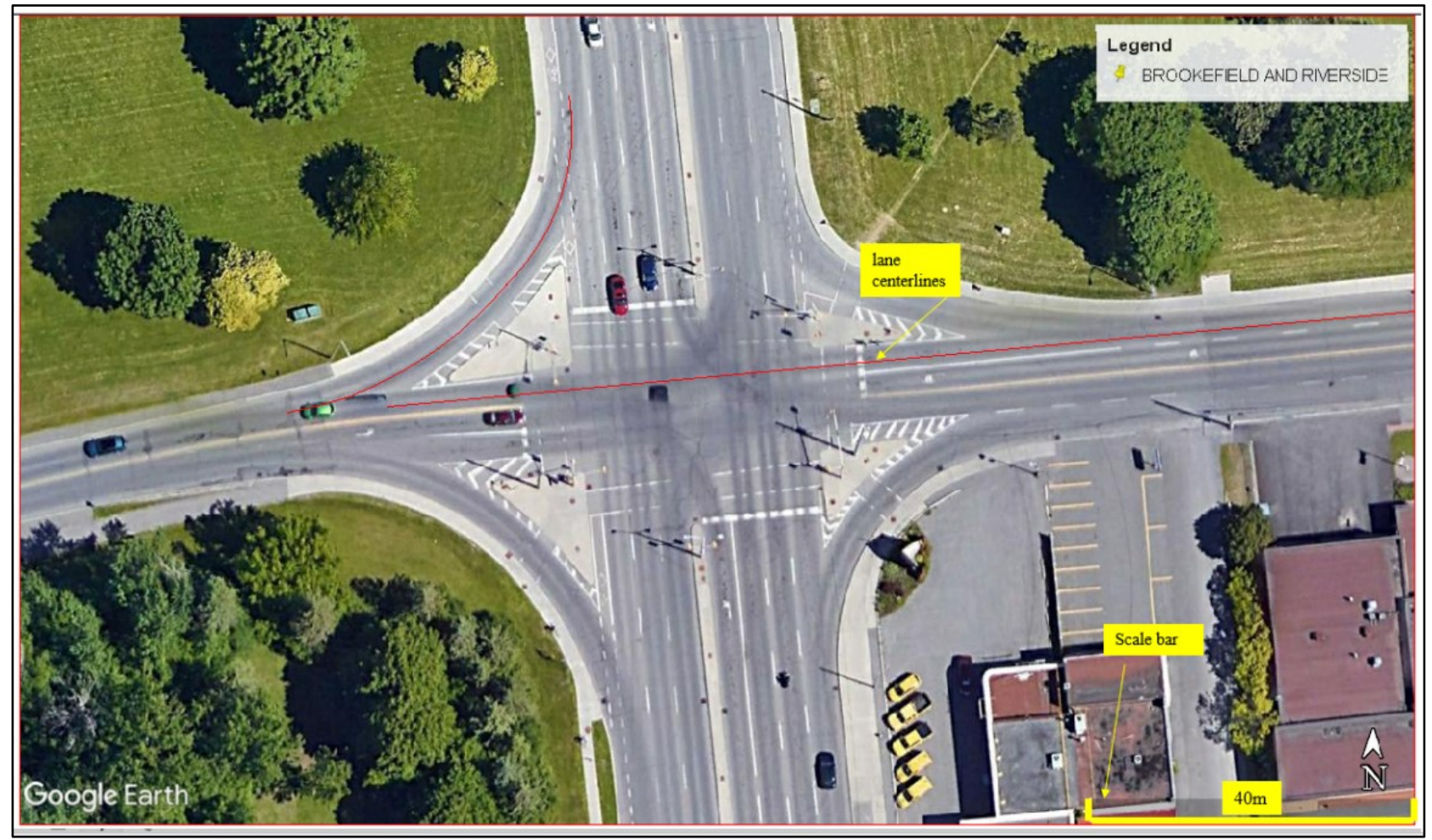

Figure 5-4: Image showing lane centerlines and scale bar 


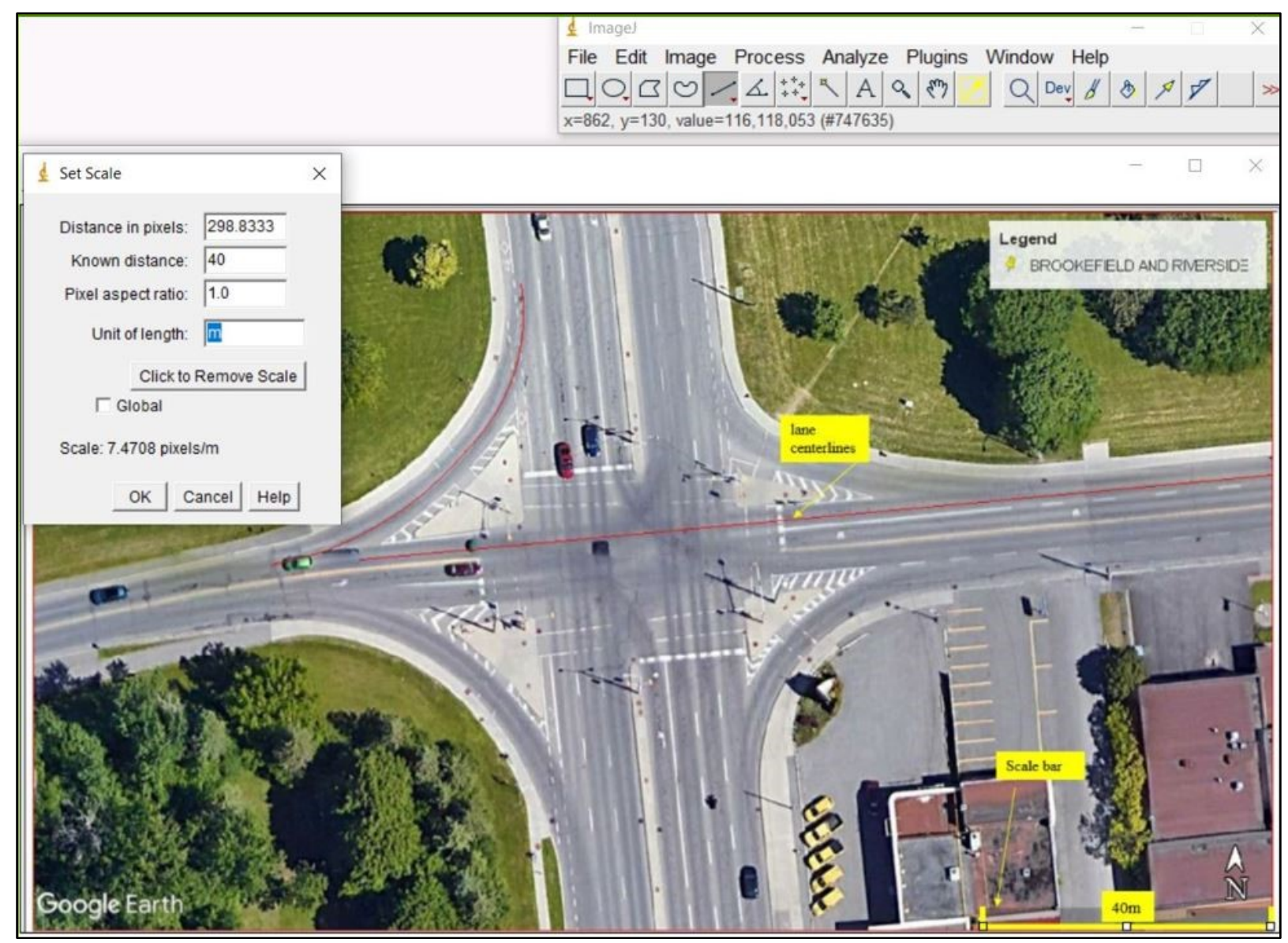

Figure 5-5: Procedure of setting image scale

Once the scale of the image was set, sightline distances were measured. ImageJ can measure multiple lines and store those lengths within the program, which can be reproduced later if needed. Using the Analyze-Tools- Region of Interest (ROI) manager, the ROI manager window popped up and was used to record the measured sightline lengths' coordinates. The vehicles' relative position of the (right-turn and through vehicle) locations identified in Virtualdub mentioned above were mapped onto the aerial image in ImageJ using the line tool, and the sightline distance measured. Each sightline drawn is labelled in sequence, as coordinates of the distance drawn on the image shown in the ROI manager. Each measurement made is recorded within the 
program through this method. Selecting a measurement in the ROI manager highlights the line measured and can be edited if needed.

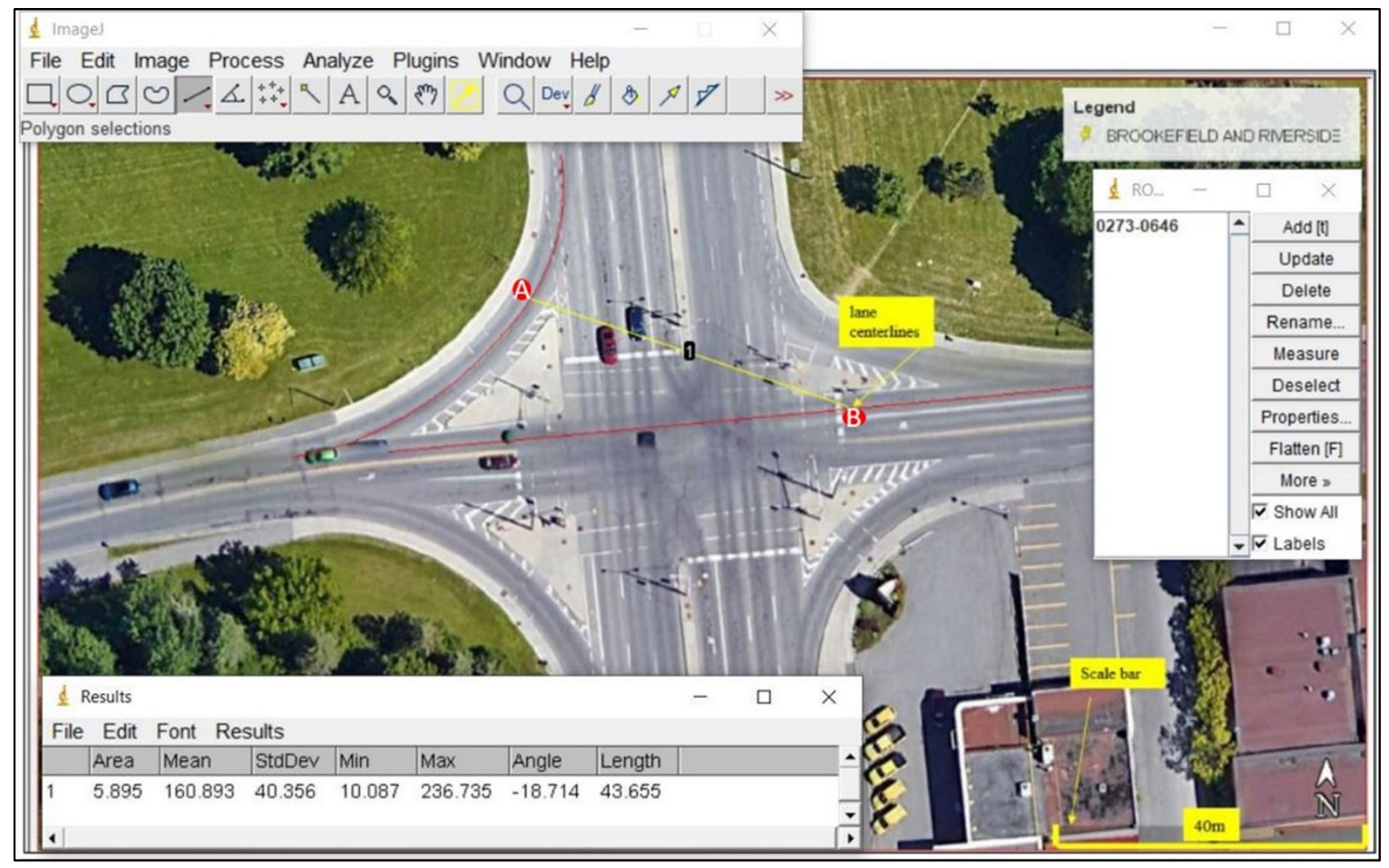

Figure 5-6: ROI manager to save measured distances

After mapping all the distances onto the image, the "measure" button on the ROI manager was used to record the measured distances and a pop-up up window with the measured distances appeared. The measurements in the results window were saved as a Microsoft Excel file. The measurements used for illustration are for video one (6:45 am-7:45 am) out of the twelve videos at Riverside and Brookefield. Line 1, shown in the results window in Figure 5-6, is the sightline. 
Once the sightline was drawn, the right turning sightline angle was measured using the angle tool on the ImageJ toolbar. The angle is drawn from the tangent of the right-turn channel's centerline to vehicle A's sightline, illustrated in Figure 5-7.

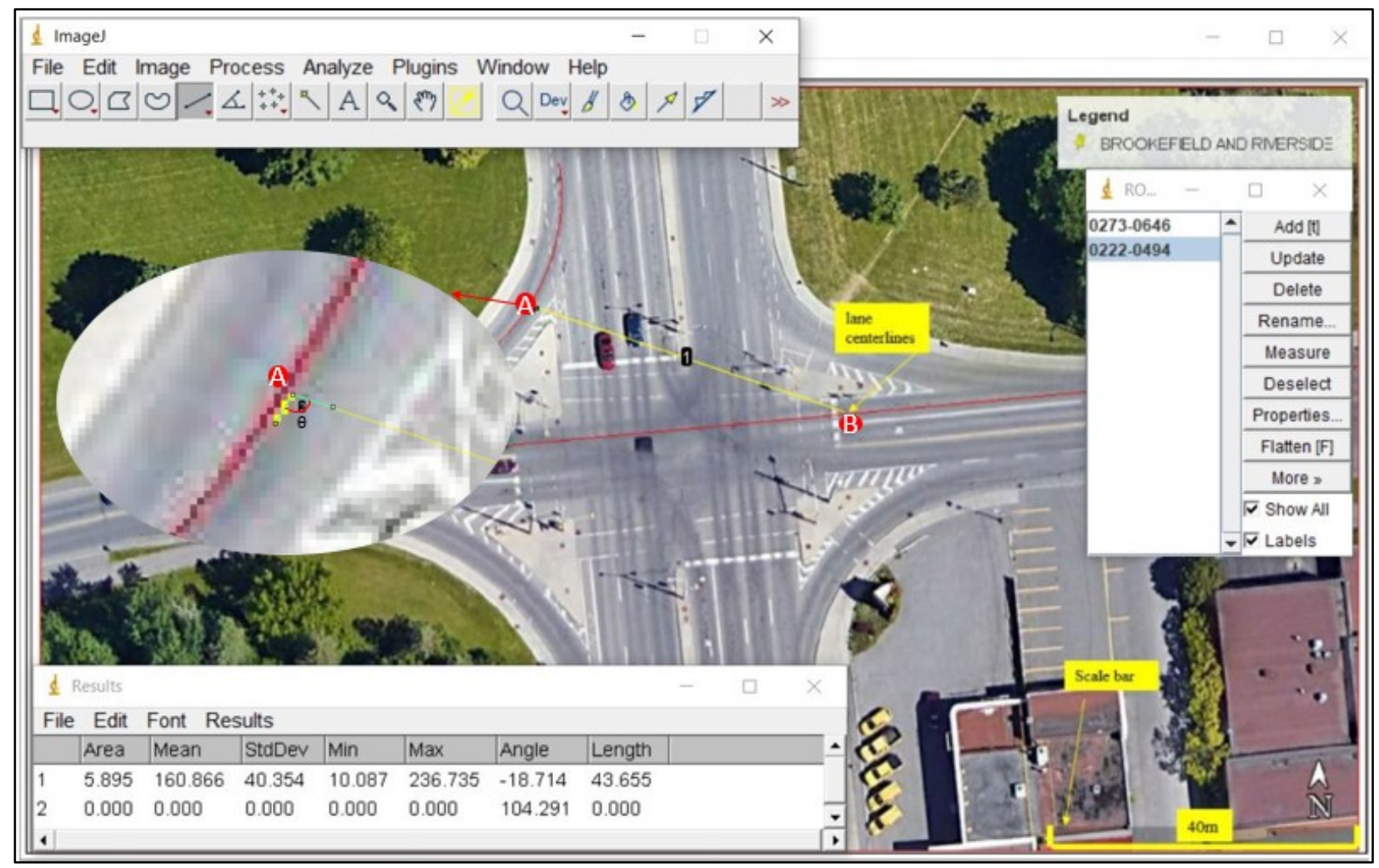

Figure 5-7: Right turning sightline angle measurement

\subsubsection{Sight Distance Triangle Leg}

The method used to obtain the SDTL as described in (TAC, 2017), is illustrated in Figure 5-3 based on the sight distance triangle. $\mathrm{D}_{1}$ in Figure 5-3 illustrates the sight distance triangle leg. After measuring the sightline distances for all observations described in Section 5.2.1, the same procedure was used to measure the decision point distance $d_{b}$. The distance $d_{b}$ is a line drawn 
from point A in Figure 5-8 to a point perpendicular to the through vehicle's lane centerline. A sample of the sightline distance $d_{c}$ and decision point distance $d_{b}$ are illustrated in Figure 5-8.

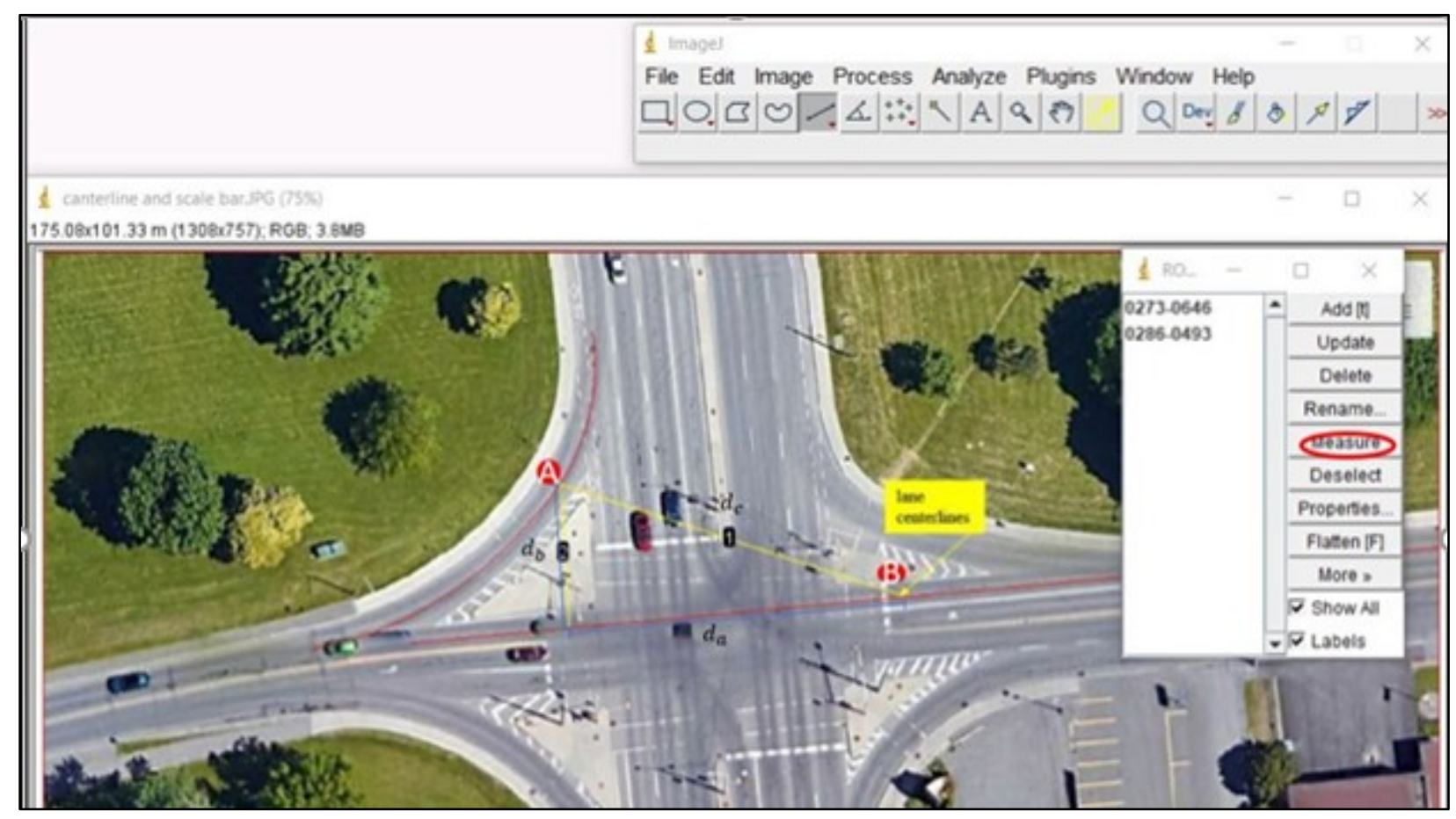

Figure 5-8: Conflicting vehicle distance measurement

The measurements of the sightline distance and decision point distance obtained were saved as a Microsoft Excel file. Line 1 is the sightline distance $d_{c}$, line 2 is the decision point distance, labelled $d_{b}$. The SDTL is labelled $d_{a}$. The SDTL is then calculated in Excel using Equation (5-1).

$$
d_{a}=\sqrt{\left(d_{c}\right)^{2}-\left(d_{b}\right)^{2}}
$$

The sample data recorded in Table 5-1 includes the intersection name, the video number out of twelve videos for each channel location, the observation ID, the measured sightline distances, the right turning sightline angles, decision point distances, SDTL and finally, the 
channel type. Sample mapped measurements for video one (6:45 am - 7:45 am) out of twelve videos at each intersection are presented in Appendix A.

Table 5-1: Intersection sight distance measurements at Riverside and Brookefield

\begin{tabular}{|c|c|c|c|c|c|c|c|}
\hline Intersection & Video & 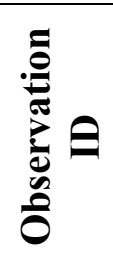 & $\begin{array}{l}\text { sightline } \\
\text { distance } \\
\text { (m) }\end{array}$ & $\begin{array}{c}\text { Right } \\
\text { turning } \\
\text { sightline } \\
\text { angle }\end{array}$ & $\begin{array}{c}\text { decision } \\
\text { point } \\
\text { distance } \\
\text { (m) }\end{array}$ & $\begin{array}{l}\text { SDTL } \\
\text { (m) }\end{array}$ & $\begin{array}{c}\text { Channel } \\
\text { type }\end{array}$ \\
\hline $\begin{array}{l}\text { Riverside \& } \\
\text { Brookefield }\end{array}$ & 1 & 1 & 43.7 & 104.30 & 16.7 & 40.4 & standard \\
\hline $\begin{array}{l}\text { Riverside \& } \\
\text { Brookefield }\end{array}$ & 1 & 2 & 39.8 & 124.33 & 14.2 & 37.2 & standard \\
\hline $\begin{array}{l}\text { Riverside \& } \\
\text { Brookefield }\end{array}$ & 1 & 3 & 59.3 & 144.78 & 4.9 & 59.0 & standard \\
\hline $\begin{array}{l}\text { Riverside \& } \\
\text { Brookefield }\end{array}$ & 1 & 4 & 39.1 & 119.06 & 14.0 & 36.5 & standard \\
\hline $\begin{array}{l}\text { Riverside \& } \\
\text { Brookefield }\end{array}$ & 1 & 5 & 48.3 & 145.16 & 5.1 & 48.1 & standard \\
\hline $\begin{array}{l}\text { Riverside \& } \\
\text { Brookefield }\end{array}$ & 1 & 6 & 46.5 & 117.69 & 13.0 & 44.6 & standard \\
\hline $\begin{array}{l}\text { Riverside \& } \\
\text { Brookefield }\end{array}$ & 1 & 7 & 51.4 & 124.57 & 12.4 & 49.8 & standard \\
\hline
\end{tabular}

\subsubsection{Time Headway Measurement}

Time headway is measured based on arrival time to conflict point for the through vehicle as a measure for ISD for each potential conflict event. Time headway is measured as the time difference between the point the conflicting through vehicle from the left is first seen by the rightturning vehicle, and the point the through vehicle arrives at/ leaves the area of potential conflict depending on the type of manoeuvre.

The time headway was measured using the frame count in Virtualdub, similar to PET. The difference while measuring time headway is that only one vehicle was observed (the conflicting through vehicle) to obtain these measurements. An example measurement at Riverside and 
Brookefield is illustrated by position 1 in Figure 5-9, the point where the right turn vehicle driver first sees the conflicting through vehicle from the left. This position is indicated by the frame count 9187. Position 2 in Figure 5-10 is when the conflicting through vehicle's rear end leaves the point of potential conflict. This specific conflict involved the right-turn vehicle arriving at the potential conflict area after the conflicting through vehicle. This position is indicated by the frame count 9350. The frame count difference divided by the camera frame rate gives the time headway for each event shown by Equation (5-2). The camera frame rate is 29.97 frames/second, approximately 30 frames/second.

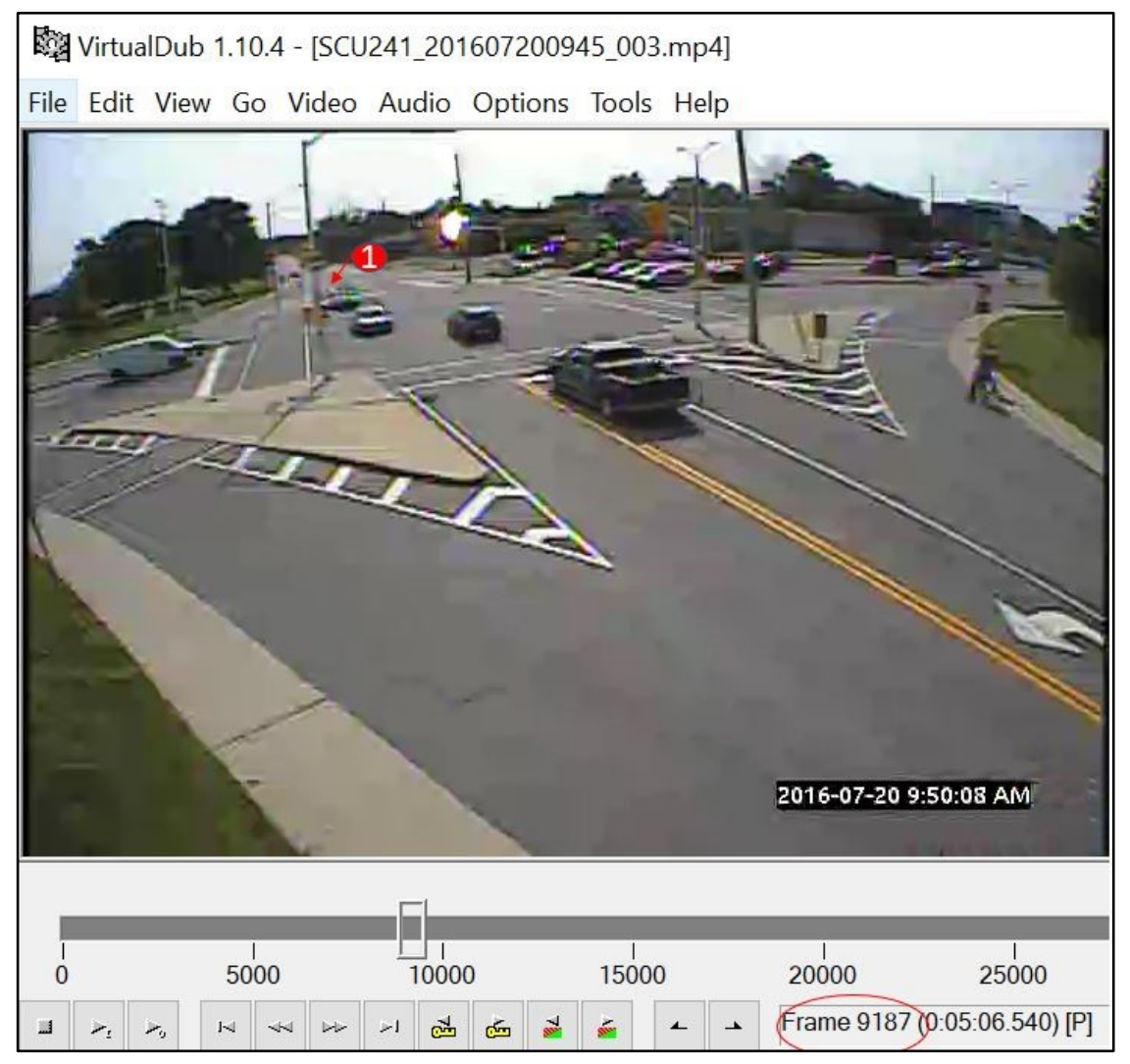

Figure 5-9: First position of approaching conflicting through vehicle 


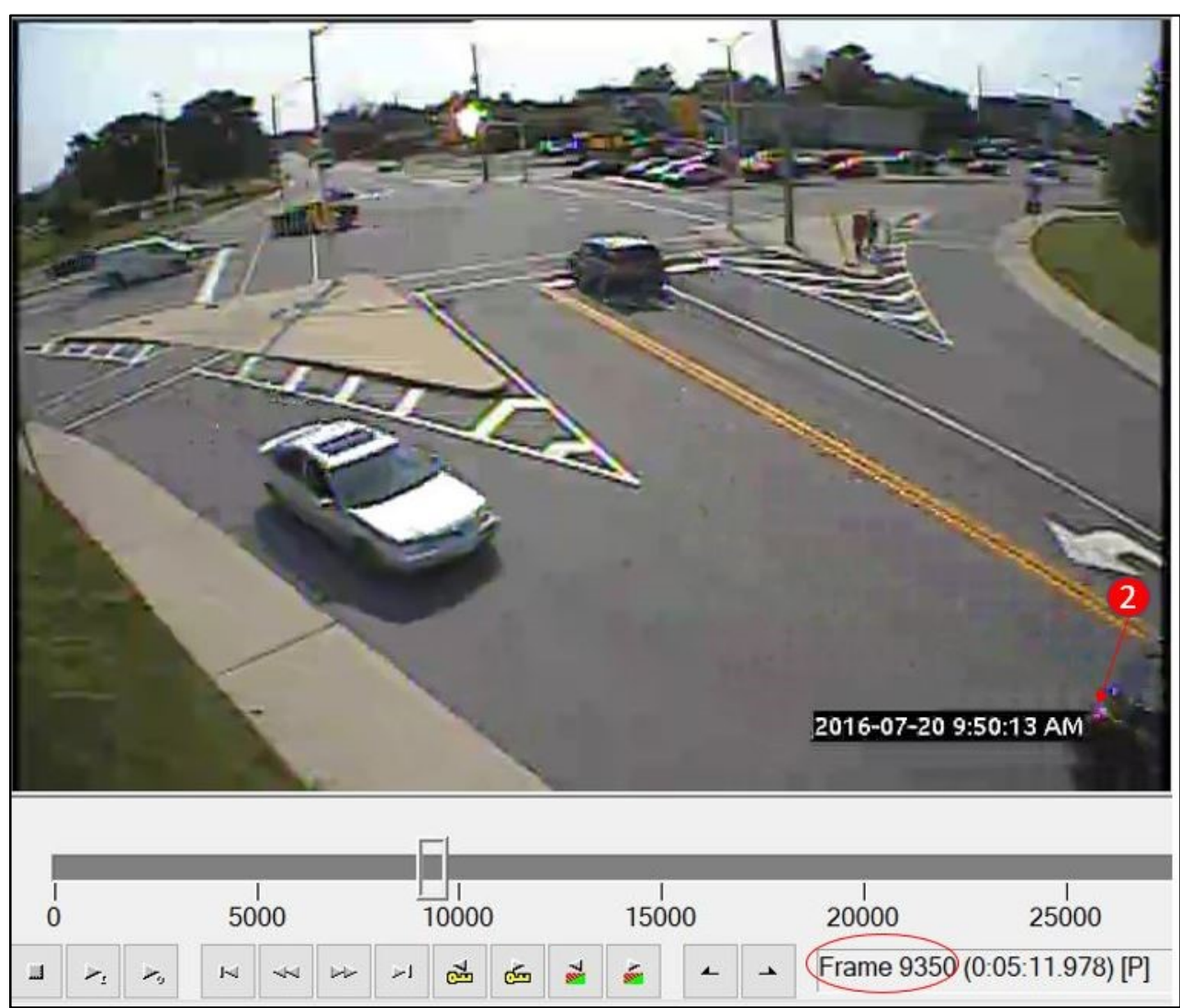

Figure 5-10: Second position of approaching conflicting through vehicle

$$
\frac{\text { Frame count } 2-\text { frame count } 1}{\text { frame rate }(\text { frames } / \text { second })}
$$

The sample data of the time headway measurements at Riverside and Brookefield are shown in Table 5-2 obtained using Equation (5-2). The table shows sample time headway measurements obtained, the video number the data was obtained, the observation ID, calculated time headway(s.) using the frame count and frame rate, and the channel type at which the measurements were made. 
Table 5-2: Time headway sample measurements

\begin{tabular}{|c|c|c|c|c|}
\hline Intersection & Video & $\begin{array}{c}\text { observation } \\
\text { ID }\end{array}$ & $\begin{array}{c}\text { Time } \\
\text { headway(s.) }\end{array}$ & $\begin{array}{c}\text { channel } \\
\text { type }\end{array}$ \\
\hline Riverside \& Brookefield & 4 & 1 & 5.44 & standard \\
\hline Riverside \& Brookefield & 4 & 2 & 7.71 & standard \\
\hline Riverside \& Brookefield & 5 & 1 & 6.41 & standard \\
\hline Riverside \& Brookefield & 5 & 2 & 6.57 & standard \\
\hline Riverside \& Brookefield & 5 & 3 & 3.27 & standard \\
\hline Riverside \& Brookefield & 5 & 4 & 5.44 & standard \\
\hline Riverside \& Brookefield & 5 & 5 & 5.17 & standard \\
\hline Riverside \& Brookefield & 5 & 6 & 3.84 & standard \\
\hline Riverside \& Brookefield & 5 & 7 & 8.38 & standard \\
\hline
\end{tabular}




\section{DATA ANALYSIS}

This chapter presents the statistical analysis that helps compare how different channel configurations, i.e., smart and standard channels influence both sight distance and conflicts. PET is the surrogate measure of safety used in this study, as described in Chapter Four, represented by traffic conflicts instead of collision-based data.

Strandherd and Longfields lane orientation does not have a direct link between right-turn vehicles and conflicting through vehicles. Heron and Riversides' lane orientation also differs from the other channels because of the bus lane immediately downstream of the channel's right-turn lane. In some analysis sections, the two channel locations were excluded individually to determine whether the data is significantly affected by these two intersections. The channel locations variable is coded (1-8) in SPSS using alphabetical order; 1- Baseline and Clyde, 2- Baseline and Woodroffe (EBR), 3- Baseline and Woodroffe (WBR), 4- Fisher and Meadowlands, 5- Greenbank and Strandherd, 6- Riverside and Brookefield, 7- Riverside and Heron and 8- Strandherd and Longfields.

\subsection{Data Statistical Descriptives}

This section presents descriptive statistics of the performance parameters used in this study. The statistics summarize the study's dataset comparing performance parameters at both channel configurations, at smart and standard channels. The continuous variables are PET measurements $(0,3]$ s., sightline distance, SDTL, right turning sightline angle and time headway. The descriptive statistics for each variable report central tendency measures and the measures of variability and normality tests. The categorical variable is PET severity level categorized into three groups and classified as an ordinal variable. The frequency statistics of the PET severity levels are presented, 
indicating the frequency of potential conflicts count per channel type. The percentage potential conflict count frequency at any proximity level was also obtained within each channel configuration at the four smart channels and four standard channels.

Descriptive statistics of the performance parameters are shown in Table 6-1 for smart and standard channels. There were 369 observations at standard channels and 436 observations at smart channels. The mean of the variables; PET (s.), time headway (s.), SDTL (m), sightline distance (m) and right turning sightline angle were higher at standard channels than at smart channels. There is more variability in the data variables at standard channels for time headway, SDTL, sightline distance and right turning sightline angle than at smart channels, whereas the variability in PET measurements have similar variance at both channel configurations.

The degree of skewness was determined using Fishers' skewness coefficient, where the skewness is divided by the standard error skewness, which is the z-score shown in Table 6-2. PET data at both smart and standard channels was positively skewed indicated by PET z-score which lies outside the range \pm 1.96 at the $5 \%$ level of significance. Time headway and sightline distance data are positively skewed at standard channels while at smart channels, the time headway and sightline distance distribution indicate that the data is likely to be normally distributed. The right turning sightline angle data is negatively skewed at both channels. The SDTL is positively skewed at standard channel and negatively skewed at smart channels. 
Table 6-1: Data measure of central tendency

Statistics

\begin{tabular}{|c|c|c|c|c|c|c|c|}
\hline channel & & & PET (s.) & $\begin{array}{c}\text { Time } \\
\text { headway(s.) }\end{array}$ & SDTL & $\begin{array}{l}\text { right turning } \\
\text { sightline } \\
\text { angle }\end{array}$ & $\begin{array}{c}\text { sightline } \\
\text { distance }(\mathrm{m})\end{array}$ \\
\hline \multirow[t]{10}{*}{ standard channel } & \multirow[t]{2}{*}{$\mathrm{N}$} & Valid & 369 & 369 & 369 & 369 & 369 \\
\hline & & Missing & 0 & 0 & 0 & 0 & 0 \\
\hline & \multicolumn{2}{|c|}{ Mean } & 1.64 & 7.01 & 55.73 & 114.85 & 58.05 \\
\hline & \multicolumn{2}{|c|}{ Median } & 1.53 & 6.77 & 53.70 & 118.16 & 55.50 \\
\hline & \multicolumn{2}{|c|}{ Std. Deviation } & .57 & 2.34 & 20.30 & 21.73 & 18.53 \\
\hline & \multicolumn{2}{|c|}{ Variance } & .321 & 5.454 & 412.060 & 472.400 & 343.196 \\
\hline & \multicolumn{2}{|c|}{ Skewness } & .339 & .651 & .380 & -.806 & .634 \\
\hline & \multicolumn{2}{|c|}{ Std. Error of Skewness } & .127 & .127 & .127 & .127 & .127 \\
\hline & \multicolumn{2}{|c|}{ Kurtosis } & -.611 & .968 & 447 & 1.004 & .773 \\
\hline & \multicolumn{2}{|c|}{ Std. Error of Kurtosis } & .253 & .253 & 253 & .253 & 253 \\
\hline \multirow[t]{10}{*}{ smart channel } & \multirow[t]{2}{*}{$\mathrm{N}$} & Valid & 436 & 436 & 436 & 436 & 436 \\
\hline & & Missing & 0 & 0 & 0 & 0 & 0 \\
\hline & \multicolumn{2}{|c|}{ Mean } & 1.55 & 5.43 & 46.26 & 99.62 & 48.86 \\
\hline & \multicolumn{2}{|c|}{ Median } & 1.47 & 5.49 & 46.95 & 104.69 & 48.74 \\
\hline & \multicolumn{2}{|c|}{ Std. Deviation } & .57 & 1.32 & 10.79 & 17.40 & 8.85 \\
\hline & \multicolumn{2}{|c|}{ Variance } & .322 & 1.752 & 116.472 & 302.648 & 78.246 \\
\hline & \multicolumn{2}{|c|}{ Skewness } & 465 & -.105 & -.462 & -1.043 & -.035 \\
\hline & \multicolumn{2}{|c|}{ Std. Error of Skewness } & .117 & .117 & .117 & .117 & .117 \\
\hline & \multicolumn{2}{|c|}{ Kurtosis } & -.332 & .907 & 1.050 & 1.080 & .885 \\
\hline & \multicolumn{2}{|c|}{ Std. Error of Kurtosis } & .233 & .233 & .233 & .233 & .233 \\
\hline
\end{tabular}

Table 6-2: Z-score for each variable

\begin{tabular}{|c|r|r|r|r|c|}
\hline z-score & PET & $\begin{array}{c}\text { Time } \\
\text { headway }\end{array}$ & SDTL & $\begin{array}{c}\text { Sightline } \\
\text { distance }\end{array}$ & $\begin{array}{c}\text { Right } \\
\text { turning } \\
\text { sightline } \\
\text { angle }\end{array}$ \\
\hline standard channels & 2.67 & 5.13 & 2.99 & 4.99 & -6.35 \\
\hline smart channels & 3.97 & -0.90 & -3.95 & -0.30 & -8.91 \\
\hline
\end{tabular}

The data distribution is then visually analyzed using the frequency distribution with the normal curve superimposed and compared for smart and standard channels in Figure 6-1. The figure indicates more variability in most parameters at standard channels than at smart channels. 

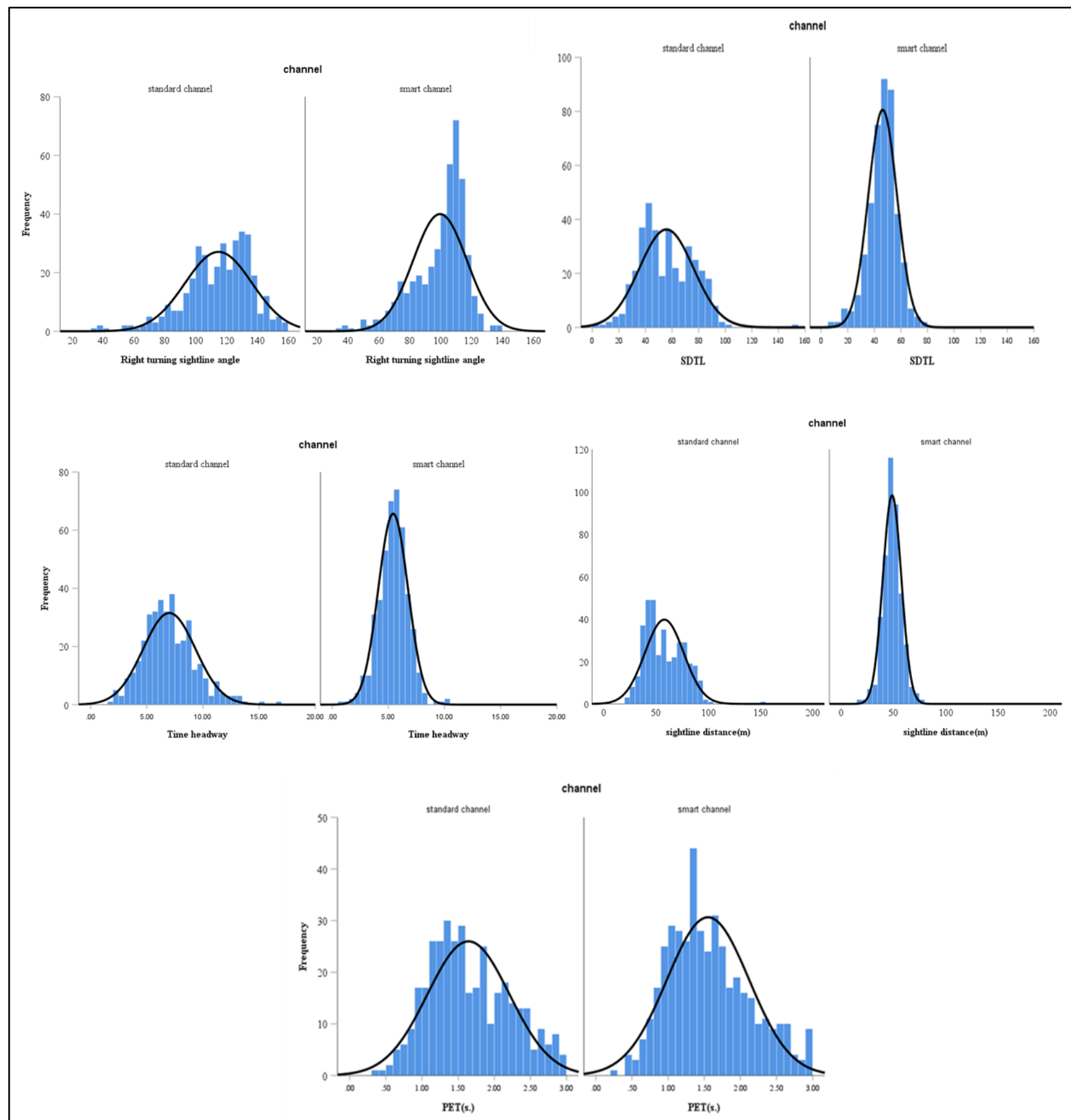

Figure 6-1: Frequency data distribution at smart and standard channels 
The normality of the data was tested using the Shapiro-Wilk and Kolmogorov-Smirnov test. At the 5\% level of significance, time headway data is normally distributed at smart channels for the Kolmogorov-Smirnov test but not normally distributed for the Shapiro-Wilk test. All other parameters in Table 6-3 indicate that they are not normally distributed, p-values $<0.05$. The normality test was repeated and shown in Table 6-3 at both channel types at each channel location using the variables; PET, time headway, SDTL, sightline distance and right turning sightline angle. It was observed that parameters at some channel locations were normally distributed. Therefore, there is not enough evidence to suggest that the data is strongly normally distributed or not when comparing channel types.

Table 6-3: Normality tests with all channel locations (1-8)

Tests of Normality

\begin{tabular}{|llcccccc|}
\hline \multirow{2}{*}{ channel } & & \multicolumn{3}{c}{ Kolmogorov-Smirnov ${ }^{\text {a }}$} & \multicolumn{3}{c|}{ Shapiro-Wilk } \\
\cline { 2 - 8 } standard channel & Statistic & df & Sig. & Statistic & df & Sig. \\
& PET (s.) & .082 & 369 & .000 & .977 & 369 & .000 \\
& Time headway(s.) & .060 & 369 & .003 & .977 & 369 & .000 \\
& SDTL & .084 & 369 & .000 & .973 & 369 & .000 \\
& right turning sightline & .069 & 369 & .000 & .962 & 369 & .000 \\
& angle & & & & & & \\
& sightline distance(m) & .105 & 369 & .000 & .951 & 369 & .000 \\
\hline smart channel & PET (s.) & .074 & 436 & .000 & .976 & 436 & .000 \\
& Time headway(s.) & .041 & 436 & .080 & .990 & 436 & .006 \\
& SDTL & .057 & 436 & .002 & .981 & 436 & .000 \\
& right turning sightline & .130 & 436 & .000 & .925 & 436 & .000 \\
& angle & & & & & .936 & .006 \\
\hline
\end{tabular}

a. Lilliefors Significance Correction 


\subsection{PET Severity Levels Analysis}

The PET measurements at PET threshold $(0,3] \mathrm{s}$. were categorized into three severity levels described in Section 4.2.2. Figure 6-2 shows that smart channels have a higher count of conflicts at medium and high severity proximity levels than at standard channels, whereas smart channels have a lower conflict count at low severity. Figure 6-3 and Figure 6-4 show the potential conflict count when channel location 8 and channel location 7 are excluded from the data, respectively.

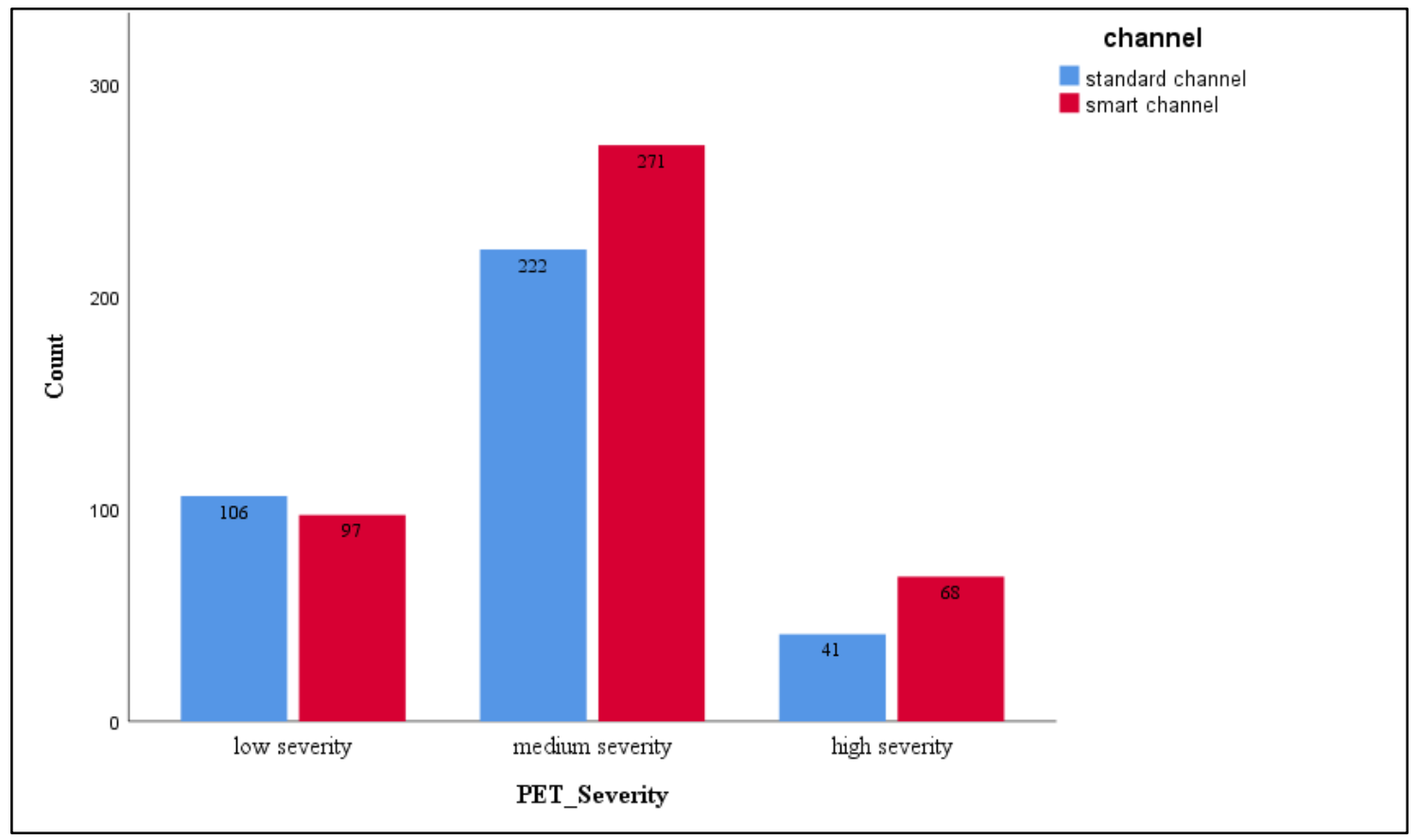

Figure 6-2: Conflict count with all intersections included

The patterns are similar when channel locations $7 \& 8$ are excluded to those when all channel locations are included in the data. The medium severity potential conflict count changes the most between the three graphs. 


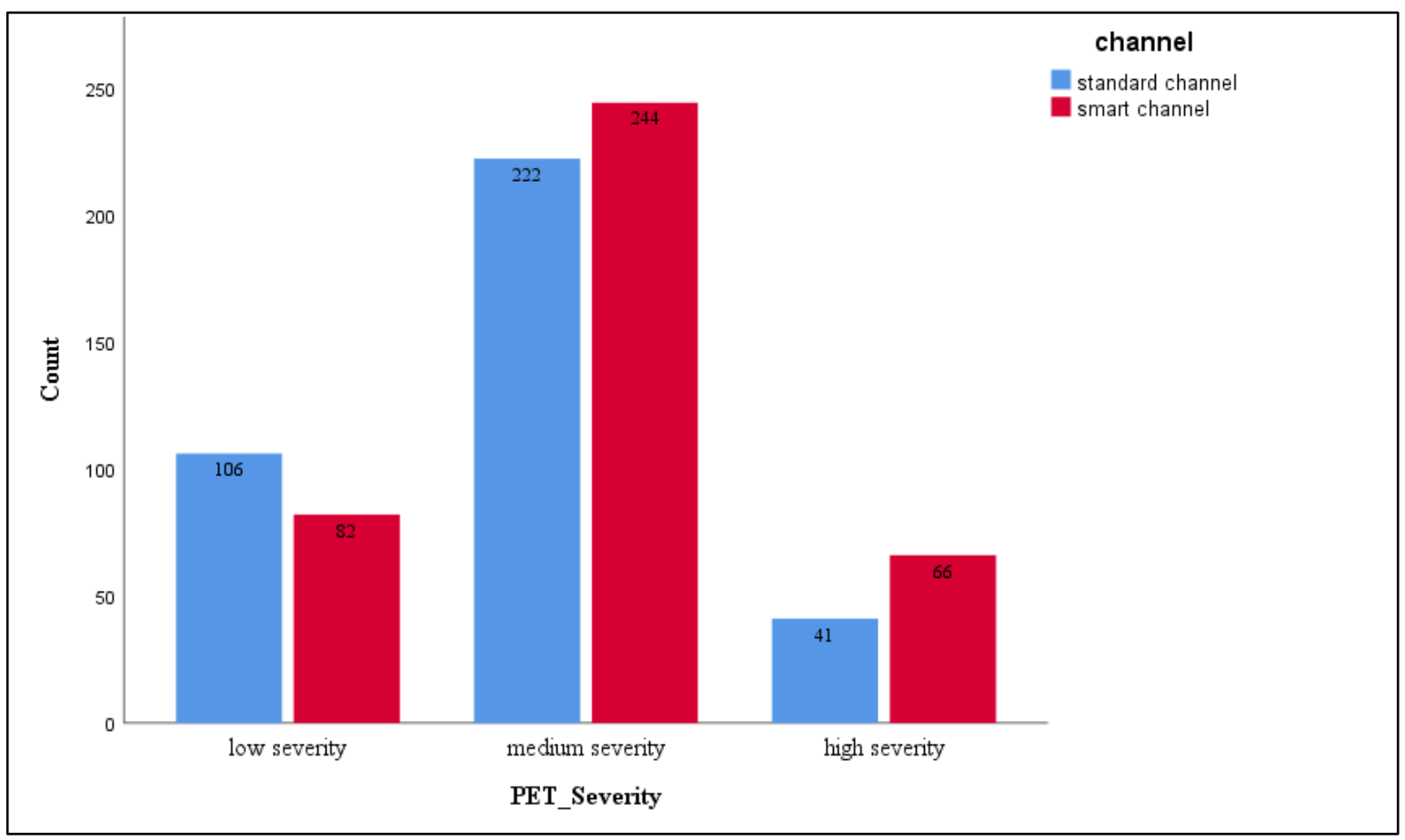

Figure 6-3: Conflict count at each severity level excluding channel location 8

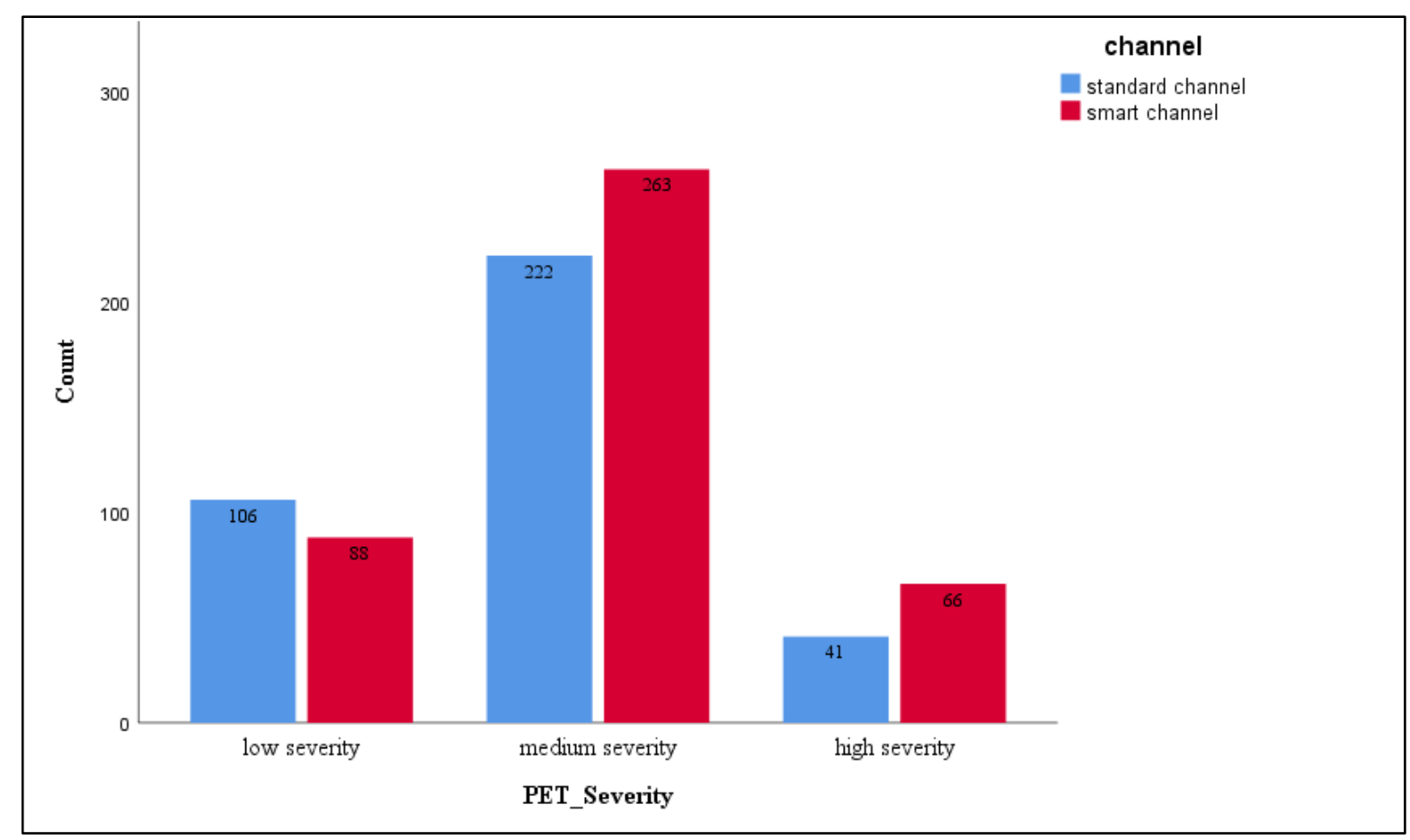

Figure 6-4: Conflict count at each severity level excluding channel location 7 
There was a need to identify which channel locations contribute more to the overall count of potential conflicts in a particular severity level. Figure 6-5 shows the percentage of potential conflict count at standard channels. It is observed that Baseline and Woodroffe WBR and Riverside and Brookefield contribute a percentage over $20 \%$ of the total potential conflict count at medium severity. The two channels also contribute a larger percentage of potential conflict count at both the low and high severity levels. Whereas, in Figure 6-6, Baseline and Clyde contributes the largest percentage of potential conflict count for low and medium severity levels. Greenbank and Strandherd location also contributes to the medium severity count and contributes the highest percentage of high severity potential conflict count at smart channel intersections.

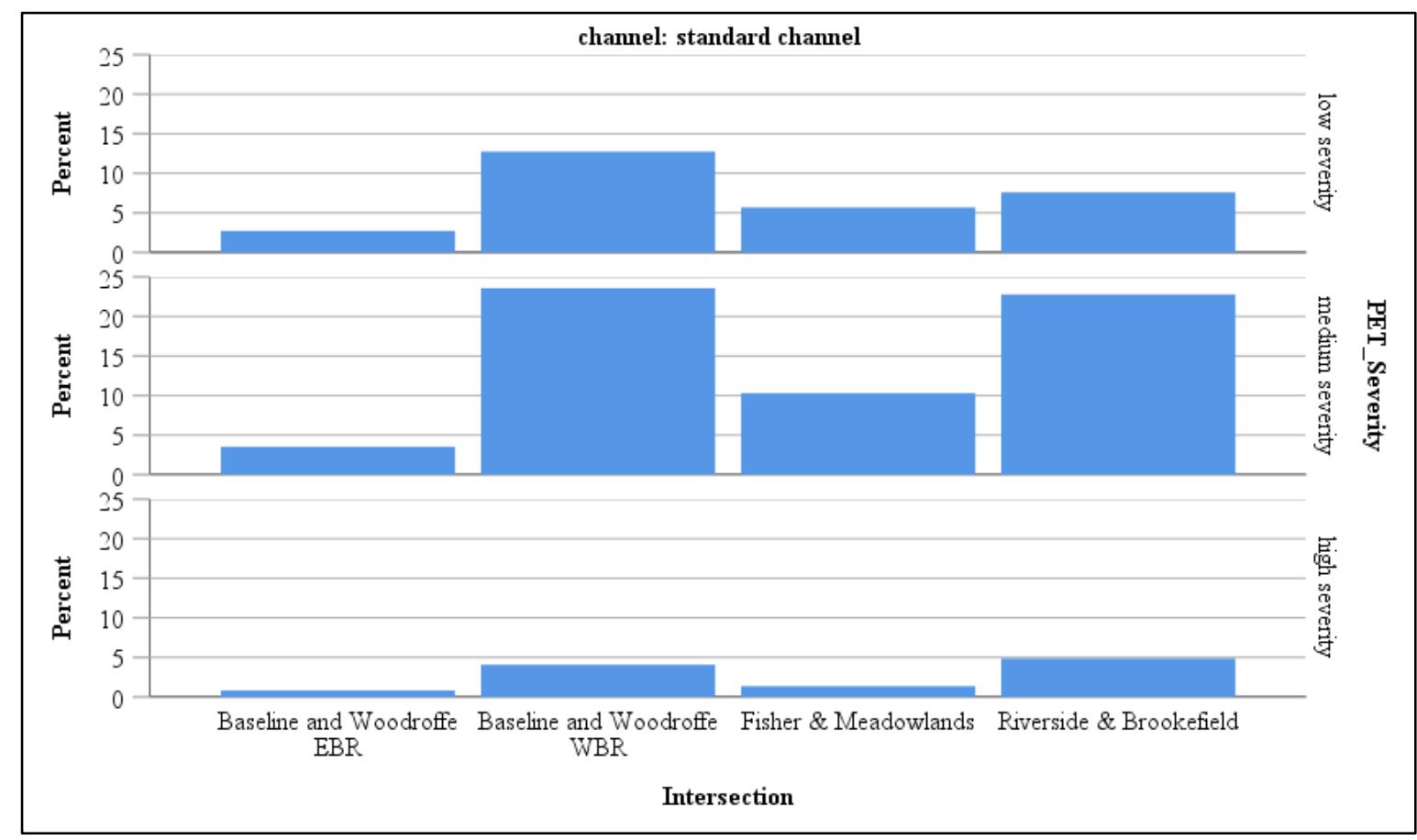

Figure 6-5: Percentage of potential conflict count at each standard channel intersection 


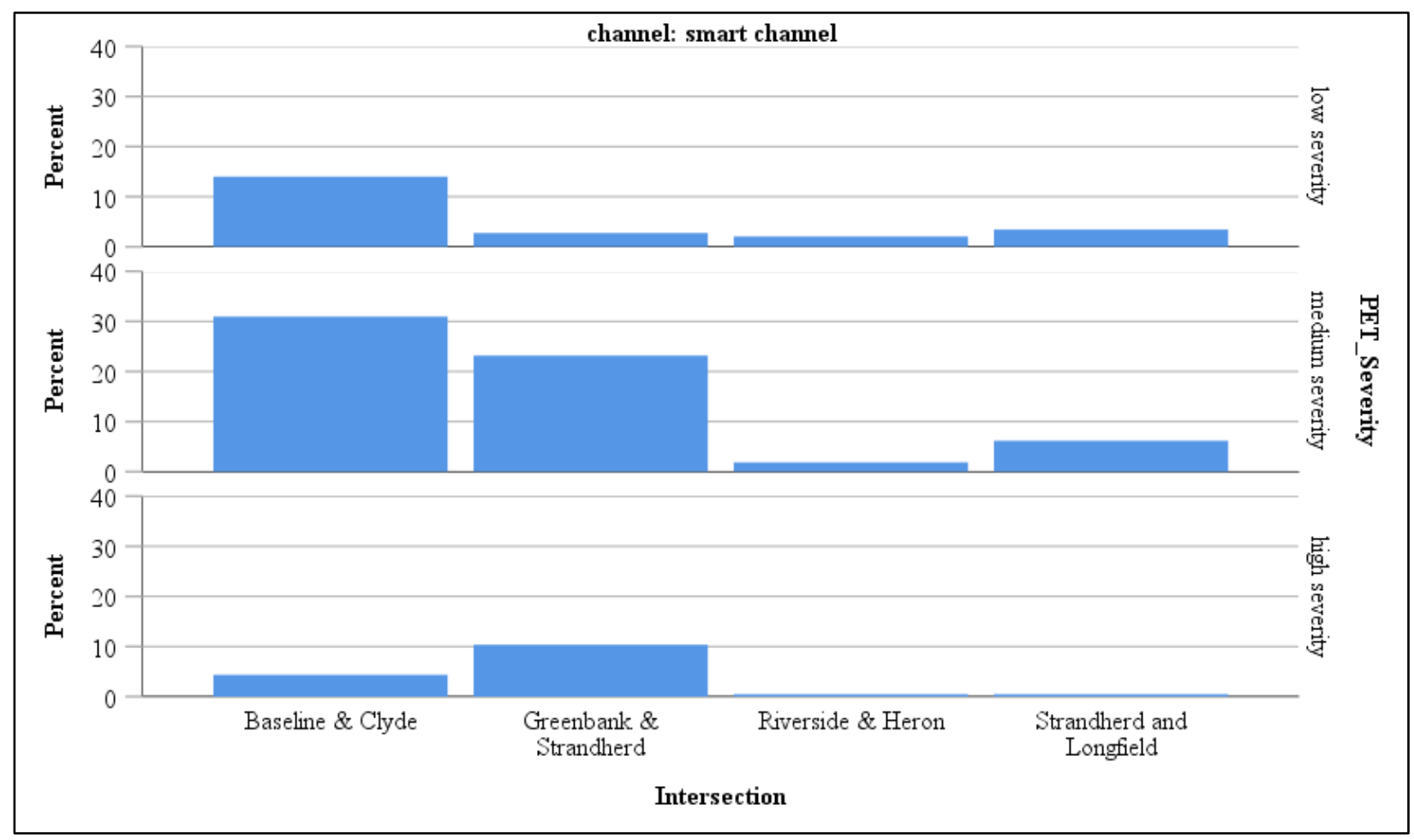

Figure 6-6: Percentage of potential conflict count at each smart channel intersection

The higher percentage of potential conflict counts at the intersections mentioned above was most likely due to a higher volume count at these channel locations. Refer to Table 4-3.

\subsection{Statistical Analysis}

The performance parameters: PET, sightline distance, right turning sightline angle, SDTL and time headway were analyzed in this section using t-tests and ordinal logistic regression. The first t-tests were done to compare parameter means at the channel configurations. ANOVA was used to compare the four channels' parameter means in each channel configuration. The results are shown in Appendix B. The Games-Howell post-hoc test was used if a statistically significant result was obtained using ANOVA, to compare all possible group combination differences for the four smart and four standard channels. The Games-Howell test aids in determining which channel 
location within a channel configuration differs significantly from the others. The tests and interpretations are presented in 0 . The second t-test tested the statistical significance of the difference in conflict rate for the different PET proximity levels at each channel configuration.

The independent t-test was conducted to test the statistical significance of the difference in parameter means; sightline distance, SDTL, PET, time headway and right turning sightline angle at smart and standard channels. The null hypothesis $\left(H_{0}\right)$ is defined as $\left(H_{0}: I_{x m}=I_{x d}\right)$, i.e., there is no difference in the means between the two groups, where $I_{x m}$ : mean of the parameter at smart channels, $I_{x d}$ : the of the parameter at standard channels. The t-test was done assuming unequal variances. The p-values for PET, sightline distance, right turning sightline angle, time headway and SDTL were less than 0.05. Therefore, there is enough evidence to reject the null hypothesis, i.e., there is a statistically significant difference between the means of the PET, sightline distance, right turning sightline angle, time headway and SDTL at smart and standard channels. The t-test results are shown in Table 6-4. Refer to Table 6-1 for the means of each parameter at smart and standard channels. Excluding channel locations 8 and 7 had similar results to the null hypothesis tested when all channel locations were included. Refer to Appendix B.

Table 6-4: Independent samples t-test

\begin{tabular}{|l|c|c|r|r|r|c|c|c|c|c|}
\hline & \multicolumn{2}{|c|}{ PET (s.) } & \multicolumn{2}{|c|}{ Time headway (s.) } & \multicolumn{2}{c|}{ Sightline distance } & \multicolumn{2}{c|}{$\begin{array}{l}\text { right turning } \\
\text { sightline angle }\end{array}$} & \multicolumn{2}{c|}{ SDTL } \\
\hline channel type & smart & standard & smart & standard & smart & standard & smart & standard & smart & standard \\
\hline Mean & 1.55 & 1.64 & 5.44 & 7.02 & 48.9 & 58.0 & 99.6 & 114.8 & 46.26 & 55.73 \\
\hline Variance & 0.32 & 0.32 & 1.86 & 5.75 & 78.2 & 343.2 & 302.7 & 472.4 & 116.48 & 412.07 \\
\hline Observations & 436 & 369 & 436 & 369 & 436 & 369 & 436 & 369 & 436 & 369 \\
\hline Hypothesized Mean Difference & 0 & & 0 & & 0 & & 0 & & 0 & \\
\hline df & 782 & & 561 & & 508 & & 701 & & 539 & \\
\hline t Stat & -2.26 & & -11.26 & & -8.728 & & -10.835 & & -8.050 & \\
\hline P(T<=t) two-tail & 0.02 & & $<0.001$ & & $<0.001$ & & $<0.001$ & & $<0.001$ & \\
\hline t Critical two-tail & 1.96 & & 1.9642 & & 1.965 & & 1.963 & & 1.964 & \\
\hline
\end{tabular}




\subsubsection{PET Conflict Rate}

The number of conflicts at each channel are used to obtain a conflict rate by dividing the number of conflicts by the exposure using Equation (6-1). In this equation, exposure is set as the maximum theoretical count of interactions that could happen in a video (Kassim et al., 2014). It is a product of the through vehicle volume in every observed video and right-turn vehicle volume in the same video, termed as the total number of vehicle-vehicle-events (VVE).

$$
\begin{aligned}
& \text { Conflict rate } \\
& \qquad=\left(\frac{\text { number of conflicts }}{V V E}\right) \times 100,000
\end{aligned}
$$

The conflict rates calculated with Equation (6-1) for each channel location are recorded in Table 6-5. The results indicated that the Baseline and Woodroffe (WBR) channel had the highest conflict rate of 4.59 at PET proximity level $(1,2] \mathrm{s}$.

Table 6-5: Data summary of the conflict rate each intersection

\begin{tabular}{|c|l|c|c|c|}
\hline \multicolumn{2}{|c|}{} & \multicolumn{3}{c|}{ PET severity level } \\
\hline $\begin{array}{c}\text { Channel } \\
\text { type }\end{array}$ & \multicolumn{1}{|c|}{ Intersection name } & PET(0,1]s & PET(1,2]s & PET(2,3)s \\
\hline \multirow{3}{*}{$\begin{array}{c}\text { Smart } \\
\text { channel }\end{array}$} & Baseline \& Clyde & 0.11 & 0.79 & 0.36 \\
\cline { 2 - 5 } & Greenbank \& Strandherd & 0.31 & 0.70 & 0.08 \\
\cline { 2 - 5 } & Riverside \& Heron & 0.02 & 0.10 & 0.11 \\
\cline { 2 - 5 } & Strandherd and Longfield & 0.05 & 0.72 & 0.40 \\
\hline \multirow{3}{*}{$\begin{array}{c}\text { Standard } \\
\text { channel }\end{array}$} & Baseline and Woodroffe WBR & 0.79 & 4.59 & 2.48 \\
\cline { 2 - 5 } & Baseline and Woodroffe SBR & 0.05 & 0.22 & 0.17 \\
\cline { 2 - 5 } & Fisher \& Meadowlands & 0.02 & 0.16 & 0.09 \\
\cline { 2 - 5 } & Riverside \& Brookefield & 0.64 & 2.96 & 0.99 \\
\hline
\end{tabular}

The independent samples t-test was used to test the statistical significance of the difference in conflict rate at the different PET proximity levels; $(0,1] \mathrm{s} .,(1,2] \mathrm{s}$. and $(2,3] \mathrm{s}$. at smart and standard channels. The null hypothesis $\left(\mathrm{H}_{0}\right)$ is defined as $\left(\mathrm{H}_{0}: P_{s m}=P_{s d}\right)$, where $P_{s \mathrm{~m}}$ : The conflict rate at smart channels, $P_{s d}$ : The conflict rate at standard channels. The p-values at all PET 
proximity levels based on conflict rates were found to have a ( $p$-value $>0.05)$ at smart and standard channels. For PET $(0,1]$ s., the p-value is 0.30 , PET $(1,2]$ s., the p-value is 0.29 , PET $(2,3]$ s., the pvalue is 0.30 . Therefore, at the $5 \%$ level of significance, there is not enough evidence to reject the null hypothesis, i.e., that there is no statistically significant difference between conflict rates at smart and standard channels for all three severity levels. The results are summarized in Table 6-6. However, each channel's group sample size is very small (four smart channels and four standard channels), and possibly, the t-test results were affected by this.

Table 6-6: PET conflict rate statistical results

\begin{tabular}{|l|r|r|r|r|r|r|}
\hline \multirow{2}{*}{} & \multicolumn{2}{|c|}{ PET (1,1]s. } & \multicolumn{2}{c|}{ PET (1,2]s. } & \multicolumn{2}{c|}{ PET (2,3]s. } \\
\cline { 2 - 7 } & \multicolumn{1}{|c|}{ smart } & \multicolumn{1}{c|}{ standard } & \multicolumn{1}{c|}{ smart } & \multicolumn{1}{c|}{ standard } & \multicolumn{1}{c|}{ smart } & standard \\
\hline Mean & 0.12 & 0.37 & 0.57 & 1.98 & 0.24 & 0.93 \\
\hline Variance & 0.02 & 0.16 & 0.10 & 4.72 & 0.03 & 1.23 \\
\hline Observations & 4 & 4 & 4 & 4 & 4 & 4 \\
\hline t Stat & 4 & & 3 & & 3 & \\
\hline P(T<=t) two-tail & -1.20 & & -1.28 & & -1.24 & \\
\hline t Critical two-tail & 0.30 & & 0.29 & & 0.30 & \\
\hline
\end{tabular}

\subsubsection{Ordinal Logistic Regression}

The dependent variable, severity level, is categorized based on the PET measurements into three levels of severity, $\operatorname{PET}(0,1] \mathrm{s}$, categorized as potential conflicts of high severity, $\operatorname{PET}(1,2] \mathrm{s}$., potential conflicts of medium severity and $\operatorname{PET}(2,3]$ s. as potential conflicts of low severity. Ordinal Logistic Regression (OLR) was used over Multinomial Logistic Regression (MLR) because the dependent variable categories are ordered from low-high severity. The model run in SPSS considered the parameters, SDTL, right turning sightline angle, time headway, sightline distance and channel type as explanatory variables to estimate the probability of PET at any 
severity level. The parameters were based on the eight channels' data at four smart channels and four standard channels with 805 observations in total. Several ordinal logistic regression models were run, and the parameters that were insignificant in estimating a potential conflicts' severity level were omitted one at a time, and the model re-run. The other models considered excluded channel location 8 (Strandherd and Longfields) and channel location 7 (Riverside and Heron), one at a time. Once again, the models were run using SPSS for each exclusion while removing the model's insignificant parameters. In all three cases, all intersections present, excluding channel location 8 and excluding channel location 7, only channel type was statistically significant in estimating the probability of a potential conflicts' severity level at the $5 \%$ level of significance.

The model included and interpreted in this section is one with channel type as the only explanatory variable when all intersections were included, and the rest of the models are shown in Appendix D. The variable "channel" in the output shown in Table 6-9 indicates the intersection's channel configuration, coded $1=$ smart channels and $0=$ standard channels in the program. "PET_A" indicated in Table 6-9 is an ordered categorical variable for PET severity levels, coded $1=$ low severity, $2=$ medium severity and $3=$ high severity.

Ordinal logistic regression is an extension to binary logistic regression, using the log-odds probability transformation. It requires thinking about cumulative probabilities instead of individual category probabilities. Hence, this technique requires the dependent variable to be an ordinal variable, i.e., the cumulative probabilities of attaining at least a given category is possible if categories are ordered (Harbaugh, 2019).

In logistic regression, producing minimum variance unbiased parameter estimates is not possible using the least squares estimation (Czepiel, 2012). Therefore, in place of the least squares estimation, maximum likelihood estimation is used to solve for the parameters that fit the data 
best. This involves finding the parameter set which the probability of the data observed is greatest. The probability distribution of the dependent variable derives the maximum likelihood equation. Since $y_{j}$ represents a binomial count in the $j^{\text {th }}$ population, there are $\left(\frac{n_{j}}{y_{j}}\right)$ ways to arrange $y_{j}$ successes among $n_{j}$ attempts, and the probability of a success for any one of the $n_{j}$ attempts is $\pi_{j}$, the probability of $y_{j}$ successes is $\pi_{j}^{y_{j}}$. Similarly, the probability of $\pi_{j}^{y_{j}}$ failures is $\left(1-\pi_{j}\right)^{n_{j}-y_{j}}$. The likelihood function has a similar form to the probability density function, with the function parameters reversed; the values of $\beta$ from the likelihood function are expressed in terms of known, fixed y values in the form in Equation (6-2). The maximum likelihood estimates are the $\beta$ values that maximize the likelihood function in Equation (6-2).

$$
L(\beta \mid y)=\prod_{j=1}^{N} \frac{n_{j} !}{y_{j} !\left(n_{j}-y_{j}\right) !} \pi_{j}^{y_{j}}\left(1-\pi_{j}\right)^{n_{j}-y_{j}}
$$

Ordinal logistic regression uses log-odds of cumulative probabilities. Consider an ordinal dependent variable with ordinal level, $Y_{j}(\mathrm{j}=1, \ldots, \mathrm{n}-1$ levels $)$, given a vector of $x$ explanatory variables. The cumulative probability that an observation y will be less than or equal to ordinal level $Y_{j}$ is obtained using Equation(6-3).

$$
F_{j}(x)=P\left(y \leq Y_{j} \mid x\right)
$$

The cumulative probability obtained from Equation (6-3) is transformed into odds $\left(\frac{F_{j}(x)}{1-F_{j}(x)}\right)$, and the log of the odds transforms it into the logit, which is the log odds of being in category j or less shown in Equation (6-4) (Harbaugh, 2019). 


$$
\begin{array}{r}
L_{j}(x)=\operatorname{logit}\left(F_{j}(x)\right)=\log \left(\frac{F_{j}(x)}{1-F_{j}(x)}\right) \\
L_{j}(x)=\alpha_{j}-\left(\beta_{1} \cdot x_{1}+\beta_{2} \cdot x_{2}+\cdots+\beta_{k} \cdot x_{k}\right)
\end{array}
$$

Using the information above, the regression model was run for $n-1$ equations in total (since the cumulative probability of being in the highest category is 1). $\alpha_{j}$ is the intercept of level $\mathrm{j}$, obtained from the logistic regression output, $\beta$ is the explanatory variables' estimate obtained from the logistic regression output. However, it is essential to note that the model estimate values obtained are subtracted because of the nature of the outcome variable being ordinal, shown in Equation (6-5). Compared to binary regression with categories 0 and 1, when estimating the probability of finding category 1 instead of category 0 , the model's signs change accordingly in ordinal logistic regression. The equation helps to interpret the relationship between the independent variables with the ordered categorical variable for the dependent variable.

The "Goodness-of-fit" results in Table 6-7 contain non-significant test results for the Deviance and Pearson chi-square tests, which indicate that the model fits the data well.

\section{Table 6-7: Goodness-of-fit}

Goodness-of-Fit
\begin{tabular}{|lccc|}
\hline & Chi-Square & df & Sig. \\
\hline Pearson & .042 & 1 & .838 \\
Deviance & .042 & 1 & .838 \\
\hline
\end{tabular}

Link function: Logit.

Ordinal Logistic Regression assumes that the relationship between independent variables are the same across all possible comparisons, also known as the proportional odds assumption. 
This assumption is tested in SPSS using the "test of parallel lines", and the results are shown in Table 6-8. The p-value of 0.838 indicates that the null hypothesis should not be rejected at the $5 \%$ level of significance, therefore, the assumption of proportional odds is satisfied.

Table 6-8: Test of parallel lines to test proportional odds assumption

\begin{tabular}{|c|c|c|c|c|}
\hline Model & $\begin{array}{c}-2 \text { Log } \\
\text { Likelihood }\end{array}$ & Chi-Square & df & Sig. \\
\hline Null Hypothesis & 23.591 & & & \\
\hline General & 23.549 & .042 & 1 & .838 \\
\hline
\end{tabular}

The output of the ordinal logistic regression using SPSS is shown in Table 6-9. The estimates and intercepts from Table 6-9 are used in Equation (6-5) to calculate the different cumulative probabilities for each ordinal level. PET_A $=1$ and PET_A $=2$. The intercepts for this model for each boundary are; low severity|medium severity $=-0.901$ and medium severity|high severity $=2.060$.

Table 6-9: Ordinal logistic regression output with all intersections

Parameter Estimates

\begin{tabular}{|c|c|c|c|c|c|c|c|c|}
\hline & \multirow[b]{2}{*}{ Estimate } & \multirow[b]{2}{*}{ Std. Error } & \multirow[b]{2}{*}{ Wald } & \multirow[b]{2}{*}{$\mathrm{df}$} & \multirow[b]{2}{*}{ Sig. } & \multicolumn{2}{|c|}{$95 \%$ Confidence Interva } \\
\hline & & & & & & & $\begin{array}{l}\text { Lower } \\
\text { Bound }\end{array}$ & $\begin{array}{l}\text { Upper } \\
\text { Bound }\end{array}$ \\
\hline \multirow[t]{2}{*}{ Threshold } & {$[$ PET_A $=1]$} & -.901 & .108 & 68.980 & 1 & .000 & -1.114 & -.688 \\
\hline & {$\left[\mathrm{PET} \_\mathrm{A}=2\right]$} & 2.060 & .133 & 239.324 & 1 & .000 & 1.799 & 2.321 \\
\hline Location & channel & .359 & .142 & 6.376 & 1 & .012 & .080 & .637 \\
\hline
\end{tabular}

Link function: Logit.

Equation (6-6) is the logit of the cumulative probability of a potential conflict having low severity $\left(\operatorname{Logit}\left(F_{\text {low severity }}\right)\right)$, and the second Equation (6-7) gives the logit of the cumulative probability of a potential conflict having low to medium severity $\left(\operatorname{Logit}\left(F_{\text {medium|low severity }}\right)\right)$. 
The model estimate values are the same, refer to Equation (6-6) and Equation (6-7) and are subtracted from the corresponding intercepts obtained in the output for each ordinal level.

$$
\begin{gathered}
\operatorname{Logit}\left(F_{\text {low severity }}\right)=-0.901-(0.359 * \text { channel }) \\
\operatorname{Logit}\left(F_{\text {medium } \mid \text { low severity }}\right)=2.060-(0.359 * \text { channel })
\end{gathered}
$$

For a conflict at a smart channel, channel code $=1$, the log odds of reaching the low severity level and reaching the medium severity level are calculated using Equation (6-6) and Equation(6-7). The log odds values are $\operatorname{logit}\left(F_{\text {low severity }}\right)=-1.260 ; \operatorname{logit}\left(F_{\text {medium } \mid \text { low severity }}\right)=$ -1.701, exponentiating the log odds $\left(e^{\text {logit }}\right)$ gives the odds for each category. The odds of being in the low severity category is 0.284 , and the odds of being in the medium severity category or low severity is 5.479 . The odds are then transferred to cumulative probabilities; $\mathrm{p}=\left(e^{\operatorname{logit}} /\left(1+e^{\text {logit }}\right)\right)$, it is observed that the cumulative probability of a potential conflict having low severity is 0.221 , and the cumulative probability of a potential conflict having medium to low severity is 0.846 . Therefore, obtaining the probability of a conflict having a specific severity category is calculated in Table 6-10.

Table 6-10: Calculated probability of each severity level at a smart channel

\begin{tabular}{|l|l|l|l|}
\hline \multicolumn{2}{|l|}{ Probability } & $=F_{(\text {low severity) }}$ & $\begin{array}{l}\text { Calculated } \\
\text { probability }\end{array}$ \\
\hline $\begin{array}{l}\text { (low } \\
\text { severity) }\end{array}$ & $P(Y \leq 2)-P(Y \leq 1)$ & $\left.=F_{(\text {medium } \mid \text { low severity }}-F_{\text {low severity })}\right)$ & $\begin{array}{l}=0.221 \\
=0.846-0.221 \\
=0.625\end{array}$ \\
\hline $\begin{array}{l}\text { (medium } \\
\text { severity) }\end{array}$ & $1-P(Y \leq 2)$ & $=1-F_{(\text {medium } \mid \text { low severity) }}$ & $\begin{array}{l}=0.846 \\
=0.154\end{array}$ \\
\hline $\begin{array}{l}\text { (high } \\
\text { severity) }\end{array}$ & & & \\
\hline
\end{tabular}


Following the same procedure, the estimated probabilities for each severity level for a conflict at a standard channel (channel=0), are calculated and presented in Table 6-11.

Table 6-11: Calculated probability for each severity level at a standard channel

\begin{tabular}{|c|c|c|c|}
\hline \multicolumn{3}{|c|}{ Probability } & \multirow{2}{*}{$\begin{array}{l}\begin{array}{l}\text { Calculated } \\
\text { probability }\end{array} \\
=0.289\end{array}$} \\
\hline $\begin{array}{l}\text { (low } \\
\text { severity) }\end{array}$ & & $=F_{\text {low severity }}$ & \\
\hline $\begin{array}{l}\text { (medium } \\
\text { severity) }\end{array}$ & $P(Y \leq 2)-P(Y \leq 1)$ & $=F_{(\text {medium } \mid \text { low severity }}-F_{\text {low severity })}$ & $\begin{array}{l}=0.887-0.289 \\
=0.598\end{array}$ \\
\hline $\begin{array}{l}\text { (high } \\
\text { severity) }\end{array}$ & 1- $P(Y \leq 2)$ & $=1-F_{(\text {medium } \mid \text { low severity })}$ & $\begin{array}{l}=1-0.887 \\
=0.113\end{array}$ \\
\hline
\end{tabular}

The OLR results indicate that the probability of a conflict having low severity at standard channels is $6.8 \%$ higher than smart channels. In comparison, the probability of a conflict having high severity is $4.1 \%$ higher at smart channels than standard channels. 


\section{CONCLUSIONS AND RECOMMENDATIONS}

\subsection{Summary and Conclusions}

This study's primary objective was to compare whether different configurations, i.e., standard and smart channels at channelized signalized intersections, have different safety performances based on conflicts and sight distance.

The performance parameters were observed at the different intersections and include the following indicators: post encroachment time involving very close proximity between motor vehicles and intersection sight distance measured for each unique conflict case using time headway as a measure of ISD. Sightline distance, SDTL and right turning sightline angle were used as visibility parameters.

The City of Ottawa provided the videos used for data extraction, and each channel location had twelve one-hour long videos recorded by the City from 6:45 am-6:45 pm. Data extraction was done over four months to obtain the required variables.

A total of 805 interactions with PET less than or equal to 3s. were observed, out of observations involving the movements of 44,048 through vehicles and 14,498 right-turn vehicles on eight different channels: 109 interactions within proximity level PET(0,1]s., 493 within PET proximity level $(1,2] \mathrm{s}$. and 203 within the PET proximity level $(2,3] \mathrm{s}$.

Chapter Two presented the literature review focusing on sight distance effects on conflicts observed at channelized intersections. A few studies have addressed the role of intersection sight distance in collisions; (David and Norman, 1975; Mitchell, 1973; Moore and Humphries, 1975). Only two of them provided a form of relationship between intersection sight distance and 
accidents. Sight distance horizontally and vertically must also be maintained to enable drivers to have an adequate sightline as they approach the intersection (FHWA, 2013). The availability of sight distance on a roadway should be sufficient to enable drivers to "correctly" judge the road traffic environment, determine the appropriate driving behaviour, and control adequate execution time to avoid conflicts and accidents when manoeuvring the intersection. Vehicles adjacent to the right-turning vehicle may contribute to sight obstruction. The line-of-sight envelope is essential, according to Liu et al. (2010), while a driver is about to enter the intersection to avoid conflict with the approaching vehicles. Safety-related factors are the primary concern as drivers look inside the intersection's landscape to obtain information (Liu et al., 2010). Judging the intersection road situation is a recurring movement process accompanying the constant moving of a vehicle as a driver obtains road information. The driver's line of sight continually tangents to the inside landscape or road elements to form a continuous sight distance. Therefore, a good sight distance could ensure that a vehicle passes through the intersection safely (Liu et al., 2010).

Chapter Three presents the study area and how the intersections used in this study were selected. It also gives a detailed description of each channel based on location and channel characteristics and travel direction for each channel location. The chapter then describes the parameters used in this study.

Chapter Four presented the methodology of measuring an objective conflict indicator known as; Post Encroachment Time (PET). PET was used to characterize interactions between motor vehicles at signalized channelized intersections for both smart and standard channels. A manual video analysis technique was used to measure PET between motor vehicles. The method used is the Manual Frame Count Method (MFCM) suggested by Kassim et al. (2014) to obtain PET measurements for each interaction event from videos for all eight-channel locations, 
consisting of four smart channels and four standard channels. The PET measurements counted were less than or equal to 3 s. i.e. traffic conflicts were registered if the conflict measure values are less than the predetermined threshold (Sayed et al., 2013).

Although an accurate method, the shortcoming of the MFCM method is how timeconsuming it is to manually obtain PET measurements. Estimating PET for each interaction could benefit from Automated Methods such as one suggested by (Kassim et al., 2014).

Chapter Five presented a methodology used to measure intersection sight distance for each interaction using time headway as a measure of ISD. Sightline distance, right turning sightline angle and SDTL were used as visibility parameters. The SDTL was calculate based on the sight distance triangle described in (TAC, 2017). The right turning sightline angle was measured as the angle the driver needed to turn their head to view approaching traffic. Sightline distance was measured as the line of sight from the right turning driver's location to the oncoming through vehicles' location. The sight distance measured corresponding to each interaction event was between motor vehicles at signalized channelized intersections at the point where a driver making a right-turn through the channel had an unobstructed view of the conflicting through vehicles. Despite the camera orientation and location on the site being unfavourable to measure distances directly from the video, an alternative method was used. The alternative method involved using a Google Earth aerial view screenshot of each intersection of interest, and each was imported into ImageJ software. The vehicles' approximate relative position was identified from the video using Virtualdub and manually mapped onto the aerial view from Google Earth. However, this method of measuring sight distance is subjective as one needs to visually identify the vehicles' relative positions when the sight distance triangle is free from obstructions. The proposed technique would have benefited more from a camera height, orientation and camera location that could view the 
intersection in an aerial view without the need for perspective correction. The camera position and orientation would reduce the subjectivity in determining the relative positions of vehicles. This method would also benefit from computer vision techniques that can easily map the coordinates of each vehicle. Hence, making the procedure less time-consuming.

Chapter Six presents descriptive statistics of the variables used in this study for both the dependent and independent variables. The study area consists of two groups of channel configurations, smart and standard channels. The focus was on potential conflicts between rightturn vehicles and through vehicles at channelized intersections. The performance parameters included; PET measurements $(0,3]$ s., SDTL, right turning sightline angle measurements, sightline distance and time headway. The descriptive statistics summarize the study's data set at the two channel configurations. The descriptive statistics for each performance parameter reported central tendency measures and measures of variability. The categorical variables are PET severity level, an ordinal variable, categorized into three groups, and a binary variable, channel type.

The frequency statistics for each PET severity levels are presented, indicating the frequency of potential conflicts per channel configuration. It was observed that smart channels have a higher count of conflicts of medium and high severity levels compared to standard channels, whereas smart channels have a lower conflict count at low severity. The percentage count frequency for each severity level was also presented for each channel location. It is observed from the graphs that Baseline and Woodroffe (WBR) and Riverside and Brookefield contribute significantly to the total potential conflict count at medium severity. The two channels contribute a bigger percentage to both the low and high severity level potential conflicts count. Baseline and Clyde contribute to the larger percentage of potential conflict count for low and medium severity levels. Greenbank and Strandherd also contributes to the medium severity count, contributing the 
most to high severity potential conflict count at smart channels intersections. Smart channel intersections appear to have a higher conflict count for high severity level.

T-tests were done to determine whether there are statistically significant differences between group means based on channel configurations, at smart and standard channels, for the continuous variables; PET measurements, SDTL, time headway, right turning sightline angle and sightline distance. The t-tests showed statistically significant differences between the means of PET measurements, SDTL, time headway, sightline distance and right turning sightline angle at smart and standard channels.

A one-way ANOVA was performed, and the results are shown in Appendix B. There was a statistically significant difference between the means for PET, SDTL, sightline distance and right turning sightline angle at the four smart channels. However, there was no statistically significant difference between means of time headway at the four smart channels at the 5\% significance level. At the four standard channels, it was found that there was a statistically significant difference between the means for time headway, sightline distance, SDTL and right turning sightline angle. However, no statistically significant difference between the PET means at the four standard channels at the 5\% significance level. Due to the different sample sizes at each channel location within each channel configuration, the Games-Howell test, which accounts for this sample size difference, was used to identify the specific differences based on channel type for the four smart channels and four standard channels. Using PET as an example at the different channel locations within a channel configuration, although the mean of PET is statistically significantly higher at smart channels than that at standard channels, the result is likely due to the PET means at the four standard channel locations having no statistically significant differences between them. Whereas the PET means at the four smart channels are statistically significantly different from each other. 
Despite this being the case for smart channel locations, some locations combinations exhibited no statistical significance within the group. In conclusion, there is not enough evidence to conclude that the PET mean at standard channels is statistically significantly higher than at smart channels using the t-test.

The number of potential conflicts at each channel were used to obtain a conflict rate by dividing the number of potential conflicts at each intersection by the exposure, estimated as the maximum possible theoretical count of potential conflicts for each severity level. Based on this analysis, it was found that there is no statistically significant difference between smart and standard channel conflict rates for all three levels of proximity. The sample size used for this analysis was very small; therefore, the results might be biased. This analysis could benefit from increasing the intersection sample size for each channel type.

The ordinal logistic regression results indicate that the probability of a potential conflict having low severity at standard channels is $6.8 \%$ higher than at smart channel intersections. In contrast, the probability of a potential conflict having high severity at smart channels is $4.1 \%$ higher than standard channels. The results indicated that intersection sight distance is not statistically significant in affecting the probability of the severity of a potential conflict at the $5 \%$ significance level, $\mathrm{p}$-value $>0.05$. In conclusion, although smart channels have a higher probability of a high severity potential conflict, it does not necessarily mean that they are less safe. It is likely that drivers were more comfortable merging at lower thresholds of PET at smart channels than at standard channel.

This study's shortcomings were all based on the video limitations from which data was extracted. The location and orientation of the stationary video cameras operated by the City of Ottawa were set up for a vehicle count study and not a conflict study—-hence rendering these 
videos undesirable to measure sight distance and PET. The shortcomings are attributed to the cameras' low height and the video resolution that made it unsuitable for identifying interactions between vehicles and the corresponding sight distances. Preferably, the cameras should have been at a much greater height, high enough to give an aerial like view of the intersection and allow for perspective correction where required. Manually extracting data from videos was a common limitation for all methodologies in this study. Automating these procedures would be beneficial in processing larger-scale data and timesaving.

\subsection{Recommendations}

The following can be recommended based on the results of this study:

1. The measurement methods discussed in this thesis would benefit from automated video analysis to detect and track motor vehicles to identify which events may lead to collisions. An automated video analysis would result in a more efficient method of vehicle data collection.

2. The statistical analysis results from comparing the safety effect of standard and smart channels, based on conflicts and sight distance, provide useful information that could be considered in intersection geometric design to improve safety.

3. It is recommended to use a camera position height during the on-site video data collection process to simplify identifying vehicle-vehicle events and ease sight distance measurement for each unique event.

4. The instantaneous speed of a vehicle (spot speed) at a specified location can be used to design road geometry, such as determining and evaluating proper intersection sight distance. During the crash mitigation process at intersections, intersection safety 
involves characterizing the field conditions, which requires traffic data studies that include: traffic volume, traffic conflict study, spot speed and evaluating sight distance (Kennaugh, 2010). Three of these field conditions were included in this study's analysis besides spot speed. It is recommended to include the spot speed.

5. In conclusion, future work recommendations include obtaining collision data at each intersection used in the study, studying the correlation between collisions and conflicts, and increasing the sample sizes for each channel configuration. 


\section{REFERENCES}

AASHTO. (2001). A Policy on Geometric Design of Highways and Streets 19901. AASHTO (1990) A Policy on Geometric Design of Highways and Streets 1990, 7th Editio. www.transportation.org

AASHTO. (2011). A policy on Geometric Design of Highways and Streets, 6th edition.

AASHTO. (2018). A Policy on Geometric Design of Highways and Streets, 7th Edition. In American Association of State Highway and Transportation Officials (7th Editio).

Allen, B. L., Shin, B. T., \& Cooper, P. (1978). Analysis of Traffic Conflicts and Collisions. Transportation Research Record, 667, 67-74.

Autey, J. (2010). Before and after traffic safety evaluations using computer vision techniques. In The University of British Columbia. https://doi.org/10.1017/CBO9781107415324.004

Autey, J., Sayed, T., \& Zaki, M. H. (2012). Safety evaluation of right-turn smart channels using automated traffic conflict analysis. Accident Analysis and Prevention, 45, 120-130. https://doi.org/10.1016/j.aap.2011.11.015

Brown, G. R. (1994). Traffic conflicts for road user safety studies. Canadian Journal of Civil Engineering, 21(1), 1-15.

Chin, H. C., \& Quek, S. T. (1997). Measurement of traffic conflicts. Safety Science, 26(3), 169185. https://doi.org/10.1016/S0925-7535(97)00041-6

City of Ottawa. (2009). Ottawa Pedestrian Plan (Final Report June 2009). 16.

City of Ottawa. (2010). Pedestrian Intersection Safety Countermeasure Handbook. delphi MRC. 
City of Ottawa. (2020). Ottawa's Population. https://ottawa.ca/en/city-hall/get-know-yourcity/statistics-and-economic-profile/statistics/ottawas-population

Czepiel, S. A. (2012). Maximum Likelihood Estimation of Logistic Regression Models: Theory and Implementation. Class Notes, 1-23. papers3://publication/uuid/4E1E1B7E-9CAC-45708949-E96B51D9C91D

David, N. A., \& Norman, J. R. (1975). Motor vehicle accidents in relation to geometric and Traffic Features of Highway Intersections. In Report FHWA-RD-6-128.FHWA.

De Ceunynck, T. (2017). Defining and applying surrogate safety measures and behavioural indicators through site-based observations Document Version: Publisher 's PDF, also known as Version of record.

Easa, S. M. (2000). Reliability approach to intersection sight distance design. Transportation Research Record, 1701, 42-52. https://doi.org/10.3141/1701-06

FHWA. (2013). Signalized Intersections: An information Guide. Federal Highway Administraion Office of Safety. https://doi.org/10.5040/9781472596161-bed-g019

Gemar, M., Wafa, Z., Duthi, J., \& Bhat, C. (2015). A Report on the Development of Guidelines for Applying Right-Turn Slip Lanes. FHWA/TX-14, 1-144.

Glennon, J. C. (2004). Effect of Sight Distance on Highway Safety. In TRB State of the Art Report. http://onlinepubs.trb.org/Onlinepubs/state-of-the-art/6/6-005.pdf

Harbaugh, G. (2019). Introduction to Ordinal Regression [Video] YouTube. https://www.youtube.com/watch?v=jWIJ7P1G9P4

Harwood, D. W., Bauer, K. M., Potts, I. B., Torbic, D. J., Richard, K. R., Kohlman Rabbani, E. 
R., Hauer, E., Elefteriadou, L., \& Griffith, M. S. (2003). Safety Effectiveness of Intersection Left- and Right-Turn Lanes. Transportation Research Record, 1840, 131-139. https://doi.org/10.3141/1840-15

Harwood, D. W., Mason, J. M., Brydia, R. E., Pietrucha, M. T., \& Gittings, G. L. (1996). NCHRP Report 383: Intersection Sight Distance. In Journal of the International Commission on Radiation Units and Measurements (Vol. os20, Issue 1). https://doi.org/10.1093/jicru/os20.1.report38

Hauer, E. (2000). Safety in Geometric Design Standards II: Rift, Roots and Reform. June 14-17.

Hayward, J. C. (1972). Near-Miss Determination Through. Highway Research Board, 24-35. http://onlinepubs.trb.org/Onlinepubs/hrr/1972/384/384-004.pdf

Huang, L., \& Wu, J. (2003). Study on the cyclist behavior at signalized intersections. IEEE Conference on Intelligent Transportation Systems, Proceedings, ITSC, 1(4), 317-322. https://doi.org/10.1109/ITSC.2003.1251970

Hyden, C., \& Linderholm, L. (1984). The Swedish Traffic-Conflicts Technique. Department of Traffic Planning and Engineering, May 1983, 0-1.

Kassim, A., Ismail, K., \& Hassan, Y. (2014). Automated measuring of cyclist-motor vehicle post encroachment time at signalized intersections.

Kennaugh, D. P. E. (2010). Intersection Safety. 1(March 2006), 1-43.

Laureshyn, A., Svensson, Å., \& Hydén, C. (2010). Evaluation of traffic safety, based on microlevel behavioural data: Theoretical framework and first implementation. Accident Analysis and Prevention, 42(6), 1637-1646. https://doi.org/10.1016/j.aap.2010.03.021 
Layton, R. (2012). Intersection Sight Distance:The Kiewit Center for Infrastructure and Transportation. April.

Liu, M., Lu, G., \& Li, Y. (2010). The impact analysis of intersection sight distance on vehicle speed. Proceedings of the Conference on Traffic and Transportation Studies, ICTTS, 383(July 2010), 295-304. https://doi.org/10.1061/41123(383)26

Lord, D. (1996). Analysis of pedestrian conflicts with left-turning traffic. Transportation Research Record, 1538, 61-67. https://doi.org/10.3141/1538-08

Michigan Department of Transportation. (2015). Sight distance guidelines.

Minderhoud, M. M., \& Bovy, P. H. L. (2001). Extended time-to-collision measures for road traffic safety assessment. Accident Analysis and Prevention, 33(1), 89-97. https://doi.org/10.1016/S0001-4575(00)00019-1

Mitchell, R. (1973). Identifying and Improving High Accident Locations. Public Works.

Montana Department Of Transportation. (2016). Road Design Manual. September, 1-30.

Moore, W. L., \& Humphries, J. B. (1975). Sight Distance Obstructions on Private Property at Urban Intersections. In Transportation Research Board 541, TRB, National Research Council, Wahington, D.C., 31-39.

Peesapati, L. N., Hunter, M. P., \& Rodgers, M. O. (2018). Can post encroachment time substitute intersection characteristics in crash prediction models? Journal of Safety Research, 66, 205211. https://doi.org/10.1016/j.jsr.2018.05.002

Potts, I. B., Harwood, D. W., Torbic, D. J., Hennum, S. A., Tiesler, C. B., Zegeer, J. D., Ringer, J. F., Harkey, D. L., \& Barlow, J. M. (2005). Synthesis on channelized right turns at 
intersections on urban and suburban arterials. In Transp. Res. Board, Washington, DC, USA, Tech. Rep. NCHRP Project (pp. 3-72).

Roefaro, S. A. (2011). Channelized right-turning lanes at signalized intersections: A review of practice and an empirical study. Journal of Chemical Information and Modeling, 53(9), 16891699. https://doi.org/10.1017/CBO9781107415324.004

Sayed, T., Gettman, D., Pu, L., \& Shelby, S. (2008). Surrogate Safety Assessment Model and Validation: Final Report. Publication No. FHWA-HRT-08-051, June, 1-324.

Sayed, T., Sacchi, E., \& Deleur, P. (2013). A comparison of collision-based and conflict-based safety evaluations: The case of right-turn smart channels. Accident Analysis and Prevention, 59, 260-266. https://doi.org/10.1016/j.aap.2013.06.002

Suderman, S., Redmond, J., \& Cantor, M. (2015). Geometric Design Strategies for Improving Pedestrian Safety and Accessibility at Signalized Intersections.

TAC. (2017). Geometric Design Guide for Canadian Roads. In Geometric Design Guide for Canadian Roads.

Tarko, A. P., Saunier, N., \& Sayed, T. (2009). Surrogate Measure of Safety. January.

Wu, Y. S. (1973). Effect of Clear Vision Right-of way on Traffic Accidents at Urban and Rural Signalized Intersections.

Zheng, L., Ismail, K., \& Meng, X. (2014). Traffic conflict techniques for road safety analysis: Open questions and some insights. Canadian Journal of Civil Engineering, 41(7), 633-641. https://doi.org/10.1139/cjce-2013-0558 


\section{Appendix A. Sight Distance Measurements Mapped Using ImageJ}

Sample measurements in video one out of twelve for each channel location

a)

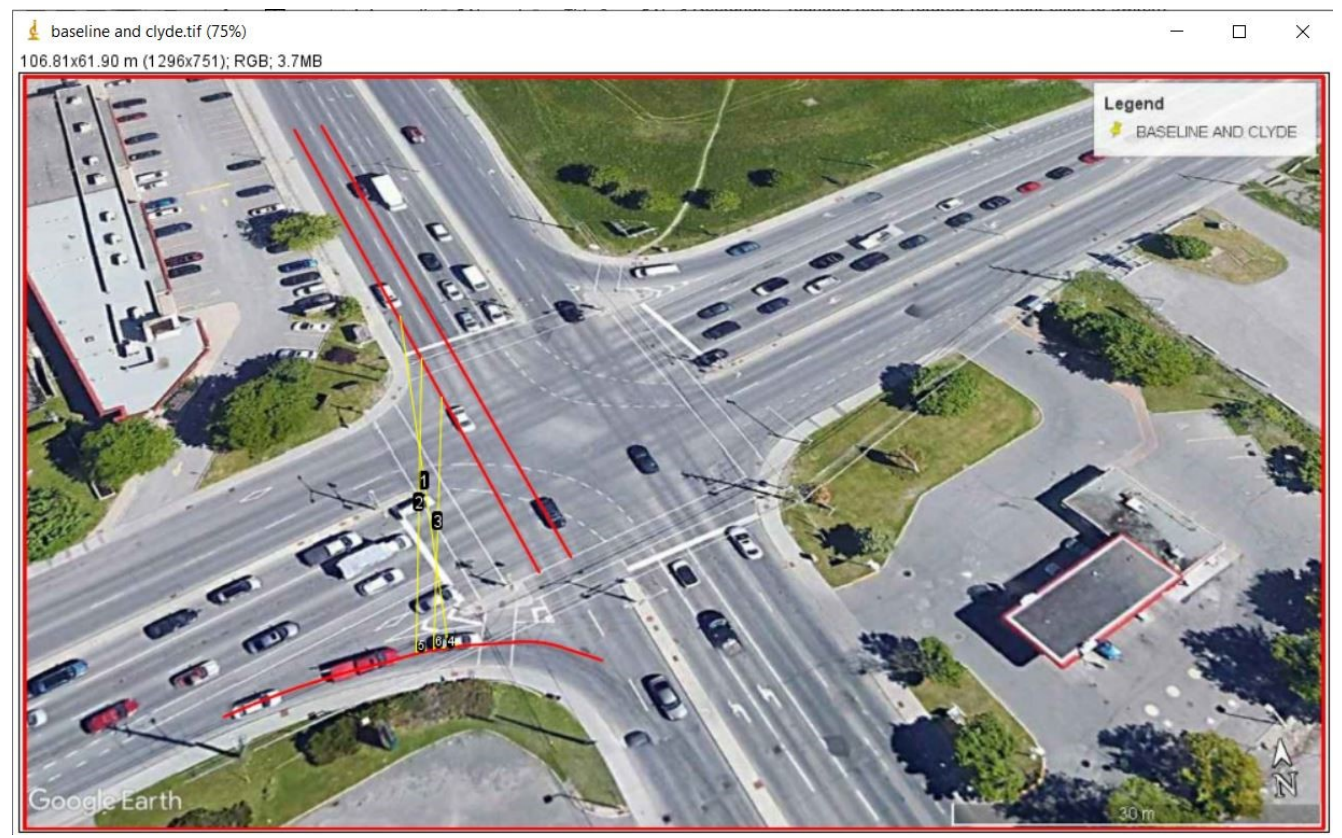

b)

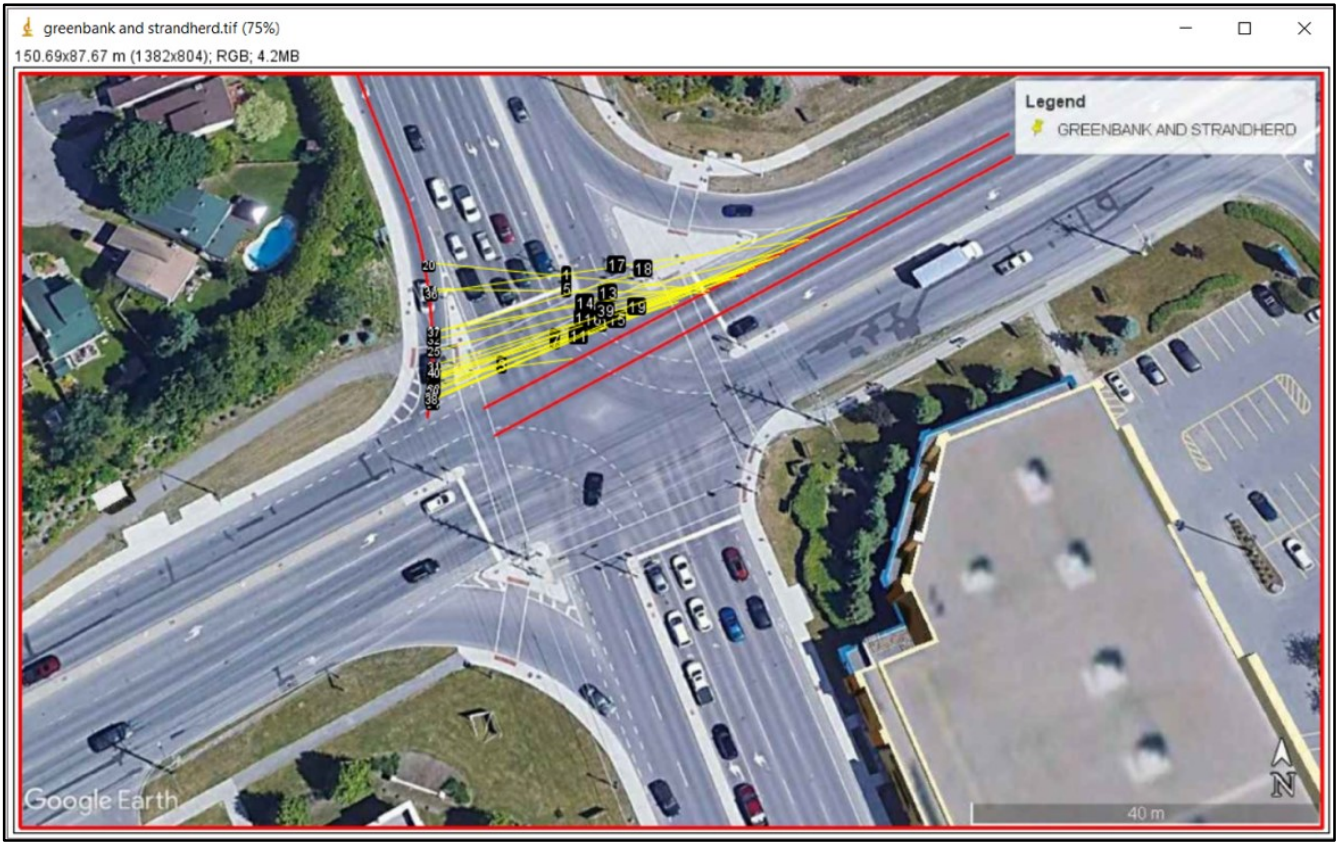


c)

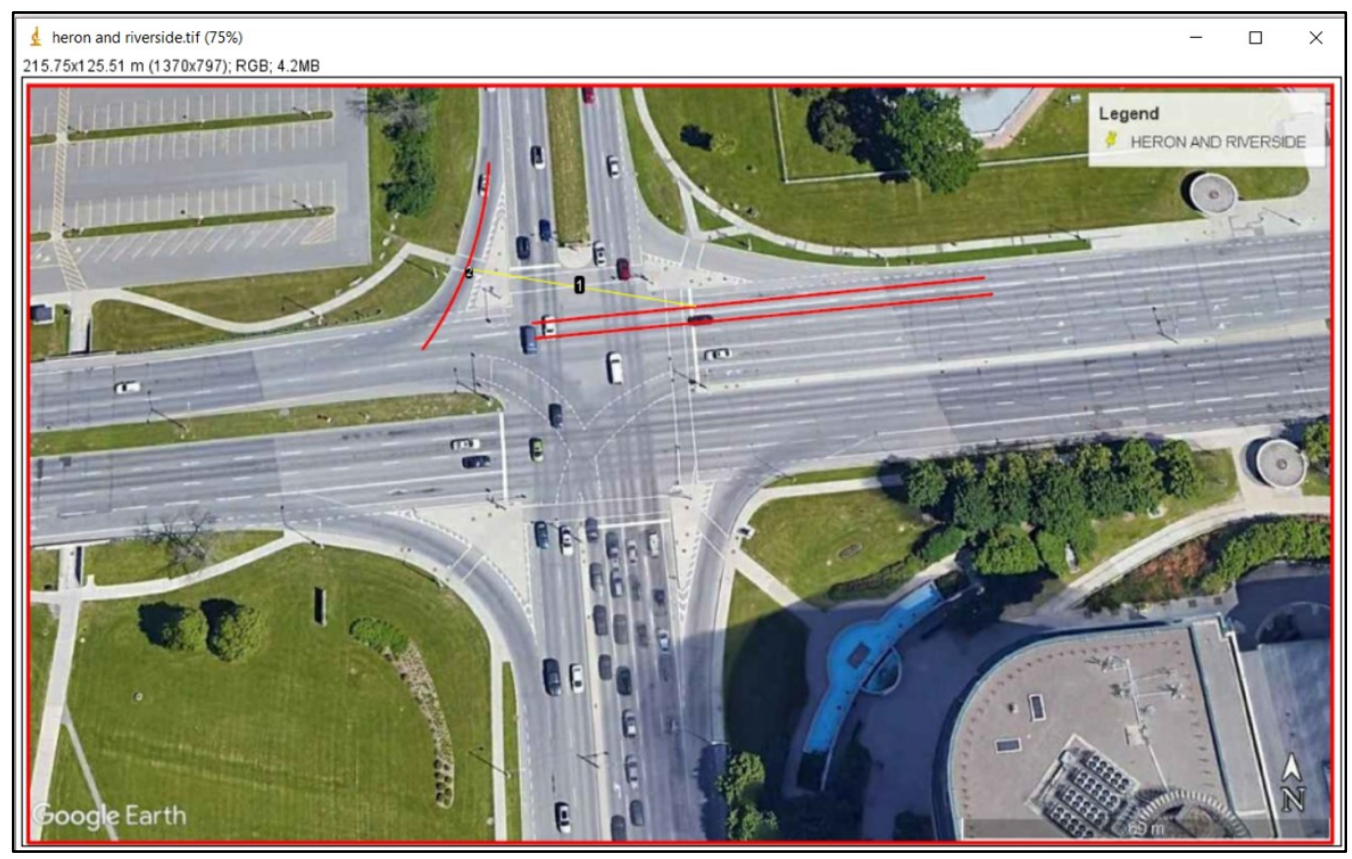

d)

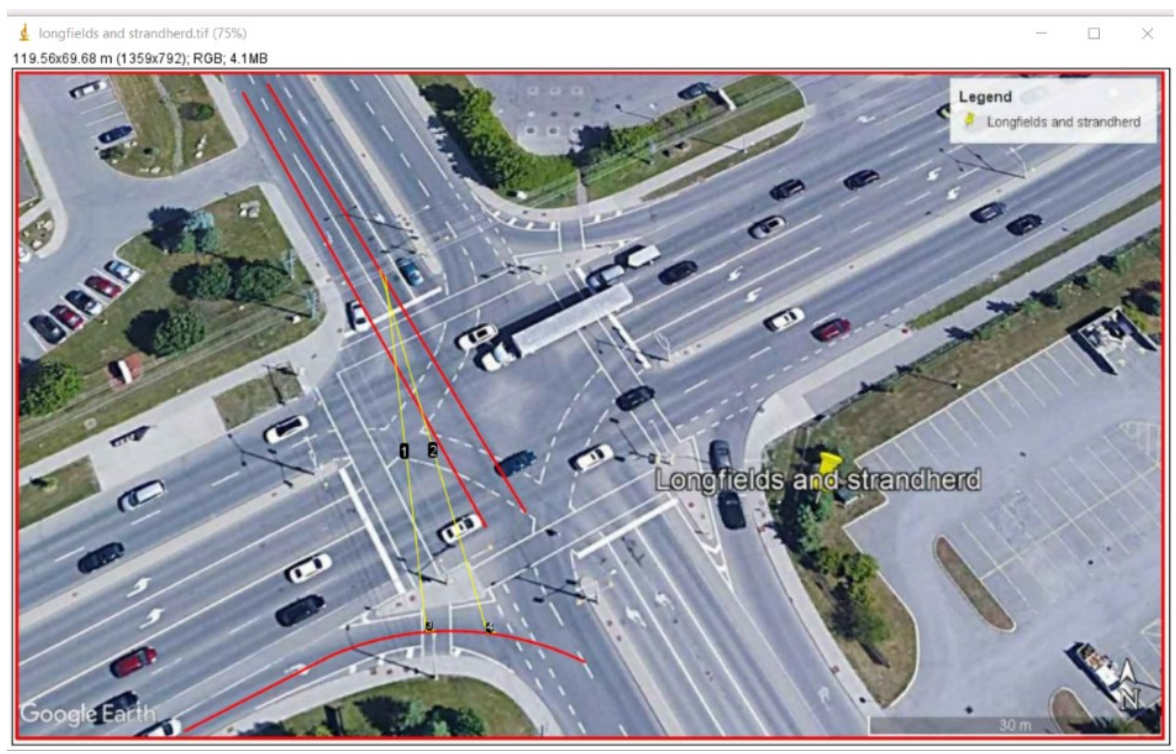

Figure A-1: Sight distance measurements at smart channels. a) Baseline and Clyde, b) Greenbank and Strandherd, c) Riverside and Heron, d) Strandherd and Longfields 
e)

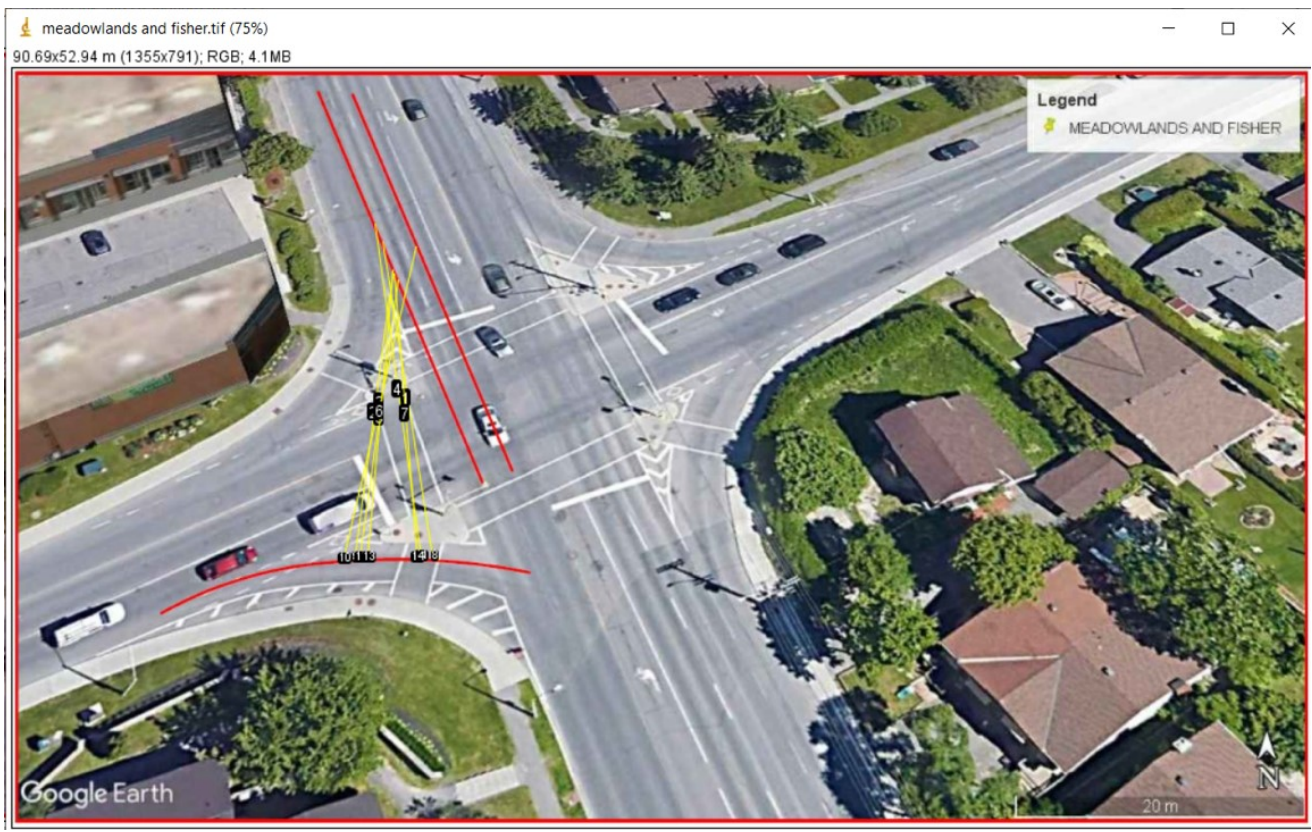

f)

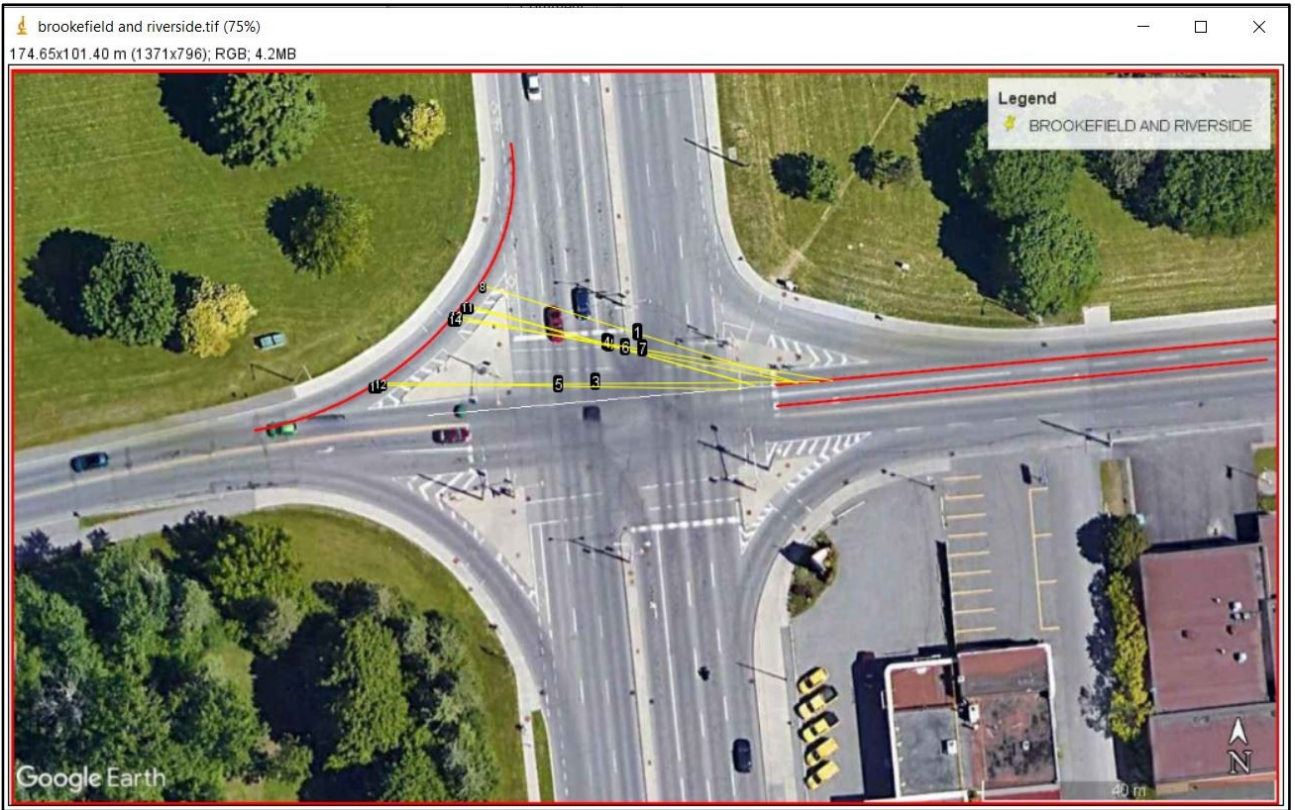


g)

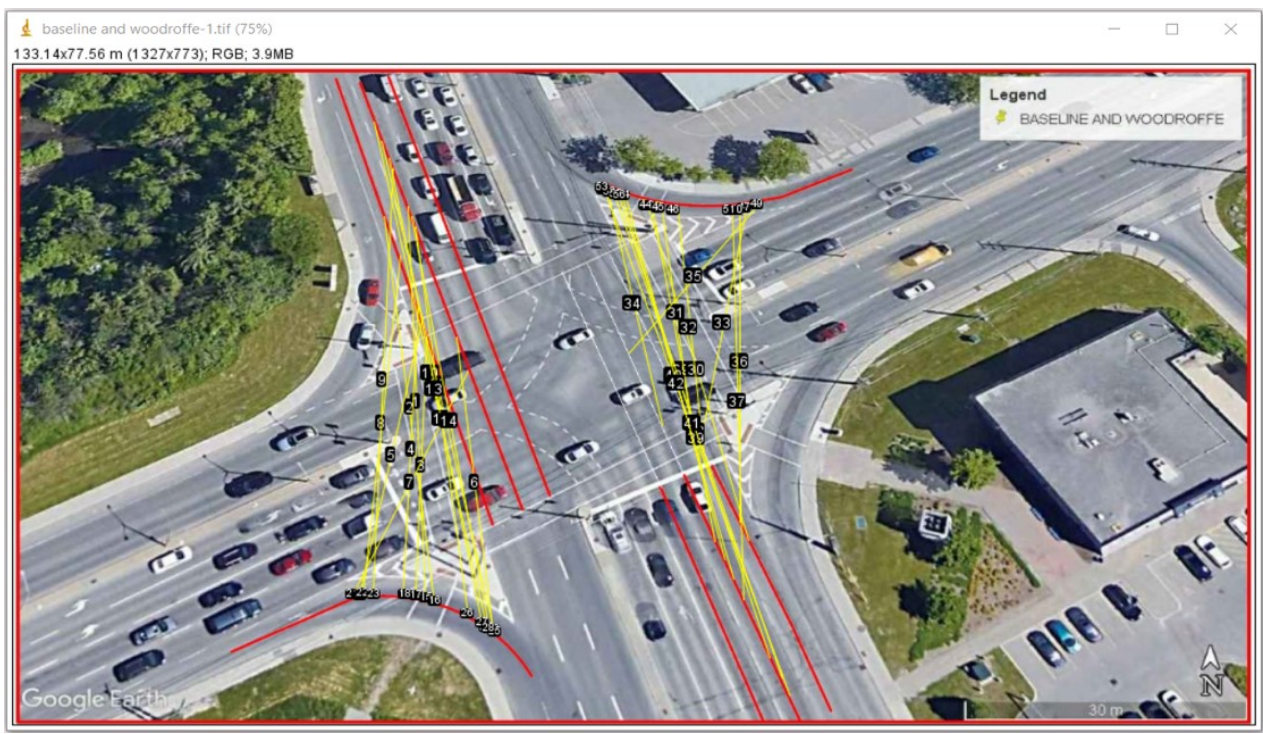

Figure A-2: Sight distance measurements at standard channels. e) Fisher and Meadowlands, f) Riverside and Brookefield, g) Baseline and Woodroffe (EBR and WBR) 


\section{Appendix B. Normality Tests, Additional T-tests and ANOVA}

\section{Table B-1: Data descriptives at all standard channel locations}

Satiatic:

\begin{tabular}{|c|c|c|c|c|c|c|c|}
\hline charnel & Intersection & & PET (s) & $\begin{array}{c}\text { True } \\
\text { hesdaryy(1) }\end{array}$ & SDTL & $\begin{array}{l}\text { neht turmes } \\
\text { reptime } \\
\text { mugie }\end{array}$ & $\begin{array}{l}\text { sighline } \\
\text { ditance }(\mathrm{m})\end{array}$ \\
\hline \multirow[t]{40}{*}{ standard channel } & \multirow{10}{*}{$\begin{array}{l}\text { Baselne and } \\
\text { Woodroffe EBR. }\end{array}$} & Vabd & 26 & 26 & 26 & 26 & 26 \\
\hline & & Missing & 0 & 0 & 0 & 0 & 0 \\
\hline & & 1Sean & 16542 & 6,7003 & 713231 & 126.7472 & 72.7073 \\
\hline & & 14edian & 1.4014 & 6.5399 & 712000 & 136.2240 & 730800 \\
\hline & & Std Deriabot & 67517 & 171353 & 2156136 & 2645937 & 21.07368 \\
\hline & & Vanunce & 456 & 2.936 & 464.892 & 700.098 & 444100 \\
\hline & & Skewness & 264 & 345 & 2.206 & -1900 & 2314 \\
\hline & & Std Error of Skewness & 456 & 456 & 456 & 456 & 456 \\
\hline & & Kurtotsis & -1.101 & -273 & 7.958 & 4.976 & 8.558 \\
\hline & & Std Error of Kurtosis & 887 & 887 & 887 & 887 & 887 \\
\hline & \multirow{10}{*}{$\begin{array}{l}\text { Bastlave and } \\
\text { Wostrotfe WBR. }\end{array}$} & N $\quad$ Vabd & 149 & 149 & 149 & 149 & 149 \\
\hline & & Lisseg & 0 & 0 & 0 & 0 & 0 \\
\hline & & Mean & 1.6661 & 7.6300 & 65.9691 & 119.2732 & 67.6929 \\
\hline & & 1Sedun & 15682 & 74074 & 716000 & 136.1700 & 72.3700 \\
\hline & & Std Deriaboe & 54957 & 245109 & 19.11253 & 16.94347 & 17.39955 \\
\hline & & Variance & 302 & 6.008 & 365.289 & 287.081 & 302396 \\
\hline & & Skewness & 231 & 511 & -577 & -1366 & -347 \\
\hline & & Std Error of Skewness & 199 & 199 & 199 & 199 & 199 \\
\hline & & Kuttosis & -752 & 816 & .406 & 2.838 & .1 .096 \\
\hline & & Std Errer of Kurtosis & 395 & 395 & 395 & 395 & 395 \\
\hline & \multirow{10}{*}{$\begin{array}{l}\text { Fisher \& } \\
\text { Meadowlands }\end{array}$} & N $\quad$ Vabd & 64 & 64 & 64 & 64 & 64 \\
\hline & & Mussing & 0 & 0 & 0 & 0 & 0 \\
\hline & & 1Sean & 1.7601 & 58044 & 36.2656 & 89.9716 & 41.1547 \\
\hline & & 14edan & 1.7184 & 56712 & 37.1000 & 92.6750 & 42.3750 \\
\hline & & Std Denasos & 55360 & 208231 & 10.48579 & 19.50511 & 7.45652 \\
\hline & & Vanance & 306 & 4.336 & 109.910 & 380.449 & 55.600 \\
\hline & & Skewness & 361 & 767 & .432 & .583 & -147 \\
\hline & & Std Error of Skewness & 299 & 299 & 399 & .299 & 399 \\
\hline & & Kuxtoms & -584 & 1354 & 161 & 008 & -070 \\
\hline & & Std Error of Kurtosis & 590 & 590 & 590 & 590 & 590 \\
\hline & \multirow{10}{*}{$\begin{array}{l}\text { Rewernade \& } \\
\text { Besokebeld }\end{array}$} & N $\quad$ Vabd & 130 & 190 & 130 & 130 & 130 \\
\hline & & 14isseng & 0 & 0 & 0 & 0 & 0 \\
\hline & & 14em & 15554 & 6.9418 & 50.4615 & 1196462 & 52.3791 \\
\hline & & Medum & 14681 & 6.7234 & 47.8500 & 118.6580 & 49.6650 \\
\hline & & Std Deriation & 56219 & 2.18839 & 1505299 & 17,75959 & 13.93392 \\
\hline & & Vanince & 316 & 4.789 & 226.592 & 315.403 & 194.154 \\
\hline & & Skewness & 516 & 791 & 383 & -075 & 539 \\
\hline & & Std. Error of Skewness & 212 & 212 & 212 & 212 & 212 \\
\hline & & Kutons &. .226 & 1.416 & 388 & 236 & 457 \\
\hline & & Std Error of Kutosin & 422 & 422 & 422 & 422 & 432 \\
\hline
\end{tabular}


Table B-2: Data descriptives for all smart channel locations

\begin{tabular}{|c|c|c|c|c|c|c|c|c|}
\hline \multirow[t]{40}{*}{ smart channel } & \multirow[t]{10}{*}{ Baseline \& Clyde } & \multirow[t]{2}{*}{$\mathrm{N}$} & Vabd & 215 & 215 & 215 & 215 & 215 \\
\hline & & & Missing & 0 & 0 & 0 & 0 & 0 \\
\hline & & \multicolumn{2}{|c|}{ Mean } & 1.6634 & 5.5041 & 49.0181 & 103.2951 & 50.9460 \\
\hline & & \multicolumn{2}{|c|}{ Median } & 1.6016 & 5.5389 & 49.5000 & 106.7980 & 50.9300 \\
\hline & & \multicolumn{2}{|c|}{ Std Denation } & .56137 & 1.35917 & 8.12012 & 15.00910 & 6.49167 \\
\hline & & \multicolumn{2}{|c|}{ Variance } & 315 & 1.847 & 65.936 & 225.273 & 42.142 \\
\hline & & \multicolumn{2}{|c|}{ Skewness } & 236 & 018 & -.520 & -.927 & 027 \\
\hline & & \multicolumn{2}{|c|}{ Std Error of Skewness } & 166 & .166 & .166 & 166 & .166 \\
\hline & & \multicolumn{2}{|c|}{ Kurtosis } & -410 & 1.522 & .744 & 1.129 & 168 \\
\hline & & \multicolumn{2}{|c|}{ Std. Error of Kurtosis } & 330 & .330 & 330 & 330 & 330 \\
\hline & \multirow{10}{*}{$\begin{array}{l}\text { Greenbank \& } \\
\text { Strandherd }\end{array}$} & \multirow[t]{2}{*}{$\mathrm{N}$} & Vabd & 158 & 158 & 158 & 158 & 158 \\
\hline & & & Missing & 0 & 0 & 0 & 0 & 0 \\
\hline & & \multicolumn{2}{|c|}{ Mean } & 1.3068 & 5.4415 & 41.6930 & 94.0664 & 45.0792 \\
\hline & & \multicolumn{2}{|c|}{ Median } & 1.2513 & 5.5556 & 413500 & 98.4580 & 44.2600 \\
\hline & & \multicolumn{2}{|c|}{ Std Denation } & 48157 & 1.26536 & 11.95855 & 18.50027 & 9.86477 \\
\hline & & \multicolumn{2}{|c|}{ Variance } & $23 ?$ & 1.601 & 143.007 & 342.260 & 97,314 \\
\hline & & \multicolumn{2}{|c|}{ Skewness } & 920 & -154 & -.209 & -.933 & 199 \\
\hline & & \multicolumn{2}{|c|}{ Std Error of Skewness } & 193 & 193 & .193 & 193 & .193 \\
\hline & & \multicolumn{2}{|c|}{ Kuttosis } & 1.102 & -115 & 367 & 485 & 354 \\
\hline & & \multicolumn{2}{|c|}{ Std. Error of Kurtoss } & 384 & 384 & .384 & 384 & 384 \\
\hline & \multirow[t]{10}{*}{ Piverside \& Heron } & \multirow[t]{2}{*}{$\mathrm{N}$} & Vabd & 19 & 19 & 19 & 19 & 19 \\
\hline & & & Missing & 0 & 0 & 0 & 0 & 0 \\
\hline & & \multicolumn{2}{|c|}{ Mean } & 1.8791 & 5.1069 & 53.0211 & 98.3203 & 54.9495 \\
\hline & & \multicolumn{2}{|c|}{ Median } & 1.9353 & 4.9383 & 524000 & 96.0850 & 52.5600 \\
\hline & & Std & & .68454 & 1.28900 & 18.15772 & 17.72930 & 16.36097 \\
\hline & & Var & & 469 & 1.662 & 329.703 & 314.328 & 267.681 \\
\hline & & Ske & & 102 & -180 & -.264 & -370 & .133 \\
\hline & & Std & Skewness & 524 & 524 & .524 & 524 & 524 \\
\hline & & Ktr & & -1.337 & -458 & -1.128 & -1.339 & -1.348 \\
\hline & & Std & fKurtosas & 1.014 & 1014 & 1014 & 1.014 & 1.014 \\
\hline & Strandherd and & $\mathrm{N}$ & Vabd & 44 & 44 & 44 & 44 & 44 \\
\hline & Longfeld & & Missing & 0 & 0 & 0 & 0 & 0 \\
\hline & & Me & & 1.7472 & 5.1643 & 46.2523 & 102.2052 & 49.5648 \\
\hline & & Me & & 1.7518 & 5.1552 & 46.6000 & 107.7905 & 49.0600 \\
\hline & & Std & & 52748 & 1.35896 & 7.42179 & 19.25802 & 4.82612 \\
\hline & & Var & & 278 & 1.847 & 55.083 & 370.871 & 23.291 \\
\hline & & Ske & & 249 & -619 & -2168 & -1.657 & .805 \\
\hline & & Std & f Skewness & 357 & 357 & .357 & 357 & 357 \\
\hline & & Ktw & & -.533 & 1.024 & 8935 & 2.814 & 3.061 \\
\hline & & Std & Kurtosas & 702 & 702 & 702 & 702 & 702 \\
\hline
\end{tabular}


Table B-3: Normality tests at each channel location

Tests of Normality

\begin{tabular}{|c|c|c|c|c|c|c|c|c|}
\hline \multirow[b]{2}{*}{ channel } & \multirow[b]{2}{*}{ Intersection } & & \multicolumn{3}{|c|}{ Kolmogorov-Smirnov ${ }^{\text {a }}$} & \multicolumn{3}{|c|}{ Shapiro-Wilk } \\
\hline & & & Statistic & $\mathrm{df}$ & Sig. & Statistic & $\mathrm{df}$ & Sig. \\
\hline \multirow[t]{20}{*}{ standard channel } & \multirow{5}{*}{$\begin{array}{l}\text { Baseline and } \\
\text { Woodroffe EBR }\end{array}$} & PET (s.) & .182 & 26 & .027 & .926 & 26 & .063 \\
\hline & & Time headway(s.) & .133 & 26 & $200^{*}$ & .963 & 26 & .444 \\
\hline & & SDTL & .167 & 26 & .061 & .796 & 26 & .000 \\
\hline & & $\begin{array}{l}\text { right turning sightline } \\
\text { angle }\end{array}$ & .178 & 26 & .033 & .823 & 26 & .000 \\
\hline & & sightline distance $(\mathrm{m})$ & .177 & 26 & .035 & .788 & 26 & .000 \\
\hline & \multirow{5}{*}{$\begin{array}{l}\text { Baseline and } \\
\text { Woodroffe WBR }\end{array}$} & PET (s.) & .091 & 149 & .004 & .979 & 149 & .022 \\
\hline & & Time headway(s.) & .055 & 149 & $200^{*}$ & .982 & 149 & .052 \\
\hline & & SDTL & .122 & 149 & .000 & .948 & 149 & .000 \\
\hline & & $\begin{array}{l}\text { right turning sightline } \\
\text { angle }\end{array}$ & .161 & 149 & .000 & .880 & 149 & .000 \\
\hline & & sightline distance $(\mathrm{m})$ & .118 & 149 & .000 & .940 & 149 & .000 \\
\hline & \multirow{5}{*}{$\begin{array}{l}\text { Fisher \& } \\
\text { Meadowlands }\end{array}$} & $\operatorname{PET}(\mathrm{s}$.) & .079 & 64 & $200^{*}$ & .967 & 64 & .082 \\
\hline & & Time headway(s.) & .105 & 64 & .077 & .947 & 64 & .008 \\
\hline & & SDTL & .071 & 64 & $200^{*}$ & .975 & 64 & .220 \\
\hline & & $\begin{array}{l}\text { right turning sightline } \\
\text { angle }\end{array}$ & .101 & 64 & .168 & .967 & 64 & .080 \\
\hline & & sightline distance $(\mathrm{m})$ & .086 & 64 & $200^{*}$ & .987 & 64 & .749 \\
\hline & \multirow{5}{*}{$\begin{array}{l}\text { Riverside \& } \\
\text { Brookefield }\end{array}$} & PET (s.) & .083 & 130 & .027 & .969 & 130 & .005 \\
\hline & & Time headway(s.) & .067 & 130 & $200^{*}$ & .965 & 130 & .002 \\
\hline & & SDTL & .083 & 130 & .030 & .984 & 130 & .129 \\
\hline & & $\begin{array}{l}\text { right turning sightline } \\
\text { angle }\end{array}$ & .054 & 130 & $200^{*}$ & .987 & 130 & .278 \\
\hline & & sightline distance $(\mathrm{m})$ & .087 & 130 & .017 & .979 & 130 & .037 \\
\hline \multirow[t]{20}{*}{ smart channel } & \multirow[t]{5}{*}{ Baseline \& Clyde } & PET (s.) & .064 & 215 & .031 & .987 & 215 & .050 \\
\hline & & Time headway(s.) & .055 & 215 & $200^{*}$ & .978 & 215 & .002 \\
\hline & & SDTL & .063 & 215 & .040 & .981 & 215 & .006 \\
\hline & & $\begin{array}{l}\text { right turning sightline } \\
\text { angle }\end{array}$ & .129 & 215 & .000 & .930 & 215 & .000 \\
\hline & & sightline distance $(\mathrm{m})$ & .043 & 215 & $200^{*}$ & .995 & 215 & .730 \\
\hline & \multirow{5}{*}{$\begin{array}{l}\text { Greenbank \& } \\
\text { Strandherd }\end{array}$} & $\mathrm{PET}(\mathrm{s})$. & .087 & 158 & .006 & .948 & 158 & .000 \\
\hline & & Time headway(s.) & .060 & 158 & $200^{*}$ & .993 & 158 & .586 \\
\hline & & SDTL & .077 & 158 & .024 & .986 & 158 & .116 \\
\hline & & $\begin{array}{l}\text { right turning sightline } \\
\text { angle }\end{array}$ & .115 & 158 & .000 & .923 & 158 & .000 \\
\hline & & sightline distance $(\mathrm{m})$ & .064 & 158 & $200^{*}$ & .984 & 158 & .065 \\
\hline & \multirow[t]{5}{*}{ Riverside \& Heron } & $\operatorname{PET}(\mathrm{s})$. & .146 & 19 & $200^{*}$ & .941 & 19 & .270 \\
\hline & & Time headway(s.) & .082 & 19 & $200^{*}$ & .973 & 19 & .836 \\
\hline & & SDTL & .185 & 19 & .086 & .910 & 19 & .074 \\
\hline & & $\begin{array}{l}\text { right turning sightline } \\
\text { angle }\end{array}$ & .207 & 19 & .031 & .889 & 19 & .031 \\
\hline & & sightline distance $(\mathrm{m})$ & .195 & 19 & .056 & .904 & 19 & .057 \\
\hline & \multirow{5}{*}{$\begin{array}{l}\text { Strandherd and } \\
\text { Longfield }\end{array}$} & PET (s.) & .070 & 44 & $.200^{*}$ & .980 & 44 & .650 \\
\hline & & Time headway(s.) & .072 & 44 & $200^{*}$ & .967 & 44 & .242 \\
\hline & & SDTL & .129 & 44 & .064 & .837 & 44 & .000 \\
\hline & & $\begin{array}{l}\text { right turning sightline } \\
\text { angle }\end{array}$ & .207 & 44 & .000 & .831 & 44 & .000 \\
\hline & & sightline distance $(\mathrm{m})$ & .097 & 44 & $200^{*}$ & .943 & 44 & .031 \\
\hline
\end{tabular}

*. This is a lower bound of the true significance

a. Lilliefors Significance Correction 


\section{T-test excluding channel location 8}

After excluding channel location 8 (Strandherd and Longfields) from the data, the means of PET measurements, sightline distance, SDTL, time headway and right turning sightline angle are statistically significantly different from one another.

Table B-4: T-test of parameters excluding channel location 8

Independent Samples Test

\begin{tabular}{|c|c|c|c|c|c|c|c|c|c|c|}
\hline & & $\begin{array}{r}\text { Levene's T } \\
\mathrm{V}\end{array}$ & quality & & & & est for Equal & f Means & & \\
\hline & & & & & & Sig. (2- & Mean & Std. Error & $\begin{array}{l}95 \% \text { Confi } \\
\text { the I }\end{array}$ & $\begin{array}{l}\text { Interval of } \\
\text { ence }\end{array}$ \\
\hline & & $\mathrm{F}$ & Sig. & $\mathrm{t}$ & df & tailed) & Difference & Difference & Lower & Upper \\
\hline PET (s.) & $\begin{array}{l}\text { Equal variances } \\
\text { assumed }\end{array}$ & .227 & .634 & 2.732 & 759 & .006 & .11246 & .04116 & .03166 & .19326 \\
\hline & $\begin{array}{l}\text { Equal variances not } \\
\text { assumed }\end{array}$ & & & 2.732 & 756.502 & .006 & .11246 & .04116 & .03166 & .19326 \\
\hline $\begin{array}{l}\text { right turning sightline } \\
\text { angle }\end{array}$ & $\begin{array}{l}\text { Equal variances } \\
\text { assumed }\end{array}$ & 17.045 & .000 & 10.958 & 759 & .000 & 15.51485 & 1.41589 & 12.73532 & 18.29439 \\
\hline & $\begin{array}{l}\text { Equal variances not } \\
\text { assumed }\end{array}$ & & & 10.881 & 700.164 & .000 & 15.51485 & 1.42583 & 12.71544 & 18.31426 \\
\hline Time headway(s.) & $\begin{array}{l}\text { Equal variances } \\
\text { assumed }\end{array}$ & 85.482 & .000 & 11.328 & 759 & .000 & 1.54581 & .13646 & 1.27793 & 1.81369 \\
\hline & $\begin{array}{l}\text { Equal variances not } \\
\text { assumed }\end{array}$ & & & 11.152 & 573.324 & .000 & 1.54581 & .13861 & 1.27357 & 1.81806 \\
\hline SDTL & $\begin{array}{l}\text { Equal variances } \\
\text { assumed }\end{array}$ & 152.439 & .000 & 8.046 & 759 & .000 & 9.47147 & 1.17722 & 7.16047 & 11.78248 \\
\hline & $\begin{array}{l}\text { Equal variances not } \\
\text { assumed }\end{array}$ & & & 7.915 & 562.806 & .000 & 9.47147 & 1.19658 & 7.12117 & 11.82178 \\
\hline sightline distance $(\mathrm{m})$ & $\begin{array}{l}\text { Equal variances } \\
\text { assumed }\end{array}$ & 206.971 & .000 & 8.824 & 759 & .000 & 9.27288 & 1.05083 & 7.21001 & 11.33576 \\
\hline & $\begin{array}{l}\text { Equal variances not } \\
\text { assumed }\end{array}$ & & & 8.664 & 531.350 & .000 & 9.27288 & 1.07025 & 7.17044 & 11.37533 \\
\hline
\end{tabular}




\section{T-test, excluding channel location 7}

The t-test results interpretation does not change from those when channel location 8 is excluded from the data.

Table B-5: T-test of parameters excluding channel location 7

Independent Samples Test

\begin{tabular}{|c|c|c|c|c|c|c|c|c|c|c|}
\hline & & $\begin{array}{r}\text { Levene's } \mathrm{T}_{\mathrm{e}} \\
\mathrm{V}\end{array}$ & quality of & & & & est for Equalit & f Means & & \\
\hline & & & & & & Sig. (2- & Mean & Std. Error & $\begin{array}{r}95 \% \text { Confid } \\
\text { the I }\end{array}$ & $\begin{array}{l}\text { e Interval of } \\
\text { rence }\end{array}$ \\
\hline & & $\mathrm{F}$ & Sig. & $\mathrm{t}$ & df & tailed) & Difference & Difference & Lower & Upper \\
\hline PET (s.) & $\begin{array}{l}\text { Equal variances } \\
\text { assumed }\end{array}$ & .666 & .415 & 2.625 & 784 & .009 & .10545 & .04017 & .02659 & .18431 \\
\hline & $\begin{array}{l}\text { Equal variances not } \\
\text { assumed }\end{array}$ & & & 2.623 & 769.431 & .009 & .10545 & .04021 & .02652 & .18439 \\
\hline $\begin{array}{l}\text { right turning sightline } \\
\text { angle }\end{array}$ & $\begin{array}{l}\text { Equal variances } \\
\text { assumed }\end{array}$ & 17.434 & .000 & 10.851 & 784 & .000 & 15.16573 & 1.39762 & 12.42220 & 17.90925 \\
\hline & $\begin{array}{l}\text { Equal variances not } \\
\text { assumed }\end{array}$ & & & 10.707 & 703.600 & .000 & 15.16573 & 1.41645 & 12.38475 & 17.94670 \\
\hline Time headway(s.) & $\begin{array}{l}\text { Equal variances } \\
\text { assumed }\end{array}$ & 88.067 & .000 & 11.688 & 784 & .000 & 1.56091 & .13355 & 1.29876 & 1.82305 \\
\hline & $\begin{array}{l}\text { Equal variances not } \\
\text { assumed }\end{array}$ & & & 11.327 & 566.835 & .000 & 1.56091 & .13780 & 1.29024 & 1.83157 \\
\hline SDTL & $\begin{array}{l}\text { Equal variances } \\
\text { assumed }\end{array}$ & 194.792 & .000 & 8.667 & 784 & .000 & 9.78033 & 1.12850 & 7.56509 & 11.99556 \\
\hline & $\begin{array}{l}\text { Equal variances not } \\
\text { assumed }\end{array}$ & & & 8.358 & 529.366 & .000 & 9.78033 & 1.17018 & 7.48157 & 12.07909 \\
\hline sightline distance $(\mathrm{m})$ & $\begin{array}{l}\text { Equal variances } \\
\text { assumed }\end{array}$ & 268.417 & .000 & 9.431 & 784 & .000 & 9.47090 & 1.00421 & 7.49964 & 11.44216 \\
\hline & $\begin{array}{l}\text { Equal variances not } \\
\text { assumed }\end{array}$ & & & 9.054 & 495.725 & .000 & 9.47090 & 1.04606 & 7.41564 & 11.52617 \\
\hline
\end{tabular}




\section{One Way-ANOVA test}

The null hypothesis is that the means at all channel locations within each group are equal. At standard channels locations, it was observed that the means of time headway, sightline distance, right turning sightline angle and SDTL are statistically significantly different from one another, $\mathrm{p}<0.05$ at the $5 \%$ level of significance. PET means at all intersections are not statistically significantly different from one another. For smart channel intersections, PET, sightline distance, right turning sightline angle and SDTL means are statistically significantly different from one another, while time headway means of the four channels are not statistically significantly different.

The one way ANOVA results after excluding channel locations 8 and 7 from the data, shown in Table B-7 and Table B-8 show a similar pattern of results to those obtained when all channel locations were included at the four smart channels four standard channel locations. Therefore, channel locations at 7 and 8 will not be eliminated from the data when using the GamesHowell post-hoc tests when determining which channel locations significantly differ from the rest. 
Table B-6: ANOVA with all channel locations included

ANOVA

\begin{tabular}{|c|c|c|c|c|c|c|c|}
\hline channel & & & $\begin{array}{l}\text { Sum of } \\
\text { Squares }\end{array}$ & $\mathrm{df}$ & $\begin{array}{l}\text { Mean } \\
\text { Square }\end{array}$ & $\mathrm{F}$ & Sig. \\
\hline \multirow[t]{15}{*}{ standard channel } & \multirow[t]{3}{*}{ PET (s.) } & Between Groups & 1.958 & 3 & .653 & 2.050 & .106 \\
\hline & & Within Groups & 116.176 & 365 & .318 & & \\
\hline & & Total & 118.134 & 368 & & & \\
\hline & \multirow[t]{3}{*}{ Time headway(s.) } & Between Groups & 153.397 & 3 & 51.132 & 10.069 & .000 \\
\hline & & Within Groups & 1853.518 & 365 & 5.078 & & \\
\hline & & Total & 2006.915 & 368 & & & \\
\hline & \multirow{3}{*}{$\begin{array}{l}\text { right turning sighline } \\
\text { angle }\end{array}$} & Between Groups & 49197.455 & 3 & 16399.152 & 48.022 & .000 \\
\hline & & Within Groups & 124645.784 & 365 & 341.495 & & \\
\hline & & Total & 173843.239 & 368 & & & \\
\hline & \multirow{3}{*}{$\operatorname{SDTL}(\mathrm{m})$} & Between Groups & 49798.395 & 3 & 16599.465 & 59.493 & .000 \\
\hline & & Within Groups & 101839.796 & 365 & 279.013 & & \\
\hline & & Total & 151638.192 & 368 & & & \\
\hline & \multirow[t]{3}{*}{ sightline distance $(\mathrm{m})$} & Between Groups & 41890.174 & 3 & 13963.391 & 60.383 & .000 \\
\hline & & Within Groups & 84405.833 & 365 & 231.249 & & \\
\hline & & Total & 126296.006 & 368 & & & \\
\hline \multirow[t]{15}{*}{ smart channel } & \multirow[t]{3}{*}{ PET (s.) } & Between Groups & 15.876 & 3 & 5.292 & 18.400 & .000 \\
\hline & & Within Groups & 124.248 & 432 & .288 & & \\
\hline & & Total & 140.123 & 435 & & & \\
\hline & \multirow[t]{3}{*}{ Time headway(s.) } & Between Groups & 6.292 & 3 & 2.097 & 1.198 & .310 \\
\hline & & Within Groups & 756.032 & 432 & 1.750 & & \\
\hline & & Total & 762.323 & 435 & & & \\
\hline & \multirow{3}{*}{$\begin{array}{l}\text { right turning sighline } \\
\text { angle }\end{array}$} & Between Groups & 8103.165 & 3 & 2701.055 & 9.445 & .000 \\
\hline & & Within Groups & 123548.579 & 432 & 285.992 & & \\
\hline & & Total & 131651.744 & 435 & & & \\
\hline & \multirow{3}{*}{$\operatorname{SDTL}(\mathrm{m})$} & Between Groups & 5799.532 & 3 & 1933.177 & 18.614 & .000 \\
\hline & & Within Groups & 44865.683 & 432 & 103.856 & & \\
\hline & & Total & 50665.215 & 435 & & & \\
\hline & \multirow[t]{3}{*}{ sightline distance $(\mathrm{m})$} & Between Groups & 3920.421 & 3 & 1306.807 & 18.745 & .000 \\
\hline & & Within Groups & 30116.376 & 432 & 69.714 & & \\
\hline & & Total & 34036.797 & 435 & & & \\
\hline
\end{tabular}


Table B-7: ANOVA excluding channel location 8

ANOVA

\begin{tabular}{|c|c|c|c|c|c|c|c|}
\hline channel & & & $\begin{array}{l}\text { Sum of } \\
\text { Squares }\end{array}$ & df & $\begin{array}{l}\text { Mean } \\
\text { Square }\end{array}$ & F & Sig. \\
\hline \multirow[t]{15}{*}{ standard channel } & \multirow[t]{3}{*}{ PET (s.) } & Between Groups & 1.958 & 3 & .653 & 2.050 & .106 \\
\hline & & Within Groups & 116.176 & 365 & .318 & & \\
\hline & & Total & 118.134 & 368 & & & \\
\hline & \multirow[t]{3}{*}{ Time headway(s.) } & Between Groups & 153.397 & 3 & 51.132 & 10.069 & .000 \\
\hline & & Within Groups & 1853.518 & 365 & 5.078 & & \\
\hline & & Total & 2006.915 & 368 & & & \\
\hline & \multirow{3}{*}{$\begin{array}{l}\text { right turning sighline } \\
\text { angle }\end{array}$} & Between Groups & 49197.455 & 3 & 16399.152 & 48.022 & .000 \\
\hline & & Within Groups & 124645.784 & 365 & 341.495 & & \\
\hline & & Total & 173843.239 & 368 & & & \\
\hline & \multirow{3}{*}{$\operatorname{SDTL}(\mathrm{m})$} & Between Groups & 49798.395 & 3 & 16599.465 & 59.493 & .000 \\
\hline & & Within Groups & 101839.796 & 365 & 279.013 & & \\
\hline & & Total & 151638.192 & 368 & & & \\
\hline & \multirow[t]{3}{*}{ sightline distance $(\mathrm{m})$} & Between Groups & 41890.174 & 3 & 13963.391 & 60.383 & .000 \\
\hline & & Within Groups & 84405.833 & 365 & 231.249 & & \\
\hline & & Total & 126296.006 & 368 & & & \\
\hline \multirow[t]{15}{*}{ smart channel } & \multirow[t]{3}{*}{ PET (s.) } & Between Groups & 14.011 & 2 & 7.006 & 24.271 & .000 \\
\hline & & Within Groups & 112.283 & 389 & .289 & & \\
\hline & & Total & 126.295 & 391 & & & \\
\hline & \multirow[t]{3}{*}{ Time headway(s.) } & Between Groups & 2.841 & 2 & 1.420 & .817 & .443 \\
\hline & & Within Groups & 676.620 & 389 & 1.739 & & \\
\hline & & Total & 679.461 & 391 & & & \\
\hline & \multirow{3}{*}{$\begin{array}{l}\text { right turning sighline } \\
\text { angle }\end{array}$} & Between Groups & 7777.111 & 2 & 3888.555 & 14.058 & .000 \\
\hline & & Within Groups & 107601.114 & 389 & 276.610 & & \\
\hline & & Total & 115378.225 & 391 & & & \\
\hline & \multirow{3}{*}{ SDTL(m) } & Between Groups & 5799.530 & 2 & 2899.765 & 26.543 & .000 \\
\hline & & Within Groups & 42497.113 & 389 & 109.247 & & \\
\hline & & Total & 48296.643 & 391 & & & \\
\hline & \multirow[t]{3}{*}{ sightline distance $(\mathrm{m})$} & Between Groups & 3895.770 & 2 & 1947.885 & 26.025 & .000 \\
\hline & & Within Groups & 29114.844 & 389 & 74.845 & & \\
\hline & & Total & 33010.614 & 391 & & & \\
\hline
\end{tabular}


Table B-8: ANOVA excluding channel location 7

ANOVA

\begin{tabular}{|c|c|c|c|c|c|c|c|}
\hline channel & & & $\begin{array}{l}\text { Sum of } \\
\text { Squares }\end{array}$ & $\mathrm{df}$ & $\begin{array}{l}\text { Mean } \\
\text { Square }\end{array}$ & $\mathrm{F}$ & Sig. \\
\hline \multirow[t]{15}{*}{ standard channel } & \multirow[t]{3}{*}{ PET (s.) } & Between Groups & 1.958 & 3 & .653 & 2.050 & .106 \\
\hline & & Within Groups & 116.176 & 365 & .318 & & \\
\hline & & Total & 118.134 & 368 & & & \\
\hline & \multirow[t]{3}{*}{ Time headway(s.) } & Between Groups & 153.397 & 3 & 51.132 & 10.069 & .000 \\
\hline & & Within Groups & 1853.518 & 365 & 5.078 & & \\
\hline & & Total & 2006.915 & 368 & & & \\
\hline & \multirow{3}{*}{$\begin{array}{l}\text { right turning sighline } \\
\text { angle }\end{array}$} & Between Groups & 49197.455 & 3 & 16399.152 & 48.022 & .000 \\
\hline & & Within Groups & 124645.784 & 365 & 341.495 & & \\
\hline & & Total & 173843.239 & 368 & & & \\
\hline & \multirow{3}{*}{ SDTL(m) } & Between Groups & 49798.395 & 3 & 16599.465 & 59.493 & .000 \\
\hline & & Within Groups & 101839.796 & 365 & 279.013 & & \\
\hline & & Total & 151638.192 & 368 & & & \\
\hline & \multirow[t]{3}{*}{ sightline distance $(\mathrm{m})$} & Between Groups & 41890.174 & 3 & 13963.391 & 60.383 & .000 \\
\hline & & Within Groups & 84405.833 & 365 & 231.249 & & \\
\hline & & Total & 126296.006 & 368 & & & \\
\hline \multirow[t]{15}{*}{ smart channel } & \multirow[t]{3}{*}{ PET (s.) } & Between Groups & 13.751 & 2 & 6.875 & 24.578 & .000 \\
\hline & & Within Groups & 115.813 & 414 & .280 & & \\
\hline & & Total & 129.564 & 416 & & & \\
\hline & \multirow[t]{3}{*}{ Time headway(s.) } & Between Groups & 4.220 & 2 & 2.110 & 1.203 & .301 \\
\hline & & Within Groups & 726.124 & 414 & 1.754 & & \\
\hline & & Total & 730.344 & 416 & & & \\
\hline & \multirow{3}{*}{$\begin{array}{l}\text { right turning sighline } \\
\text { angle }\end{array}$} & Between Groups & 8069.400 & 2 & 4034.700 & 14.169 & .000 \\
\hline & & Within Groups & 117890.675 & 414 & 284.760 & & \\
\hline & & Total & 125960.074 & 416 & & & \\
\hline & \multirow{3}{*}{$\operatorname{SDTL}(\mathrm{m})$} & Between Groups & 4891.151 & 2 & 2445.575 & 26.007 & .000 \\
\hline & & Within Groups & 38931.031 & 414 & 94.036 & & \\
\hline & & Total & 43822.182 & 416 & & & \\
\hline & \multirow[t]{3}{*}{ sightline distance $(\mathrm{m})$} & Between Groups & 3182.568 & 2 & 1591.284 & 26.041 & .000 \\
\hline & & Within Groups & 25298.113 & 414 & 61.107 & & \\
\hline & & Total & 28480.681 & 416 & & & \\
\hline
\end{tabular}




\section{Appendix C. Games-Howell Post-Hoc Test}

This test compared the channels within each group for smart and standard channel intersections, to determine which intersection within each group significantly differs from the others at the four smart channel intersections and four standard channel intersections.

ANOVA was performed with the Games-Howell post-hoc Test in SPSS, and the characteristics of the data were considered when selecting this test to make multiple comparisons between intersections as the independent variable. The independent variable is split based on channel type with two levels: smart and standard channel intersections. The continuous dependent variables for the comparison at all intersections are sightline distance, SDTL, PET measurements, right turning sightline angle and time headway. Each variable is explained in Section 3.2 as to how it relates to safety at channelized intersections.

Before performing ANOVA, assumptions were considered and tested. These include at least one categorical variable with two or more levels, in this case, four locations for each channel type. The second assumption is that there is one dependent variable measured with a continuous level. Independence of observations was assumed. The dependent variable is assumed to have homogeneity of variance. Games-Howell post-hoc advantage is its ability to manage unequal sample sizes. 


\section{PET Games-Howell Post- Hoc test}

Table C-1 illustrates the unequal sample sizes at the intersections considered, which validates the use of the Games-Howell post-Hoc test. The test can also be used when the homogeneity of variance is violated. Table $\mathrm{C}-1$ also shows the descriptive statistics for smart and standard channels for PET measurements as the dependent variable. It is observed that at smart channels, the means of PET are different compared to those at the standard channel intersections, whose means are closer to each other. The standard deviations vary for the smart channel but not as much for standard channels.

\section{Table C-1: PET descriptives for each smart channel intersection}

Descriptive Statistics

\begin{tabular}{|c|c|c|c|c|}
\hline channel & Intersection & Mean & $\begin{array}{c}\text { Std. } \\
\text { Deviation }\end{array}$ & $\mathrm{N}$ \\
\hline \multirow[t]{5}{*}{ standard channel } & $\begin{array}{l}\text { Baseline and } \\
\text { Woodroffe EBR }\end{array}$ & 1.65 & .675 & 26 \\
\hline & $\begin{array}{l}\text { Baseline and } \\
\text { Woodroffe WBR }\end{array}$ & 1.67 & .550 & 149 \\
\hline & $\begin{array}{l}\text { Fisher \& } \\
\text { Meadowlands }\end{array}$ & 1.76 & .554 & 64 \\
\hline & $\begin{array}{l}\text { Riverside \& } \\
\text { Brookefield }\end{array}$ & 1.56 & .562 & 130 \\
\hline & Total & 1.64 & .567 & 369 \\
\hline \multirow[t]{5}{*}{ smart channel } & Baseline \& Clyde & 1.66 & .561 & 215 \\
\hline & $\begin{array}{l}\text { Greenbank \& } \\
\text { Strandherd }\end{array}$ & 1.31 & .482 & 158 \\
\hline & Riverside \& Heron & 1.88 & .685 & 19 \\
\hline & $\begin{array}{l}\text { Strandherd and } \\
\text { Longfield }\end{array}$ & 1.75 & .527 & 44 \\
\hline & Total & 1.55 & 568 & 436 \\
\hline
\end{tabular}

Using Levene's test in Table C-2 to test homogeneity of variance, at standard channels, the

finding is not statistically significant, $\mathrm{p}$ value $=0.570>0.05$; this provides evidence that variances 
may be equal at standard channels and unequal at smart channel intersections with p-value $=0.007$ $<0.05$ which is statistically significant.

Table C-2: PET homogeneity of variance test

Levene's Test of Equality of Error Variances ${ }^{a, b}$
\begin{tabular}{|llccccc|}
\hline \multirow{2}{*}{ channel } & & $\begin{array}{l}\text { Levene } \\
\text { Statistic }\end{array}$ & df1 & df2 & Sig. \\
\hline standard channel & PET (s.) & $\begin{array}{l}\text { Based on Mean } \\
\text { Based on Median }\end{array}$ & .563 & 2 & 366 & .570 \\
& & .371 & 2 & 366 & .690 \\
& $\begin{array}{l}\text { Based on Median and } \\
\text { with adjusted df }\end{array}$ & .371 & 2 & 364.012 & .690 \\
& $\begin{array}{l}\text { Based on trimmed } \\
\text { mean }\end{array}$ & .573 & 2 & 366 & .564 \\
\hline smart channel & PET (s.) & $\begin{array}{l}\text { Based on Mean } \\
\text { Based on Median }\end{array}$ & 4.056 & 3 & 432 & .007 \\
& $\begin{array}{l}\text { Based on Median and } \\
\text { with adjusted df } \\
\text { Based on trimmed } \\
\text { mean }\end{array}$ & 3.740 & 3 & 432 & .011 \\
& & 3.740 & 3 & 429.782 & .011 \\
& & 4.073 & 3 & 432 & .007 \\
\hline
\end{tabular}

Tests the null hypothesis that the error variance of the dependent variable is equal across groups.

a. Dependent variable: PET (s.)

b. Design: Intercept + Intersection

The test of between subject effects results in Table C-3 indicate that at standard channels, the p-value is 0.106 and is not statistically significant indicating that the PET means at the four standard channels are not statistically significantly different from each other. The partial $\mathrm{R}^{2}$ is 0.017, this means that standard channel types explain $1.7 \%$ of the variance in the dependent variable PET. At smart channels, the p-value is $<0.001$, indicating statistical significance; the partial $\mathrm{R}^{2}$ is 0.113 ; this means that smart channel types explain $11.3 \%$ of the variance in the dependent variable PET. 


\section{Table C-3: PET test of between subjects effects for each channel type}

\begin{tabular}{|c|c|c|c|c|c|c|c|}
\hline \multicolumn{8}{|c|}{ Dependent Variable: PET (s.) } \\
\hline channel & Source & $\begin{array}{l}\text { Type II } \\
\text { Sum of } \\
\text { Squares }\end{array}$ & $\mathrm{df}$ & $\begin{array}{l}\text { Mean } \\
\text { Square }\end{array}$ & $\mathrm{F}$ & Sig. & $\begin{array}{c}\text { Partial Eta } \\
\text { Squared }\end{array}$ \\
\hline \multirow[t]{6}{*}{ standard channel } & Corrected Model & $1.958^{\mathrm{a}}$ & 3 & .653 & 2.050 & .106 & .017 \\
\hline & Intercept & 642.921 & 1 & 642.921 & 2019.922 & .000 & .847 \\
\hline & Intersection & 1.958 & 3 & .653 & 2.050 & .106 & .017 \\
\hline & Error & 116.176 & 365 & .318 & & & \\
\hline & Total & 1113.697 & 369 & & & & \\
\hline & Corrected Total & 118.134 & 368 & & & & \\
\hline \multirow[t]{6}{*}{ smart channel } & Corrected Model & $15.876^{b}$ & 3 & 5.292 & 18.400 & .000 & .113 \\
\hline & Intercept & 503.977 & 1 & 503.977 & 1752.293 & .000 & .802 \\
\hline & Intersection & 15.876 & 3 & 5.292 & 18.400 & .000 & .113 \\
\hline & Error & 124.248 & 432 & .288 & & & \\
\hline & Total & 1190.333 & 436 & & & & \\
\hline & Corrected Total & 140.123 & 435 & & & & \\
\hline
\end{tabular}

a. $R$ Squared $=.017$ (Adjusted R Squared $=.008$ )

b. $\mathrm{R}$ Squared $=.113($ Adjusted $\mathrm{R}$ Squared $=.107)$

The post-hoc test for PET at each channel type for homogeneity of variance was violated for smart channels and not standard channels using Levene's test. However, considering the different sample sizes for the intersections, the same post-Hoc test (Games-Howell) was used for interpretation of results. At smart channel intersections, there was a statistically significant difference between groups determined by One-way ANOVA $(\mathrm{F}=18.44, \mathrm{p}=<0.001)$. A GamesHowell post-Hoc test revealed that the time to proximity at Baseline and Clyde, Riverside and Heron and Strandherd and Longfields were significantly higher compared to Greenbank and Strandherd. There was no statistically significant difference between the three channels, Riverside and Heron, Strandherd and Longfields. Whereas at standard channel intersections, there was no statistically significant difference between groups, see Table C-4. 
Table C-4: PET post-hoc results at smart channels

\begin{tabular}{|c|c|c|c|c|c|c|c|}
\hline \multicolumn{8}{|c|}{ Multiple Comparisons ${ }^{a}$} \\
\hline & \multirow[b]{2}{*}{ (I) Intersection } & \multirow[b]{2}{*}{ (J) Intersection } & \multirow{2}{*}{$\begin{array}{c}\text { Mean } \\
\text { Difference } \\
(I-J)\end{array}$} & \multirow[b]{2}{*}{ Std. Error } & \multirow[b]{2}{*}{ Sig. } & \multicolumn{2}{|c|}{$95 \%$ Confidence Interval } \\
\hline & & & & & & $\begin{array}{l}\text { Lower } \\
\text { Bound }\end{array}$ & $\begin{array}{l}\text { Upper } \\
\text { Bound }\end{array}$ \\
\hline \multirow[t]{12}{*}{ Tukey HSD } & \multirow[t]{3}{*}{ Baseline \& Clyde } & $\begin{array}{l}\text { Greenbank \& } \\
\text { Strandherd }\end{array}$ & $.3566^{*}$ & .05620 & .000 & .2116 & .5015 \\
\hline & & Riverside \& Heron & -.2157 & .12836 & .335 & -.5467 & .1153 \\
\hline & & $\begin{array}{l}\text { Strandherd and } \\
\text { Longfield }\end{array}$ & -.0838 & .08874 & .781 & -.3127 & .1450 \\
\hline & \multirow{3}{*}{$\begin{array}{l}\text { Greenbank \& } \\
\text { Strandherd }\end{array}$} & Baseline \& Clyde & $-.3566^{*}$ & .05620 & .000 & -.5015 & -.2116 \\
\hline & & Riverside \& Heron & $-.5723^{*}$ & .13022 & .000 & -.9081 & -.2364 \\
\hline & & $\begin{array}{l}\text { Strandherd and } \\
\text { Longfield }\end{array}$ & $-.4404^{*}$ & .09142 & .000 & -.6762 & -.2046 \\
\hline & \multirow[t]{3}{*}{ Riverside \& Heron } & Baseline \& Clyde & .2157 & .12836 & .335 & -.1153 & .5467 \\
\hline & & $\begin{array}{l}\text { Greenbank \& } \\
\text { Strandherd }\end{array}$ & $.5723^{*}$ & .13022 & .000 & .2364 & .9081 \\
\hline & & $\begin{array}{l}\text { Strandherd and } \\
\text { Longfield }\end{array}$ & .1319 & .14722 & .807 & -.2478 & .5116 \\
\hline & \multirow{3}{*}{$\begin{array}{l}\text { Strandherd and } \\
\text { Longfield }\end{array}$} & Baseline \& Clyde & .0838 & .08874 & .781 & -.1450 & .3127 \\
\hline & & $\begin{array}{l}\text { Greenbank \& } \\
\text { Strandherd }\end{array}$ & $4404^{*}$ & .09142 & .000 & .2046 & .6762 \\
\hline & & Riverside \& Heron & -.1319 & .14722 & .807 & -.5116 & .2478 \\
\hline \multirow[t]{12}{*}{ Games-Howell } & \multirow[t]{3}{*}{ Baseline \& Clyde } & $\begin{array}{l}\text { Greenbank \& } \\
\text { Strandherd }\end{array}$ & $.3566^{*}$ & .05416 & .000 & .2168 & .4964 \\
\hline & & Riverside \& Heron & -.2157 & .16164 & .553 & -.6677 & .2363 \\
\hline & & $\begin{array}{l}\text { Strandherd and } \\
\text { Longfield }\end{array}$ & -.0838 & .08826 & .778 & -.3166 & .1489 \\
\hline & \multirow{3}{*}{$\begin{array}{l}\text { Greenbank \& } \\
\text { Strandherd }\end{array}$} & Baseline \& Clyde & $-.3566^{*}$ & .05416 & .000 & -.4964 & -.2168 \\
\hline & & Riverside \& Heron & $-.5723^{*}$ & .16165 & .010 & -1.0243 & -.1202 \\
\hline & & $\begin{array}{l}\text { Strandherd and } \\
\text { Longfield }\end{array}$ & $-.4404^{*}$ & .08827 & .000 & -.6732 & -.2076 \\
\hline & \multirow[t]{3}{*}{ Riverside \& Heron } & Baseline \& Clyde & .2157 & .16164 & .553 & -.2363 & .6677 \\
\hline & & $\begin{array}{l}\text { Greenbank \& } \\
\text { Strandherd }\end{array}$ & $.5723^{*}$ & .16165 & .010 & .1202 & 1.0243 \\
\hline & & $\begin{array}{l}\text { Strandherd and } \\
\text { Longfield }\end{array}$ & .1319 & .17603 & .876 & -.3491 & .6129 \\
\hline & \multirow{3}{*}{$\begin{array}{l}\text { Strandherd and } \\
\text { Longfield }\end{array}$} & Baseline \& Clyde & .0838 & .08826 & .778 & -.1489 & .3166 \\
\hline & & $\begin{array}{l}\text { Greenbank \& } \\
\text { Strandherd }\end{array}$ & $4404^{*}$ & .08827 & .000 & .2076 & .6732 \\
\hline & & Riverside \& Heron & -.1319 & .17603 & .876 & -.6129 & .3491 \\
\hline \multicolumn{7}{|c|}{$\begin{array}{l}\text { *. The mean difference is significant at the } .05 \text { level. } \\
\text { a. channel = smart channel }\end{array}$} & \\
\hline
\end{tabular}


Table C-5: PET post-hoc results at standard channels

\begin{tabular}{|c|c|c|c|c|c|c|c|}
\hline \multicolumn{8}{|c|}{$\begin{array}{l}\text { Multiple Comparisons }^{a} \\
\text { Dependent Variable: PET }\end{array}$} \\
\hline & \multirow[b]{2}{*}{ (I) Intersection } & \multirow[b]{2}{*}{ (J) Intersection } & \multirow{2}{*}{$\begin{array}{l}\text { Mean } \\
\text { Difference } \\
(I-J)\end{array}$} & \multirow[b]{2}{*}{ Std. Error } & \multirow[b]{2}{*}{ Sig. } & \multicolumn{2}{|c|}{$95 \%$ Confidence Interval } \\
\hline & & & & & & $\begin{array}{l}\text { Lower } \\
\text { Bound }\end{array}$ & $\begin{array}{l}\text { Upper } \\
\text { Bound }\end{array}$ \\
\hline \multirow[t]{12}{*}{ Tukey HSD } & $\begin{array}{l}\text { Baseline and } \\
\text { Woodroffe WBR }\end{array}$ & $\begin{array}{l}\text { Baseline and } \\
\text { Woodroffe EBR }\end{array}$ & .0119 & .11991 & 1.000 & -.2976 & .3213 \\
\hline & & $\begin{array}{l}\text { Fisher \& } \\
\text { Meadowlands }\end{array}$ & -.0940 & .08432 & .681 & -.3116 & .1236 \\
\hline & & $\begin{array}{l}\text { Riverside \& } \\
\text { Brookefield }\end{array}$ & .1107 & .06771 & .360 & -.0641 & .2854 \\
\hline & $\begin{array}{l}\text { Baseline and } \\
\text { Woodroffe EBR }\end{array}$ & $\begin{array}{l}\text { Baseline and } \\
\text { Woodroffe WBR }\end{array}$ & -.0119 & .11991 & 1.000 & -.3213 & .2976 \\
\hline & & $\begin{array}{l}\text { Fisher \& } \\
\text { Meadowlands }\end{array}$ & -.1059 & .13121 & .851 & -.4445 & .2328 \\
\hline & & $\begin{array}{l}\text { Riverside \& } \\
\text { Brookefield }\end{array}$ & .0988 & .12120 & .847 & -.2140 & .4116 \\
\hline & $\begin{array}{l}\text { Fisher \& } \\
\text { Meadowlands }\end{array}$ & $\begin{array}{l}\text { Baseline and } \\
\text { Woodroffe WBR }\end{array}$ & .0940 & .08432 & .681 & -.1236 & .3116 \\
\hline & & $\begin{array}{l}\text { Baseline and } \\
\text { Woodroffe EBR }\end{array}$ & .1059 & .13121 & .851 & -.2328 & .4445 \\
\hline & & $\begin{array}{l}\text { Riverside \& } \\
\text { Brookefield }\end{array}$ & .2047 & .08615 & .084 & -.0177 & .4270 \\
\hline & $\begin{array}{l}\text { Riverside \& } \\
\text { Brookefield }\end{array}$ & $\begin{array}{l}\text { Baseline and } \\
\text { Woodroffe WBR }\end{array}$ & -.1107 & .06771 & .360 & -.2854 & .0641 \\
\hline & & $\begin{array}{l}\text { Baseline and } \\
\text { Woodroffe EBR }\end{array}$ & -.0988 & .12120 & 847 & -.4116 & .2140 \\
\hline & & $\begin{array}{l}\text { Fisher \& } \\
\text { Meadowlands }\end{array}$ & -.2047 & .08615 & .084 & -.4270 & .0177 \\
\hline \multirow[t]{12}{*}{ Games-Howell } & $\begin{array}{l}\text { Baseline and } \\
\text { Woodroffe WBR }\end{array}$ & $\begin{array}{l}\text { Baseline and } \\
\text { Woodroffe EBR }\end{array}$ & .0119 & .13986 & 1.000 & -.3677 & .3914 \\
\hline & & $\begin{array}{l}\text { Fisher \& } \\
\text { Meadowlands }\end{array}$ & -.0940 & .08256 & .666 & -.3091 & .1211 \\
\hline & & $\begin{array}{l}\text { Riverside \& } \\
\text { Brookefield }\end{array}$ & .1107 & .06677 & .348 & -.0619 & .2833 \\
\hline & $\begin{array}{l}\text { Baseline and } \\
\text { Woodroffe EBR }\end{array}$ & $\begin{array}{l}\text { Baseline and } \\
\text { Woodroffe WBR }\end{array}$ & -.0119 & .13986 & 1.000 & -.3914 & .3677 \\
\hline & & $\begin{array}{l}\text { Fisher \& } \\
\text { Meadowlands }\end{array}$ & -.1059 & .14940 & .893 & -.5066 & .2949 \\
\hline & & $\begin{array}{l}\text { Riverside \& } \\
\text { Brookefield }\end{array}$ & .0988 & .14130 & .897 & -.2838 & .4814 \\
\hline & $\begin{array}{l}\text { Fisher \& } \\
\text { Meadowlands }\end{array}$ & $\begin{array}{l}\text { Baseline and } \\
\text { Woodroffe WBR }\end{array}$ & .0940 & .08256 & .666 & -.1211 & .3091 \\
\hline & & $\begin{array}{l}\text { Baseline and } \\
\text { Woodroffe EBR }\end{array}$ & .1059 & .14940 & 893 & -.2949 & .5066 \\
\hline & & $\begin{array}{l}\text { Riverside \& } \\
\text { Brookefield }\end{array}$ & .2047 & .08497 & .080 & -.0165 & .4259 \\
\hline & $\begin{array}{l}\text { Riverside \& } \\
\text { Brookefield }\end{array}$ & $\begin{array}{l}\text { Baseline and } \\
\text { Woodroffe WBR }\end{array}$ & -.1107 & .06677 & .348 & -.2833 & .0619 \\
\hline & & $\begin{array}{l}\text { Baseline and } \\
\text { Woodroffe EBR }\end{array}$ & -.0988 & .14130 & .897 & -.4814 & .2838 \\
\hline & & $\begin{array}{l}\text { Fisher \& } \\
\text { Meadowlands }\end{array}$ & -.2047 & .08497 & .080 & -.4259 & .0165 \\
\hline \multicolumn{8}{|c|}{$\begin{array}{l}\text { Based on observed means. } \\
\text { The error term is Mean Square (Error) }=.318 . \\
\text { a. channel = standard channel }\end{array}$} \\
\hline
\end{tabular}




\section{Right turning sightline angle Games-Howell test}

Table C-6 shows the descriptive statistics for standard channels with right turning sightline angle as the dependent variable. The standard deviations vary for both channel types.

The post-hoc test for right turning sightline angle at each channel type for homogeneity of variance was violated at smart channels using Levene's test with $p$-value $<0.05$ but not violated at standard channels, refer to Table C-7. This indicates statistical significance proving evidence that variance may be unequal at smart channels. Games-Howell post-hoc test was used to interpret the results at both channel types because of the unequal sample sizes.

The test of between subject effects in Table C-8, at standard channels indicates the p-value is $<0.001$ and is statistically significant, the partial $\mathrm{R}^{2}$ is 0.283 , this means that standard channel types explain $28.3 \%$ of the variance in the dependent variable right turning sightline angle. At smart channels, the $\mathrm{p}$-value is $<0.001$, indicating statistical significance; the partial $\mathrm{R}^{2}$ is 0.062 ; this means that smart channel types explain $6.2 \%$ of the variance in the dependent variable right turning sightline angle.

A Games-Howell post-hoc tests indicated by Table C-9 for smart and standard channels show the intersections whose right turning sightline angle measurements were significantly different from one another. 


\section{Table C-6: Right turning sightline angle descriptives}

\begin{tabular}{|c|c|c|c|c|}
\hline \multicolumn{5}{|c|}{$\begin{array}{l}\text { Descriptive Statistics } \\
\text { Dependent Variable: right turning sightline angle }\end{array}$} \\
\hline channel & Intersection & Mean & $\begin{array}{c}\text { Std. } \\
\text { Deviation }\end{array}$ & $\mathrm{N}$ \\
\hline \multirow[t]{5}{*}{ standard channel } & $\begin{array}{l}\text { Baseline and } \\
\text { Woodroffe EBR }\end{array}$ & 126.75 & 26.46 & 26 \\
\hline & $\begin{array}{l}\text { Baseline and } \\
\text { Woodroffe WBR }\end{array}$ & 119.27 & 16.94 & 149 \\
\hline & $\begin{array}{l}\text { Fisher \& } \\
\text { Meadowlands }\end{array}$ & 89.97 & 19.51 & 64 \\
\hline & $\begin{array}{l}\text { Riverside \& } \\
\text { Brookefield }\end{array}$ & 119.65 & 17.76 & 130 \\
\hline & Total & 114.85 & 21.73 & 369 \\
\hline \multirow[t]{5}{*}{ smart channel } & Baseline \& Clyde & 103.30 & 15.01 & 215 \\
\hline & $\begin{array}{l}\text { Greenbank \& } \\
\text { Strandherd }\end{array}$ & 94.07 & 18.50 & 158 \\
\hline & Riverside \& Heron & 98.32 & 17.73 & 19 \\
\hline & $\begin{array}{l}\text { Strandherd and } \\
\text { Longfield }\end{array}$ & 102.21 & 19.26 & 44 \\
\hline & Total & 99.62 & 17.40 & 436 \\
\hline
\end{tabular}

\section{Table C-7: Right turning sightline angle homogeneity of variance test}

\begin{tabular}{|c|c|c|c|c|c|c|}
\hline channel & & & $\begin{array}{l}\text { Levene } \\
\text { Statistic }\end{array}$ & df1 & df2 & Sig. \\
\hline \multirow[t]{4}{*}{ standard channel } & \multirow{4}{*}{$\begin{array}{l}\text { right turning sightline } \\
\text { angle }\end{array}$} & Based on Mean & .785 & 2 & 366 & .457 \\
\hline & & Based on Median & .704 & 2 & 366 & .495 \\
\hline & & $\begin{array}{l}\text { Based on Median and } \\
\text { with adjusted df }\end{array}$ & .704 & 2 & 352.173 & .495 \\
\hline & & $\begin{array}{l}\text { Based on trimmed } \\
\text { mean }\end{array}$ & .750 & 2 & 366 & .473 \\
\hline \multirow[t]{4}{*}{ smart channel } & \multirow{4}{*}{$\begin{array}{l}\text { right turning sightline } \\
\text { angle }\end{array}$} & Based on Mean & 4.918 & 3 & 432 & .002 \\
\hline & & Based on Median & 4.098 & 3 & 432 & .007 \\
\hline & & $\begin{array}{l}\text { Based on Median and } \\
\text { with adjusted df }\end{array}$ & 4.098 & 3 & 406.907 & .007 \\
\hline & & $\begin{array}{l}\text { Based on trimmed } \\
\text { mean }\end{array}$ & 4.745 & 3 & 432 & .003 \\
\hline
\end{tabular}

Tests the null hypothesis that the error variance of the dependent variable is equal across groups.

a. Dependent variable: right turning sightline angle

b. Design: Intercept + Intersection 
Table C-8: Right turning sightline angle tests of between subjects

Tests of Between-Subjects Effects

Dependent Variable: right turning sightline angle

\begin{tabular}{|c|c|c|c|c|c|c|c|}
\hline channel & Source & $\begin{array}{l}\text { Type III } \\
\text { Sum of } \\
\text { Squares }\end{array}$ & df & $\begin{array}{l}\text { Mean } \\
\text { Square }\end{array}$ & F & Sig. & $\begin{array}{c}\text { Partial Eta } \\
\text { Squared }\end{array}$ \\
\hline \multirow[t]{6}{*}{ standard channel } & Corrected Model & $49197.455^{\text {a }}$ & 3 & 16399.152 & 48.022 & .000 & .283 \\
\hline & Intercept & 3031178.53 & 1 & 3031178.53 & 8876.194 & .000 & .961 \\
\hline & Intersection & 49197.455 & 3 & 16399.152 & 48.022 & .000 & .283 \\
\hline & Error & 124645.784 & 365 & 341.495 & & & \\
\hline & Total & 5041070.47 & 369 & & & & \\
\hline & Corrected Total & 173843.239 & 368 & & & & \\
\hline \multirow[t]{6}{*}{ smart channel } & Corrected Model & $8103.165^{b}$ & 3 & 2701.055 & 9.445 & .000 & .062 \\
\hline & Intercept & 1833630.07 & 1 & 1833630.07 & 6411.471 & .000 & .937 \\
\hline & Intersection & 8103.165 & 3 & 2701.055 & 9.445 & .000 & .062 \\
\hline & Error & 123548.579 & 432 & 285.992 & & & \\
\hline & Total & 4458924.39 & 436 & & & & \\
\hline & Corrected Total & 131651.744 & 435 & & & & \\
\hline
\end{tabular}

a. $\mathrm{R}$ Squared $=.283$ (Adjusted $\mathrm{R}$ Squared $=.277$ )

b. R Squared $=.062$ (Adjusted R Squared $=.055)$ 
a)

Multiple Comparisons ${ }^{a}$

Dependent Variable: right turning sightline angle

\begin{tabular}{|c|c|c|c|c|c|c|c|}
\hline & \multirow[b]{2}{*}{ (I) Intersection } & \multirow[b]{2}{*}{ (J) Intersection } & \multirow{2}{*}{$\begin{array}{c}\text { Mean } \\
\text { Difference } \\
\text { (I-J) }\end{array}$} & \multirow[b]{2}{*}{ Std. Error } & \multirow[b]{2}{*}{ Sig. } & \multicolumn{2}{|c|}{ 95\% Confidence Interval } \\
\hline & & & & & & $\begin{array}{l}\text { Lower } \\
\text { Bound }\end{array}$ & $\begin{array}{l}\text { Upper } \\
\text { Bound }\end{array}$ \\
\hline \multirow[t]{12}{*}{ Tukey HSD } & \multirow[t]{3}{*}{$\begin{array}{l}\text { Baseline and } \\
\text { Woodroffe EBR }\end{array}$} & $\begin{array}{l}\text { Baseline and } \\
\text { Woodroffe WBR }\end{array}$ & 7.4740 & 3.92764 & .229 & -2.6628 & 17.6109 \\
\hline & & $\begin{array}{l}\text { Fisher \& } \\
\text { Meadowlands }\end{array}$ & $36.7756^{*}$ & 4.29771 & .000 & 25.6836 & 47.8676 \\
\hline & & $\begin{array}{l}\text { Riverside \& } \\
\text { Brookefield }\end{array}$ & 7.1011 & 3.97005 & .280 & -3.1453 & 17.3474 \\
\hline & \multirow[t]{3}{*}{$\begin{array}{l}\text { Baseline and } \\
\text { Woodroffe WBR }\end{array}$} & $\begin{array}{l}\text { Baseline and } \\
\text { Woodroffe EBR }\end{array}$ & -7.4740 & 3.92764 & .229 & -17.6109 & 2.6628 \\
\hline & & $\begin{array}{l}\text { Fisher \& } \\
\text { Meadowlands }\end{array}$ & $29.3016^{*}$ & 2.76184 & .000 & 22.1735 & 36.4296 \\
\hline & & $\begin{array}{l}\text { Riverside \& } \\
\text { Brookefield }\end{array}$ & -.3730 & 2.21784 & .998 & -6.0970 & 5.3511 \\
\hline & \multirow[t]{3}{*}{$\begin{array}{l}\text { Fisher \& } \\
\text { Meadowlands }\end{array}$} & $\begin{array}{l}\text { Baseline and } \\
\text { Woodroffe EBR }\end{array}$ & $-36.7756^{*}$ & 4.29771 & .000 & -47.8676 & -25.6836 \\
\hline & & $\begin{array}{l}\text { Baseline and } \\
\text { Woodroffe WBR }\end{array}$ & $-29.3016^{*}$ & 2.76184 & .000 & -36.4296 & -22.1735 \\
\hline & & $\begin{array}{l}\text { Riverside \& } \\
\text { Brookefield }\end{array}$ & $-29.6745^{*}$ & 2.82183 & .000 & -36.9574 & -22.3916 \\
\hline & \multirow[t]{3}{*}{$\begin{array}{l}\text { Riverside \& } \\
\text { Brookefield }\end{array}$} & $\begin{array}{l}\text { Baseline and } \\
\text { Woodroffe EBR }\end{array}$ & -7.1011 & 3.97005 & .280 & -17.3474 & 3.1453 \\
\hline & & $\begin{array}{l}\text { Baseline and } \\
\text { Woodroffe WBR }\end{array}$ & .3730 & 2.21784 & .998 & -5.3511 & 6.0970 \\
\hline & & $\begin{array}{l}\text { Fisher \& } \\
\text { Meadowlands }\end{array}$ & $29.6745^{*}$ & 2.82183 & .000 & 22.3916 & 36.9574 \\
\hline \multirow[t]{12}{*}{ Games-Howell } & \multirow[t]{3}{*}{$\begin{array}{l}\text { Baseline and } \\
\text { Woodroffe EBR }\end{array}$} & $\begin{array}{l}\text { Baseline and } \\
\text { Woodroffe WBR }\end{array}$ & 7.4740 & 5.37155 & .515 & -7.1705 & 22.1186 \\
\hline & & $\begin{array}{l}\text { Fisher \& } \\
\text { Meadowlands }\end{array}$ & $36.7756^{*}$ & 5.73336 & .000 & 21.3455 & 52.2058 \\
\hline & & $\begin{array}{l}\text { Riverside \& } \\
\text { Brookefield }\end{array}$ & 7.1011 & 5.41784 & .564 & -7.6403 & 21.8425 \\
\hline & \multirow[t]{3}{*}{$\begin{array}{l}\text { Baseline and } \\
\text { Woodroffe WBR }\end{array}$} & $\begin{array}{l}\text { Baseline and } \\
\text { Woodroffe EBR }\end{array}$ & -7.4740 & 5.37155 & .515 & -22.1186 & 7.1705 \\
\hline & & $\begin{array}{l}\text { Fisher \& } \\
\text { Meadowlands }\end{array}$ & $29.3016^{*}$ & 2.80557 & .000 & 21.9780 & 36.6251 \\
\hline & & $\begin{array}{l}\text { Riverside \& } \\
\text { Brookefield }\end{array}$ & -.3730 & 2.08636 & .998 & -5.7667 & 5.0208 \\
\hline & \multirow[t]{3}{*}{$\begin{array}{l}\text { Fisher \& } \\
\text { Meadowlands }\end{array}$} & $\begin{array}{l}\text { Baseline and } \\
\text { Woodroffe EBR }\end{array}$ & $-36.7756^{*}$ & 5.73336 & .000 & -52.2058 & -21.3455 \\
\hline & & $\begin{array}{l}\text { Baseline and } \\
\text { Woodroffe WBR }\end{array}$ & $-29.3016^{*}$ & 2.80557 & .000 & -36.6251 & -21.9780 \\
\hline & & $\begin{array}{l}\text { Riverside \& } \\
\text { Brookefield }\end{array}$ & $-29.6745^{*}$ & 2.89322 & .000 & -37.2166 & -22.1324 \\
\hline & \multirow[t]{3}{*}{$\begin{array}{l}\text { Riverside \& } \\
\text { Brookefield }\end{array}$} & $\begin{array}{l}\text { Baseline and } \\
\text { Woodroffe EBR }\end{array}$ & -7.1011 & 5.41784 & .564 & -21.8425 & 7.6403 \\
\hline & & $\begin{array}{l}\text { Baseline and } \\
\text { Woodroffe WBR }\end{array}$ & .3730 & 2.08636 & .998 & -5.0208 & 5.7667 \\
\hline & & $\begin{array}{l}\text { Fisher \& } \\
\text { Meadowlands }\end{array}$ & $29.6745^{*}$ & 2.89322 & .000 & 22.1324 & 37.2166 \\
\hline
\end{tabular}

Based on observed means.

The error term is Mean Square(Error) $=341.495$.

*. The mean difference is significant at the .05 level.

a. channel $=$ standard channel 
b)

\section{Table C-9: Right turning sightline angle post-hoc tests. a) standard channels ,b) smart channels}

Multiple Comparisons ${ }^{a}$

Dependent Variable: right turning sightline angle

\begin{tabular}{|c|c|c|c|c|c|c|c|}
\hline & \multirow[b]{2}{*}{ (I) Intersection } & \multirow[b]{2}{*}{ (J) Intersection } & \multirow{2}{*}{$\begin{array}{c}\text { Mean } \\
\text { Difference } \\
\text { (I-J) }\end{array}$} & \multirow[b]{2}{*}{ Std. Error } & \multirow[b]{2}{*}{ Sig. } & \multicolumn{2}{|c|}{ 95\% Confidence Interval } \\
\hline & & & & & & $\begin{array}{l}\text { Lower } \\
\text { Bound }\end{array}$ & $\begin{array}{l}\text { Upper } \\
\text { Bound }\end{array}$ \\
\hline \multirow[t]{12}{*}{ Tukey HSD } & \multirow[t]{3}{*}{ Baseline \& Clyde } & $\begin{array}{l}\text { Greenbank \& } \\
\text { Strandherd }\end{array}$ & $9.2287^{*}$ & 1.77208 & .000 & 4.6584 & 13.7990 \\
\hline & & Riverside \& Heron & 4.9749 & 4.04752 & .609 & -5.4639 & 15.4137 \\
\hline & & $\begin{array}{l}\text { Strandherd and } \\
\text { Longfield }\end{array}$ & 1.0900 & 2.79822 & .980 & -6.1268 & 8.3067 \\
\hline & \multirow{3}{*}{$\begin{array}{l}\text { Greenbank \& } \\
\text { Strandherd }\end{array}$} & Baseline \& Clyde & $-9.2287^{*}$ & 1.77208 & .000 & -13.7990 & -4.6584 \\
\hline & & Riverside \& Heron & -4.2539 & 4.10637 & .728 & -14.8444 & 6.3367 \\
\hline & & $\begin{array}{l}\text { Strandherd and } \\
\text { Longfield }\end{array}$ & $-8.1388^{*}$ & 2.88269 & .026 & -15.5734 & -.7041 \\
\hline & \multirow[t]{3}{*}{ Riverside \& Heron } & Baseline \& Clyde & -4.9749 & 4.04752 & .609 & -15.4137 & 5.4639 \\
\hline & & $\begin{array}{l}\text { Greenbank \& } \\
\text { Strandherd }\end{array}$ & 4.2539 & 4. 10637 & .728 & -6.3367 & 14.8444 \\
\hline & & $\begin{array}{l}\text { Strandherd and } \\
\text { Longfield }\end{array}$ & -3.8849 & 4.64242 & .837 & -15.8580 & 8.0882 \\
\hline & \multirow{3}{*}{$\begin{array}{l}\text { Strandherd and } \\
\text { Longield }\end{array}$} & Baseline \& Clyde & -1.0900 & 2.79822 & .980 & -8.3067 & 6.1268 \\
\hline & & $\begin{array}{l}\text { Greenbank \& } \\
\text { Strandherd }\end{array}$ & $8.1388^{*}$ & 2.88269 & .026 & .7041 & 15.5734 \\
\hline & & Riverside \& Heron & 3.8849 & 4.64242 & .837 & -8.0882 & 15.8580 \\
\hline \multirow[t]{12}{*}{ Games-Howell } & \multirow[t]{3}{*}{ Baseline \& Clyde } & $\begin{array}{l}\text { Greenbank \& } \\
\text { Strandherd }\end{array}$ & $9.2287^{*}$ & 1.79276 & .000 & 4.5967 & 13.8607 \\
\hline & & Riverside \& Heron & 4.9749 & 4.19421 & .642 & -6.7471 & 16.6968 \\
\hline & & $\begin{array}{l}\text { Strandherd and } \\
\text { Longfield }\end{array}$ & 1.0900 & 3.07842 & .985 & -7.0697 & 9.2496 \\
\hline & \multirow{3}{*}{$\begin{array}{l}\text { Greenbank \& } \\
\text { Strandherd }\end{array}$} & Baseline \& Clyde & $-9.2287^{*}$ & 1.79276 & .000 & -13.8607 & -4.5967 \\
\hline & & Riverside \& Heron & -4.2539 & 4.32548 & .760 & -16.2247 & 7.7170 \\
\hline & & $\begin{array}{l}\text { Strandherd and } \\
\text { Longfield }\end{array}$ & -8.1388 & 3.25501 & .069 & -16.7156 & .4381 \\
\hline & \multirow[t]{3}{*}{ Riverside \& Heron } & Baseline \& Clyde & -4.9749 & 4.19421 & .642 & -16.6968 & 6.7471 \\
\hline & & $\begin{array}{l}\text { Greenbank \& } \\
\text { Strandherd }\end{array}$ & 4.2539 & 4.32548 & .760 & -7.7170 & 16.2247 \\
\hline & & $\begin{array}{l}\text { Strandherd and } \\
\text { Longfield }\end{array}$ & -3.8849 & 4.99725 & .864 & -17.3264 & 9.5566 \\
\hline & \multirow{3}{*}{$\begin{array}{l}\text { Strandherd and } \\
\text { Longfield }\end{array}$} & Baseline \& Clyde & -1.0900 & 3.07842 & .985 & -9.2496 & 7.0697 \\
\hline & & $\begin{array}{l}\text { Greenbank \& } \\
\text { Strandherd }\end{array}$ & 8.1388 & 3.25501 & .069 & -.4381 & 16.7156 \\
\hline & & Riverside \& Heron & 3.8849 & 4.99725 & .864 & -9.5566 & 17.3264 \\
\hline
\end{tabular}

Based on observed means.

The error term is Mean Square(Error) $=285.992$

*. The mean difference is significant at the 05 level.

a. channel $=$ smart channel 


\section{Sightline distance}

Table C-10 shows the descriptive statistics for smart and standard channels. The standard deviations at both channel types vary.

The post-hoc test for sightline distance at each channel type for homogeneity of variance was violated for both smart and standard channels using Levene's test with both $p$-values $<0.05$, refer to Table $\mathrm{C}-11$. This indicates statistical significance proving evidence that variance may be unequal within the two groups. Games-Howell post-hoc test was used to interpret the results in Table C-13.

The test of between subject effects in Table C-12, at standard channels, the p-value is $<0.001$ and is statistically significant, the partial $\mathrm{R}^{2}$ is 0.332 , this means that standard channel types explain $33.2 \%$ of the variance in the dependent variable sightline distance. At smart channels, the p-value is $<0.001$, indicating statistical significance; the partial $\mathrm{R}^{2}$ is 0.115 ; this means that smart channel types explain $11.5 \%$ of the variance in the dependent variable sightline distance.

A Games-Howell post-hoc tests indicated by Table C-13 for smart and standard channels show the intersections whose sightline distance measurements were significantly different from one another. 


\section{Table C-10: Sightline distance descriptives for each channel type}

Descriptive Statistics

\begin{tabular}{|c|c|c|c|c|}
\hline channel & Intersection & Mean & $\begin{array}{c}\text { Std. } \\
\text { Deviation }\end{array}$ & $\mathrm{N}$ \\
\hline \multirow[t]{5}{*}{ standard channel } & $\begin{array}{l}\text { Baseline and } \\
\text { Woodroffe EBR }\end{array}$ & 72.7073 & 21.07368 & 26 \\
\hline & $\begin{array}{l}\text { Baseline and } \\
\text { Woodroffe WBR }\end{array}$ & 67.6929 & 17.38955 & 149 \\
\hline & $\begin{array}{l}\text { Fisher \& } \\
\text { Meadowlands }\end{array}$ & 41.1547 & 7.45652 & 64 \\
\hline & $\begin{array}{l}\text { Riverside \& } \\
\text { Brookefield }\end{array}$ & 52.3791 & 13.93392 & 130 \\
\hline & Total & 58.0483 & 18.52554 & 369 \\
\hline \multirow[t]{5}{*}{ smart channel } & Baseline \& Clyde & 50.9460 & 6.49167 & 215 \\
\hline & $\begin{array}{l}\text { Greenbank \& } \\
\text { Strandherd }\end{array}$ & 45.0792 & 9.86477 & 158 \\
\hline & Riverside \& Heron & 54.9495 & 16.36097 & 19 \\
\hline & $\begin{array}{l}\text { Strandherd and } \\
\text { Longfield }\end{array}$ & 49.5648 & 4.82612 & 44 \\
\hline & Total & 48.8550 & 8.84565 & 436 \\
\hline
\end{tabular}

Table C-11: Sightline distance homogeneity of variance test

Levene's Test of Equality of Error Variances ${ }^{a, b}$

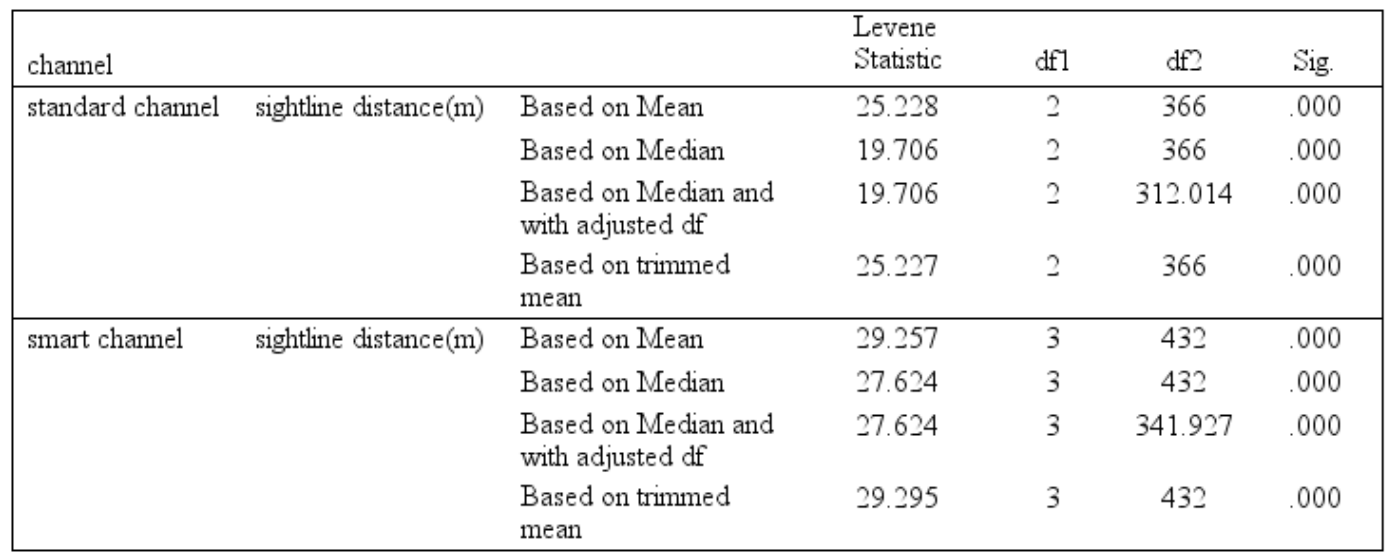

Tests the null hypothesis that the error variance of the dependent variable is equal across groups.

a. Dependent variable: sightline distance $(\mathrm{m})$

b. Design: Intercept + Intersection 
Table C-12: Sightline distance tests of between subjects effects

Tests of Between-Subjects Effects

Dependent Variable: sightline distance $(\mathrm{m})$

\begin{tabular}{|c|c|c|c|c|c|c|c|}
\hline channel & Source & $\begin{array}{l}\text { Type II } \\
\text { Sum of } \\
\text { Squares }\end{array}$ & df & $\begin{array}{l}\text { Mean } \\
\text { Square }\end{array}$ & F & Sig. & $\begin{array}{c}\text { Partial Eta } \\
\text { Squared }\end{array}$ \\
\hline \multirow[t]{6}{*}{ standard channel } & Corrected Model & $41890.174^{\mathrm{a}}$ & 3 & 13963.391 & 60.383 & .000 & .332 \\
\hline & Intercept & 799020.186 & 1 & 799020.186 & 3455.240 & .000 & .904 \\
\hline & Intersection & 41890.174 & 3 & 13963.391 & 60.383 & .000 & .332 \\
\hline & Error & 84405.833 & 365 & 231.249 & & & \\
\hline & Total & 1369678.83 & 369 & & & & \\
\hline & Corrected Total & 126296.006 & 368 & & & & \\
\hline \multirow[t]{6}{*}{ smart channel } & Corrected Model & $3920.421^{b}$ & 3 & 1306.807 & 18.745 & .000 & .115 \\
\hline & Intercept & 465792.122 & 1 & 465792.122 & 6681.488 & .000 & .939 \\
\hline & Intersection & 3920.421 & 3 & 1306.807 & 18.745 & .000 & .115 \\
\hline & Error & 30116.376 & 432 & 69.714 & & & \\
\hline & Total & 1074688.36 & 436 & & & & \\
\hline & Corrected Total & 34036.797 & 435 & & & & \\
\hline
\end{tabular}

a. $\mathrm{R}$ Squared $=.332$ (Adjusted $\mathrm{R}$ Squared $=.326$ )

b. $R$ Squared $=.115$ (Adjusted R Squared $=.109$ ) 
a)

Multiple Comparisons ${ }^{a}$

Dependent Variable: sightline distance $(\mathrm{m})$

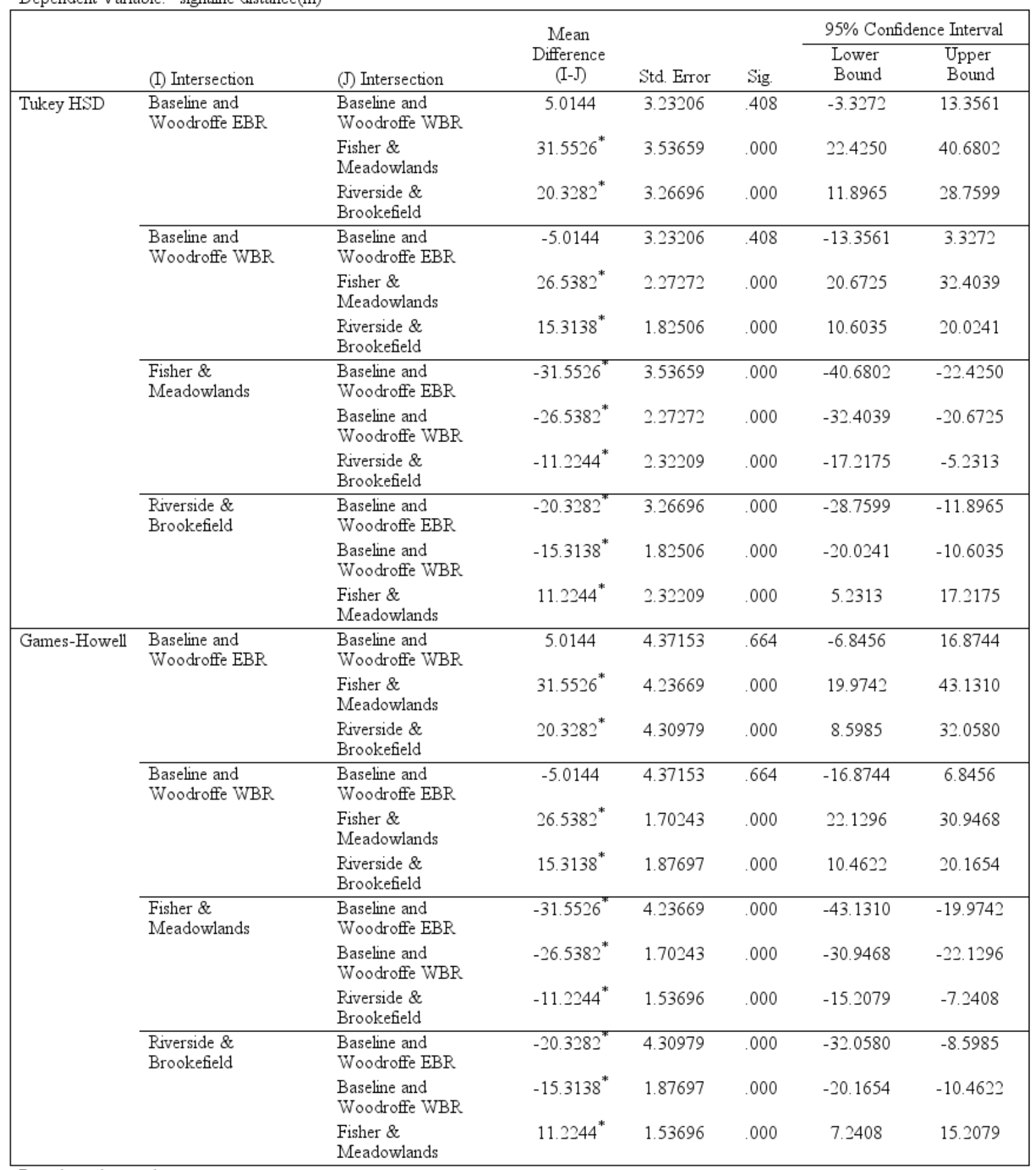

Based on observed means.

The error term is Mean Square(Error) = 231.249.

*. The mean difference is significant at the .05 level.

a. channel $=$ standard channel 
b)

\section{Table C-13: Sightline distance post-hoc tests. a) standard channels, b) smart channels}

Multiple Comparisons ${ }^{a}$

Dependent Variable: sightline distance $(\mathrm{m})$

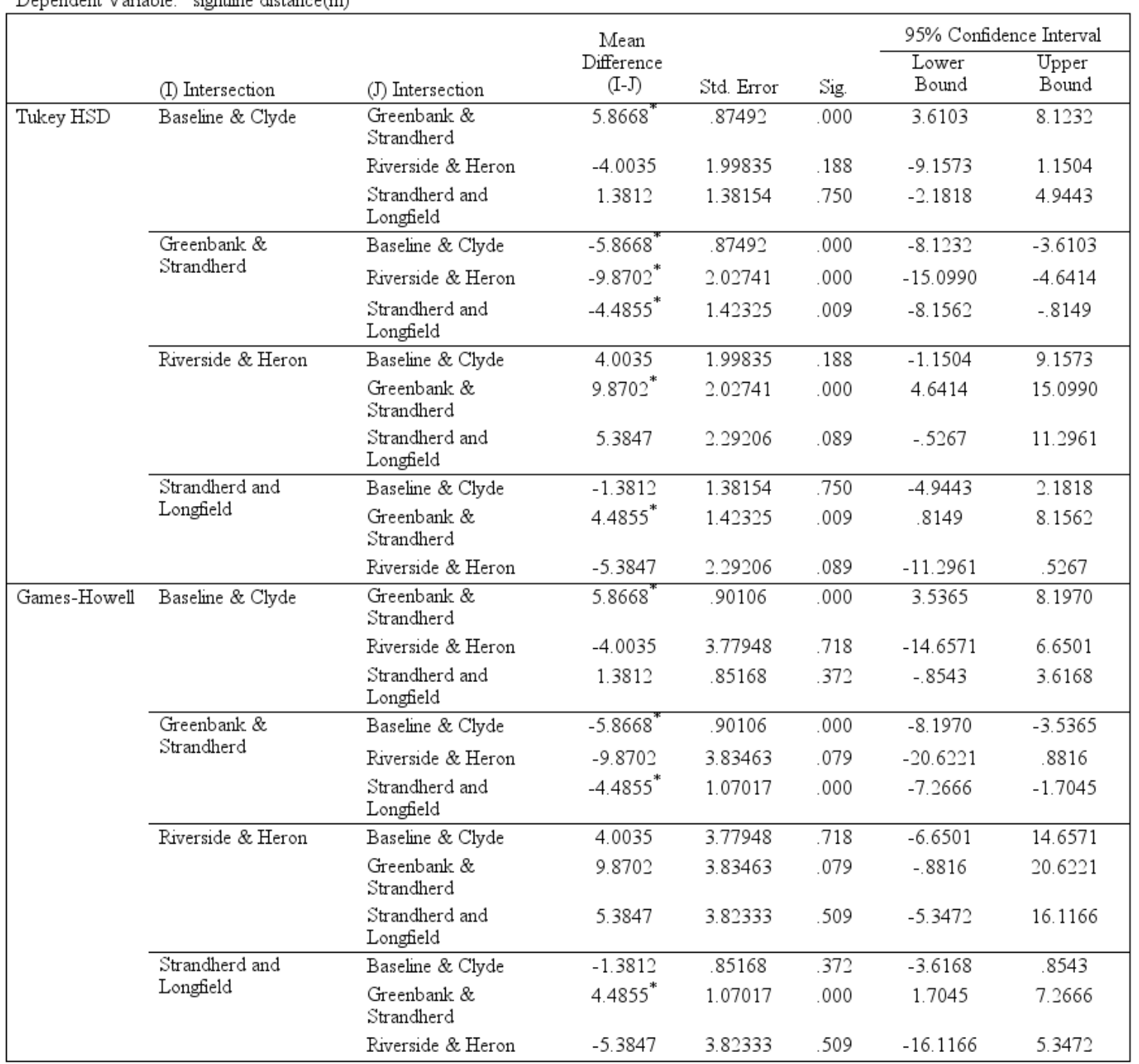

Based on observed means.

The error term is Mean Square (Error) $=69.714$.

*. The mean difference is significant at the .05 level

a. channel $=$ smart channel 


\section{SDTL Games-Howell test}

Table C-14 shows the descriptive statistics for standard channels with SDTL as the dependent variable. It is observed that at standard channels, the means of SDTL within the groups of channels. The standard deviations within each channel group also appears to vary

The post-hoc test for SDTL at each channel type for homogeneity of variance was violated for both smart and standard channels using Levene's test with both $p$-values $<0.05$. This indicates statistical significance proving evidence that variance may be unequal. Games-Howell post-hoc test was used to interpret the results in Table C-15.

The test of between subject effects in Table C-16, at standard channels, the p-value is $<0.001$ and is statistically significant, the partial $\mathrm{R}^{2}$ is 0.328 , this means that standard channel types explain $32.8 \%$ of the variance in the dependent variable SDTL. At smart channels, the p-value is $<0.001$, indicating statistical significance; the partial $\mathrm{R}^{2}$ is 0.114 ; this means that smart channel types explain $11.4 \%$ of the variance in the dependent variable SDTL.

A Games-Howell post-hoc tests indicated by Table C-17 for smart and standard channels show the intersections whose SDTL measurements were significantly different from one another. 


\section{Table C-14: SDTL descriptive statistics at each channel location}

Descriptive Statistics

Dependent Variable: SDTL(m)

\begin{tabular}{|llccc|}
\hline channel & Mean & $\begin{array}{c}\text { Std. } \\
\text { Deviation }\end{array}$ & N \\
\hline standard channel & $\begin{array}{l}\text { Bntersection } \\
\text { Baseline and } \\
\text { Woodroffe EBR }\end{array}$ & 71.32 & 21.56 & 26 \\
& $\begin{array}{l}\text { Baseline and } \\
\text { Woodroffe WBR }\end{array}$ & 65.97 & 19.11 & 149 \\
& $\begin{array}{l}\text { Fisher \& } \\
\text { Meadowlands }\end{array}$ & 36.27 & 10.48 & 64 \\
& $\begin{array}{l}\text { Riverside \& } \\
\text { Brookefield }\end{array}$ & 50.46 & 15.05 & 130 \\
& Total & 55.73 & 20.30 & 369 \\
\hline smart channel & $\begin{array}{l}\text { Baseline \& Clyde } \\
\text { Greenbank \& }\end{array}$ & 49.02 & 8.12 & 215 \\
& $\begin{array}{l}\text { Strandherd } \\
\text { Riverside \& Heron } \\
\text { Strandherd and }\end{array}$ & 53.09 & 11.96 & 158 \\
& $\begin{array}{l}\text { Longfield } \\
\text { Total }\end{array}$ & 46.25 & 7.42 & 44 \\
& 46.2589 & 10.79221 & 436 \\
\hline
\end{tabular}




\section{Table C-15: SDTL homogeneity of variance tests}

Levene's Test of Equality of Error Variances ${ }^{a, b}$

\begin{tabular}{|llcccc|}
\hline channel & & $\begin{array}{l}\text { Levene } \\
\text { Statistic }\end{array}$ & df1 & df2 & Sig. \\
\hline standard channel & Based on Mean & 15.13 & 2 & 366 & .000 \\
& $\begin{array}{l}\text { Based on Median } \\
\text { Based on Median and } \\
\text { with adjusted df }\end{array}$ & 11.33 & 2 & 366 & .000 \\
& $\begin{array}{l}\text { Based on trimmed } \\
\text { mean }\end{array}$ & 14.33 & 2 & 313.439 & .000 \\
& $\begin{array}{l}\text { Based on Mean } \\
\text { smart channel }\end{array}$ & 20.65 & 3 & 366 & .000 \\
& $\begin{array}{l}\text { Based on Median } \\
\text { Based on Median and } \\
\text { with adjusted df }\end{array}$ & 20.46 & 3 & 432 & .000 \\
Based on trimmed & 20.46 & 3 & 380.870 & .000 \\
mean & 20.791 & 3 & 432 & .000 \\
\hline
\end{tabular}

Tests the null hypothesis that the error variance of the dependent variable is equal across groups.

a. Dependent variable: : $\quad \operatorname{SDTL}(\mathrm{m})$

b. Design: Intercept + Intersection

Table C-16: SDTL Tests of between subjects effects at smart and standard channels

Tests of Between-Subjects Effects

Dependent Variable: $\operatorname{SDTL}(\mathrm{m})$

\begin{tabular}{|c|c|c|c|c|c|c|c|}
\hline channel & Source & $\begin{array}{l}\text { Type III } \\
\text { Sum of } \\
\text { Squares }\end{array}$ & df & $\begin{array}{l}\text { Mean } \\
\text { Square }\end{array}$ & $\mathrm{F}$ & Sig. & $\begin{array}{c}\text { Partial Eta } \\
\text { Squared }\end{array}$ \\
\hline \multirow[t]{6}{*}{ standard channel } & Corrected Model & $49798.395^{\text {a }}$ & 3 & 16599.465 & 59.493 & .000 & .328 \\
\hline & Intercept & 732727.259 & 1 & 732727.259 & 2626.139 & .000 & .878 \\
\hline & Intersection & 49798.395 & 3 & 16599.465 & 59.493 & .000 & .328 \\
\hline & Error & 101839.796 & 365 & 279.013 & & & \\
\hline & Total & 1297738.46 & 369 & & & & \\
\hline & Corrected Total & 151638.192 & 368 & & & & \\
\hline \multirow[t]{6}{*}{ smart channel } & Corrected Model & $5799.532^{b}$ & 3 & 1933.177 & 18.614 & .000 & .114 \\
\hline & Intercept & 418050.448 & 1 & 418050.448 & 4025.299 & .000 & .903 \\
\hline & Intersection & 5799.532 & 3 & 1933.177 & 18.614 & .000 & .114 \\
\hline & Error & 44865.683 & 432 & 103.856 & & & \\
\hline & Total & 983657.250 & 436 & & & & \\
\hline & Corrected Total & 50665.215 & 435 & & & & \\
\hline
\end{tabular}

a. $\mathrm{R}$ Squared $=.328$ (Adjusted $\mathrm{R}$ Squared $=.323$ )

b. R Squared $=.114$ (Adjusted R Squared $=.108$ ) 
a)

Multiple Comparisons ${ }^{a}$

Dependent Variable: $\operatorname{SDTL}(\mathrm{m})$

\begin{tabular}{|c|c|c|c|c|c|c|c|}
\hline & & \multirow{2}{*}{\multicolumn{2}{|c|}{$\begin{array}{c}\text { Mean } \\
\text { Difference } \\
\text { (I-J) }\end{array}$}} & \multirow[b]{2}{*}{ Std. Error } & \multirow[b]{2}{*}{ Sig. } & \multicolumn{2}{|c|}{$95 \%$ Confidence Interval } \\
\hline & (I) Intersection & & & & & $\begin{array}{l}\text { Lower } \\
\text { Bound }\end{array}$ & $\begin{array}{l}\text { Upper } \\
\text { Bound }\end{array}$ \\
\hline \multirow[t]{12}{*}{ Tukey HSD } & \multirow[t]{3}{*}{$\begin{array}{l}\text { Baseline and } \\
\text { Woodroffe EBR }\end{array}$} & $\begin{array}{l}\text { Baseline and } \\
\text { Woodroffe WBR }\end{array}$ & 5.3539 & 3.55019 & .434 & -3.8088 & 14.5167 \\
\hline & & $\begin{array}{l}\text { Fisher \& } \\
\text { Meadowlands }\end{array}$ & $35.0575^{*}$ & 3.88469 & .000 & 25.0314 & 45.0835 \\
\hline & & $\begin{array}{l}\text { Riverside \& } \\
\text { Brookefield }\end{array}$ & $20.8615^{*}$ & 3.58853 & .000 & 11.5999 & 30.1232 \\
\hline & \multirow[t]{3}{*}{$\begin{array}{l}\text { Baseline and } \\
\text { Woodroffe WBR }\end{array}$} & $\begin{array}{l}\text { Baseline and } \\
\text { Woodroffe EBR }\end{array}$ & -5.3539 & 3.55019 & .434 & -14.5167 & 3.8088 \\
\hline & & $\begin{array}{l}\text { Fisher \& } \\
\text { Meadowlands }\end{array}$ & $29.7035^{*}$ & 2.49643 & .000 & 23.2605 & 36.1465 \\
\hline & & $\begin{array}{l}\text { Riverside \& } \\
\text { Brookefield }\end{array}$ & $15.5076^{*}$ & 2.00470 & .000 & 10.3336 & 20.6815 \\
\hline & \multirow[t]{3}{*}{$\begin{array}{l}\text { Fisher \& } \\
\text { Meadowlands }\end{array}$} & $\begin{array}{l}\text { Baseline and } \\
\text { Woodroffe EBR }\end{array}$ & $-35.0575^{*}$ & 3.88469 & .000 & -45.0835 & -25.0314 \\
\hline & & $\begin{array}{l}\text { Baseline and } \\
\text { Woodroffe WBR }\end{array}$ & $-29.7035^{*}$ & 2.49643 & .000 & -36.1465 & -23.2605 \\
\hline & & $\begin{array}{l}\text { Riverside \& } \\
\text { Brookefield }\end{array}$ & $-14.1959^{*}$ & 2.55065 & .000 & -20.7789 & -7.6129 \\
\hline & \multirow[t]{3}{*}{$\begin{array}{l}\text { Riverside \& } \\
\text { Brookefield }\end{array}$} & $\begin{array}{l}\text { Baseline and } \\
\text { Woodroffe EBR }\end{array}$ & $-20.8615^{*}$ & 3.58853 & .000 & -30.1232 & -11.5999 \\
\hline & & $\begin{array}{l}\text { Baseline and } \\
\text { Woodroffe WBR }\end{array}$ & $-15.5076^{*}$ & 2.00470 & .000 & -20.6815 & -10.3336 \\
\hline & & $\begin{array}{l}\text { Fisher \& } \\
\text { Meadowlands }\end{array}$ & $14.1959^{*}$ & 2.55065 & .000 & 7.6129 & 20.7789 \\
\hline \multirow[t]{12}{*}{ Games-Howell } & \multirow[t]{3}{*}{$\begin{array}{l}\text { Baseline and } \\
\text { Woodroffe EBR }\end{array}$} & $\begin{array}{l}\text { Baseline and } \\
\text { Woodroffe WBR }\end{array}$ & 5.3539 & 4.50911 & .639 & -6.8583 & 17.5662 \\
\hline & & $\begin{array}{l}\text { Fisher \& } \\
\text { Meadowlands }\end{array}$ & $35.0575^{*}$ & 4.42694 & .000 & 23.0183 & 47.0966 \\
\hline & & $\begin{array}{l}\text { Riverside \& } \\
\text { Brookefield }\end{array}$ & $20.8615^{*}$ & 4.42984 & .000 & 8.8176 & 32.9055 \\
\hline & \multirow[t]{3}{*}{$\begin{array}{l}\text { Baseline and } \\
\text { Woodroffe WBR }\end{array}$} & $\begin{array}{l}\text { Baseline and } \\
\text { Woodroffe EBR }\end{array}$ & -5.3539 & 4.50911 & .639 & -17.5662 & 6.8583 \\
\hline & & $\begin{array}{l}\text { Fisher \& } \\
\text { Meadowlands }\end{array}$ & $29.7035^{*}$ & 2.04180 & .000 & 24.4134 & 34.9936 \\
\hline & & $\begin{array}{l}\text { Riverside \& } \\
\text { Brookefield }\end{array}$ & $15.5076^{*}$ & 2.04808 & .000 & 10.2136 & 20.8016 \\
\hline & \multirow[t]{3}{*}{$\begin{array}{l}\text { Fisher \& } \\
\text { Meadowlands }\end{array}$} & $\begin{array}{l}\text { Baseline and } \\
\text { Woodroffe EBR }\end{array}$ & $-35.0575^{*}$ & 4.42694 & .000 & -47.0966 & -23.0183 \\
\hline & & $\begin{array}{l}\text { Baseline and } \\
\text { Woodroffe WBR }\end{array}$ & $-29.7035^{*}$ & 2.04180 & .000 & -34.9936 & -24.4134 \\
\hline & & $\begin{array}{l}\text { Riverside \& } \\
\text { Brookefield }\end{array}$ & $-14.1959^{*}$ & 1.86020 & .000 & -19.0224 & -9.3694 \\
\hline & \multirow[t]{3}{*}{$\begin{array}{l}\text { Riverside \& } \\
\text { Brookefield }\end{array}$} & $\begin{array}{l}\text { Baseline and } \\
\text { Woodroffe EBR }\end{array}$ & $-20.8615^{*}$ & 4.42984 & .000 & -32.9055 & -8.8176 \\
\hline & & $\begin{array}{l}\text { Baseline and } \\
\text { Woodroffe WBR }\end{array}$ & $-15.5076^{*}$ & 2.04808 & .000 & -20.8016 & -10.2136 \\
\hline & & $\begin{array}{l}\text { Fisher \& } \\
\text { Meadowlands }\end{array}$ & $14.1959^{*}$ & 1.86020 & .000 & 9.3694 & 19.0224 \\
\hline
\end{tabular}

Based on observed means.

The error term is Mean Square(Error) $=279.013$.

*. The mean difference is significant at the .05 level.

a. channel $=$ standard channel 
b)

Table C-17: SDTL post-hoc results a) standard channel, b) smart channels

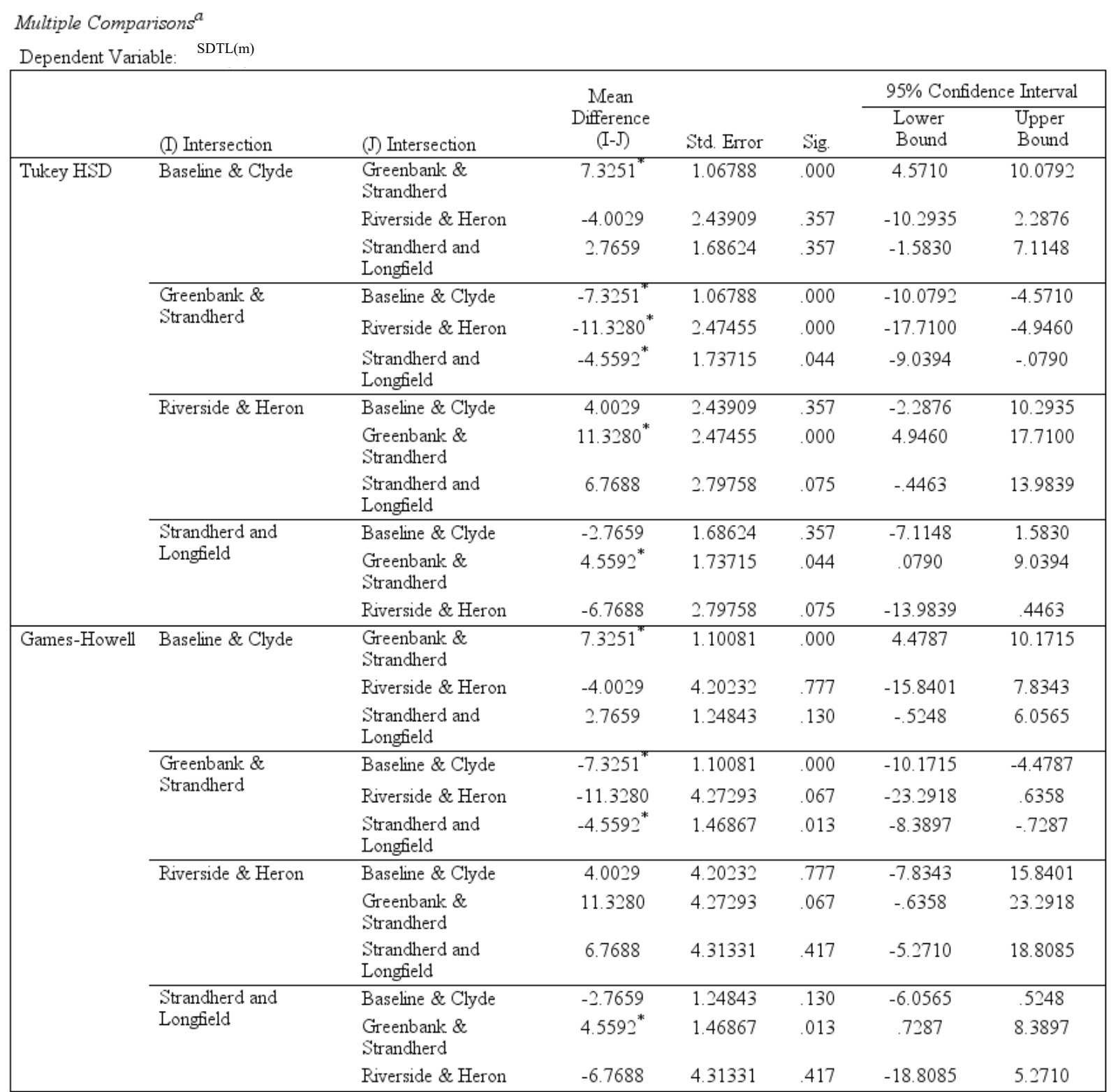

Based on observed means.

The error term is Mean Square(Error) $=103.856$

*. The mean difference is significant at the .05 level.

a. channel $=$ smart channel 


\section{Time Headway Games-Howell test}

Table C-18 results show the descriptive statistics for smart and standard channels with time headway as the dependent variable. It is observed that at smart channels, the means of time headway vary for both channel types. The standard deviations do not vary as much at both channels.

The post-hoc test results for time headway at each channel type for homogeneity of variance for both smart and standard channels in Table C-19 indicate, p-value $>0.05$ using Levene's test. This indicates statistical insignificance proving evidence that variances may be equal at both channel types, however, the Games-Howell post-Hoc test was used to interpret the results because of the unequal sample sizes.

The test of between subject effects in Table C-20, at smart channels, the p-value is $>0.001$ and is not statistically significant. The partial $\mathrm{R}^{2}$ is 0.076 for smart channels. This means that smart channel types explain $7.6 \%$ of the variance in the dependent variable time headway. The partial $\mathrm{R}^{2}$ at standard channels is 0.008 ; this means that smart channel types explain $0.8 \%$ of the variance in the dependent variable time headway.

A Games-Howell post-hoc tests indicated by Table C-21 for smart and standard channels show the intersections whose time headway measurements were significantly different from one another. 
Table C-18: Time headway descriptives at intersections at smart and standard channels

$\begin{aligned} & \text { Descriptive Statistics } \\
& \text { Dependent Variable: Time headway(s) }\end{aligned}$
\begin{tabular}{|llccc|}
\hline channel & Mean & $\begin{array}{c}\text { Std. } \\
\text { Deviation }\end{array}$ & N \\
\hline standard channel & $\begin{array}{l}\text { Intersection } \\
\text { Baseline and } \\
\text { Woodroffe EBR }\end{array}$ & 6.7003 & 1.71353 & 26 \\
& $\begin{array}{l}\text { Baseline and } \\
\text { Woodroffe WBR }\end{array}$ & 7.6300 & 2.45109 & 149 \\
& $\begin{array}{l}\text { Fisher \& } \\
\text { Meadowlands }\end{array}$ & 5.8044 & 2.08231 & 64 \\
& $\begin{array}{l}\text { Riverside \& } \\
\text { Brookefield }\end{array}$ & 6.9418 & 2.18839 & 130 \\
& Total & 7.0054 & 2.33529 & 369 \\
\hline smart channel & $\begin{array}{l}\text { Baseline \& Clyde } \\
\text { Greenbank \& }\end{array}$ & 5.5041 & 1.35917 & 215 \\
& $\begin{array}{l}\text { Strandherd } \\
\text { Riverside \& Heron }\end{array}$ & 5.4415 & 1.26536 & 158 \\
& $\begin{array}{l}\text { Strandherd and } \\
\text { Longfield }\end{array}$ & 5.1069 & 1.28900 & 19 \\
& Total & 5.1643 & 1.35896 & 44 \\
\hline
\end{tabular}




\section{Table C-19: Time headway homogeneity of variance test at smart and standard channels}

Levene's Test of Equality of Error Variances ${ }^{a, b}$

\begin{tabular}{|c|c|c|c|c|c|c|}
\hline channel & & & $\begin{array}{l}\text { Levene } \\
\text { Statistic }\end{array}$ & df1 & df2 2 & Sig. \\
\hline \multirow[t]{4}{*}{ standard channel } & Time headway(s) & Based on Mean & 1.460 & 2 & 366 & .234 \\
\hline & & Based on Median & 1.337 & 2 & 366 & .264 \\
\hline & & $\begin{array}{l}\text { Based on Median and } \\
\text { with adjusted df }\end{array}$ & 1.337 & 2 & 364.381 & .264 \\
\hline & & $\begin{array}{l}\text { Based on trimmed } \\
\text { mean }\end{array}$ & 1.417 & 2 & 366 & .244 \\
\hline \multirow[t]{4}{*}{ smart channel } & Time headway(s) & Based on Mean & .026 & 3 & 432 & .994 \\
\hline & & Based on Median & .027 & 3 & 432 & .994 \\
\hline & & $\begin{array}{l}\text { Based on Median and } \\
\text { with adjusted df }\end{array}$ & .027 & 3 & 424.459 & .994 \\
\hline & & $\begin{array}{l}\text { Based on trimmed } \\
\text { mean }\end{array}$ & .029 & 3 & 432 & .993 \\
\hline
\end{tabular}

Tests the null hypothesis that the error variance of the dependent variable is equal across groups.

a. Dependent variable: Time headway(s)

b. Design: Intercept + Intersection

Table C-20: Test of between subjects effects results at smart and standard channels

Tests of Between-Subjects Effects

Dependent Variable: Time headway(s)

\begin{tabular}{|c|c|c|c|c|c|c|c|}
\hline channel & Source & $\begin{array}{l}\text { Type III } \\
\text { Sum of } \\
\text { Squares }\end{array}$ & df & $\begin{array}{l}\text { Mean } \\
\text { Square }\end{array}$ & $\mathrm{F}$ & Sig. & $\begin{array}{c}\text { Partial Eta } \\
\text { Squared }\end{array}$ \\
\hline \multirow[t]{6}{*}{ standard channel } & Corrected Model & $153.397^{\mathrm{a}}$ & 3 & 51.132 & 10.069 & .000 & .076 \\
\hline & Intercept & 10704.260 & 1 & 10704.260 & 2107.913 & .000 & .852 \\
\hline & Intersection & 153.397 & 3 & 51.132 & 10.069 & .000 & .076 \\
\hline & Error & 1853.518 & 365 & 5.078 & & & \\
\hline & Total & 20115.896 & 369 & & & & \\
\hline & Corrected Total & 2006.915 & 368 & & & & \\
\hline \multirow[t]{6}{*}{ smart channel } & Corrected Model & $6.292^{b}$ & 3 & 2.097 & 1.198 & .310 & .008 \\
\hline & Intercept & 5213.722 & 1 & 5213.722 & 2979.145 & .000 & .873 \\
\hline & Intersection & 6.292 & 3 & 2.097 & 1.198 & .310 & .008 \\
\hline & Error & 756.032 & 432 & 1.750 & & & \\
\hline & Total & 13616.770 & 436 & & & & \\
\hline & Corrected Total & 762.323 & 435 & & & & \\
\hline
\end{tabular}

a. $\mathrm{R}$ Squared $=.076$ (Adjusted $\mathrm{R}$ Squared $=.069$ )

b. $\mathrm{R}$ Squared $=.008$ (Adjusted R Squared $=.001$ ) 
a)

Multiple Comparisons ${ }^{a}$

Dependent Variable: Time headway(s)

\begin{tabular}{|c|c|c|c|c|c|c|c|}
\hline & \multirow[b]{2}{*}{ (I) Intersection } & \multirow[b]{2}{*}{ (J) Intersection } & \multirow{2}{*}{$\begin{array}{l}\text { Mean } \\
\text { Difference } \\
\text { (I-J) }\end{array}$} & \multirow[b]{2}{*}{ Std. Error } & \multirow[b]{2}{*}{ Sig. } & \multicolumn{2}{|c|}{ 95\% Confidence Interval } \\
\hline & & & & & & $\begin{array}{l}\text { Lower } \\
\text { Bound }\end{array}$ & $\begin{array}{l}\text { Upper } \\
\text { Bound }\end{array}$ \\
\hline \multirow[t]{12}{*}{ Tukey HSD } & $\begin{array}{l}\text { Baseline and } \\
\text { Woodroffe EBR }\end{array}$ & $\begin{array}{l}\text { Baseline and } \\
\text { Woodroffe WBR }\end{array}$ & -.9297 & .47895 & .213 & -2.1659 & .3064 \\
\hline & & $\begin{array}{l}\text { Fisher \& } \\
\text { Meadowlands }\end{array}$ & .8959 & .52408 & .320 & -.4567 & 2.2485 \\
\hline & & $\begin{array}{l}\text { Riverside \& } \\
\text { Brookefield }\end{array}$ & -.2415 & .48412 & .959 & -1.4910 & 1.0080 \\
\hline & $\begin{array}{l}\text { Baseline and } \\
\text { Woodroffe WBR }\end{array}$ & $\begin{array}{l}\text { Baseline and } \\
\text { Woodroffe EBR }\end{array}$ & .9297 & .47895 & .213 & -.3064 & 2.1659 \\
\hline & & $\begin{array}{l}\text { Fisher \& } \\
\text { Meadowlands }\end{array}$ & $1.8256^{*}$ & .33679 & .000 & .9564 & 2.6949 \\
\hline & & $\begin{array}{l}\text { Riverside \& } \\
\text { Brookefield }\end{array}$ & .6882 & .27045 & .055 & -.0098 & 1.3862 \\
\hline & $\begin{array}{l}\text { Fisher \& } \\
\text { Meadowlands }\end{array}$ & $\begin{array}{l}\text { Baseline and } \\
\text { Woodroffe EBR }\end{array}$ & -.8959 & .52408 & .320 & -2.2485 & .4567 \\
\hline & & $\begin{array}{l}\text { Baseline and } \\
\text { Woodroffe WBR }\end{array}$ & $-1.8256^{*}$ & .33679 & .000 & -2.6949 & -.9564 \\
\hline & & $\begin{array}{l}\text { Riverside \& } \\
\text { Brookefield }\end{array}$ & $-1.1374^{*}$ & .34411 & .006 & -2.0255 & -.2493 \\
\hline & $\begin{array}{l}\text { Riverside \& } \\
\text { Brookefield }\end{array}$ & $\begin{array}{l}\text { Baseline and } \\
\text { Woodroffe EBR }\end{array}$ & .2415 & .48412 & .959 & -1.0080 & 1.4910 \\
\hline & & $\begin{array}{l}\text { Baseline and } \\
\text { Woodroffe WBR }\end{array}$ & -.6882 & .27045 & .055 & -1.3862 & .0098 \\
\hline & & $\begin{array}{l}\text { Fisher \& } \\
\text { Meadowlands }\end{array}$ & $1.1374^{*}$ & .34411 & .006 & .2493 & 2.0255 \\
\hline \multirow[t]{12}{*}{ Games-Howell } & $\begin{array}{l}\text { Baseline and } \\
\text { Woodroffe EBR }\end{array}$ & $\begin{array}{l}\text { Baseline and } \\
\text { Woodroffe WBR }\end{array}$ & -.9297 & .39147 & .097 & -1.9740 & .1145 \\
\hline & & $\begin{array}{l}\text { Fisher \& } \\
\text { Meadowlands }\end{array}$ & .8959 & .42506 & .163 & -.2296 & 2.0214 \\
\hline & & $\begin{array}{l}\text { Riverside \& } \\
\text { Brookefield }\end{array}$ & -.2415 & .38700 & .924 & -1.2757 & .7926 \\
\hline & $\begin{array}{l}\text { Baseline and } \\
\text { Woodroffe WBR }\end{array}$ & $\begin{array}{l}\text { Baseline and } \\
\text { Woodroffe EBR }\end{array}$ & .9297 & .39147 & .097 & -.1145 & 1.9740 \\
\hline & & $\begin{array}{l}\text { Fisher \& } \\
\text { Meadowlands }\end{array}$ & $1.8256^{*}$ & .32874 & .000 & .9708 & 2.6805 \\
\hline & & $\begin{array}{l}\text { Riverside \& } \\
\text { Brookefield }\end{array}$ & .6882 & .27778 & .066 & -.0298 & 1.4062 \\
\hline & $\begin{array}{l}\text { Fisher \& } \\
\text { Meadowlands }\end{array}$ & $\begin{array}{l}\text { Baseline and } \\
\text { Woodroffe EBR }\end{array}$ & -.8959 & .42506 & .163 & -2.0214 & .2296 \\
\hline & & $\begin{array}{l}\text { Baseline and } \\
\text { Woodroffe WBR }\end{array}$ & $-1.8256^{*}$ & .32874 & .000 & -2.6805 & -.9708 \\
\hline & & $\begin{array}{l}\text { Riverside \& } \\
\text { Brookefield }\end{array}$ & $-1.1374^{*}$ & .32340 & .003 & -1.9790 & -.2959 \\
\hline & $\begin{array}{l}\text { Riverside \& } \\
\text { Brookefield }\end{array}$ & $\begin{array}{l}\text { Baseline and } \\
\text { Woodroffe EBR }\end{array}$ & .2415 & .38700 & .924 & -.7926 & 1.2757 \\
\hline & & $\begin{array}{l}\text { Baseline and } \\
\text { Woodroffe WBR }\end{array}$ & -.6882 & .27778 & .066 & -1.4062 & .0298 \\
\hline & & $\begin{array}{l}\text { Fisher \& } \\
\text { Meadowlands }\end{array}$ & $1.1374^{*}$ & .32340 & .003 & .2959 & 1.9790 \\
\hline
\end{tabular}

Based on observed means.

The error term is Mean Square(Error) $=5.078$.

*. The mean difference is significant at the .05 level.

a. channel $=$ standard channel 
b)

\section{Table C-21: Time headway post-hoc results at a) standard, b) smart}

Multiple Comparisons ${ }^{a}$

Dependent Variable: Time headway(s)

\begin{tabular}{|c|c|c|c|c|c|c|c|}
\hline & \multirow[b]{2}{*}{ (I) Intersection } & \multirow[b]{2}{*}{ (J) Intersection } & \multirow{2}{*}{$\begin{array}{c}\text { Mean } \\
\text { Difference } \\
(I-J)\end{array}$} & \multirow[b]{2}{*}{ Std. Error } & \multirow[b]{2}{*}{ Sig. } & \multicolumn{2}{|c|}{$95 \%$ Confidence Interval } \\
\hline & & & & & & $\begin{array}{l}\text { Lower } \\
\text { Bound }\end{array}$ & $\begin{array}{l}\text { Upper } \\
\text { Bound }\end{array}$ \\
\hline \multirow[t]{12}{*}{ Tukey HSD } & \multirow[t]{3}{*}{ Baseline \& Clyde } & $\begin{array}{l}\text { Greenbank \& } \\
\text { Strandherd }\end{array}$ & .0625 & .13862 & .969 & -.2950 & .4201 \\
\hline & & Riverside \& Heron & .3972 & .31662 & .592 & -.4194 & 1.2138 \\
\hline & & $\begin{array}{l}\text { Strandherd and } \\
\text { Longfield }\end{array}$ & .3398 & .21889 & .407 & -.2247 & .9043 \\
\hline & \multirow{3}{*}{$\begin{array}{l}\text { Greenbank \& } \\
\text { Strandherd }\end{array}$} & Baseline \& Clyde & -.0625 & .13862 & .969 & -.4201 & .2950 \\
\hline & & Riverside \& Heron & .3347 & .32123 & .725 & -.4938 & 1.1631 \\
\hline & & $\begin{array}{l}\text { Strandherd and } \\
\text { Longfield }\end{array}$ & .2773 & .22550 & .608 & -.3043 & .8588 \\
\hline & \multirow[t]{3}{*}{ Riverside \& Heron } & Baseline \& Clyde & -.3972 & .31662 & .592 & -1.2138 & 4194 \\
\hline & & $\begin{array}{l}\text { Greenbank \& } \\
\text { Strandherd }\end{array}$ & -.3347 & .32123 & .725 & -1.1631 & 4938 \\
\hline & & $\begin{array}{l}\text { Strandherd and } \\
\text { Longfield }\end{array}$ & -.0574 & .36316 & .999 & -.9940 & 8792 \\
\hline & \multirow{3}{*}{$\begin{array}{l}\text { Strandherd and } \\
\text { Longfield }\end{array}$} & Baseline \& Clyde & -.3398 & .21889 & 407 & -.9043 & 2247 \\
\hline & & $\begin{array}{l}\text { Greenbank \& } \\
\text { Strandherd }\end{array}$ & -.2773 & .22550 & .608 & -.8588 & 3043 \\
\hline & & Riverside \& Heron & .0574 & .36316 & .999 & -.8792 & 9940 \\
\hline \multirow[t]{12}{*}{ Games-Howell } & \multirow[t]{3}{*}{ Baseline \& Clyde } & $\begin{array}{l}\text { Greenbank \& } \\
\text { Strandherd }\end{array}$ & .0625 & .13684 & .968 & -.2907 & .4158 \\
\hline & & Riverside \& Heron & .3972 & 30991 & .584 & -.4643 & 1.2587 \\
\hline & & $\begin{array}{l}\text { Strandherd and } \\
\text { Longfield }\end{array}$ & .3398 & .22487 & .437 & -.2539 & .9335 \\
\hline & \multirow{3}{*}{$\begin{array}{l}\text { Greenbank \& } \\
\text { Strandherd }\end{array}$} & Baseline \& Clyde & -.0625 & .13684 & .968 & -.4158 & .2907 \\
\hline & & Riverside \& Heron & .3347 & .31238 & .710 & -.5316 & 1.2009 \\
\hline & & $\begin{array}{l}\text { Strandherd and } \\
\text { Longfield }\end{array}$ & .2773 & .22827 & .620 & -.3246 & .8791 \\
\hline & \multirow[t]{3}{*}{ Riverside \& Heron } & Baseline \& Clyde & -.3972 & 30991 & .584 & -1.2587 & 4643 \\
\hline & & $\begin{array}{l}\text { Greenbank \& } \\
\text { Strandherd }\end{array}$ & -.3347 & .31238 & .710 & -1.2009 & .5316 \\
\hline & & $\begin{array}{l}\text { Strandherd and } \\
\text { Longfield }\end{array}$ & -.0574 & .35975 & .999 & -1.0263 & 9116 \\
\hline & \multirow{3}{*}{$\begin{array}{l}\text { Strandherd and } \\
\text { Longfield }\end{array}$} & Baseline \& Clyde & -.3398 & .22487 & 437 & -.9335 & .2539 \\
\hline & & $\begin{array}{l}\text { Greenbank \& } \\
\text { Strandherd }\end{array}$ & -.2773 & .22827 & .620 & -.8791 & .3246 \\
\hline & & Riverside \& Heron & .0574 & .35975 & .999 & -.9116 & 1.0263 \\
\hline
\end{tabular}

Based on observed means.

The error term is Mean Square(Error) $=1.750$

a. channel $=$ smart channel 


\section{Appendix D. Ordinal Logistic Regression}

The variables included in this regression are time headway, channel type, sightline distance, SDTL, right turning sightline angle, channel location and PET severity level; coded 1= low severity level, 2- medium severity level, 3- high severity level.

The output tables show the following abbreviations/acronyms to represent; channel is channel type; coded 1-smart channels, 0 -standard channels, right turning sightline angle, Timeheadways- time headway, SDTL. For all three cases namely, all intersections included, excluding channel location 8 and excluding channel location 7, all explanatory variables are initially input into the model, then removed one at a time, if p-value $>0.05$.

\section{All intersections- all variables included}

Goodness-of-Fit

\begin{tabular}{|lccl|}
\hline & Chi-Square & df & Sig. \\
\hline Pearson & 1604.588 & 1603 & .484 \\
Deviance & 1466.729 & 1603 & .993 \\
\hline
\end{tabular}

Link function: Logit.

\begin{tabular}{|c|c|c|c|c|c|c|c|c|}
\hline \multicolumn{9}{|c|}{ Parameter Estimates } \\
\hline & & \multirow[b]{2}{*}{ Estimate } & \multirow[b]{2}{*}{ Std. Error } & \multirow[b]{2}{*}{ Wald } & \multirow[b]{2}{*}{ df } & \multirow[b]{2}{*}{ Sig. } & \multicolumn{2}{|c|}{$95 \%$ Confidence Interval } \\
\hline & & & & & & & $\begin{array}{l}\text { Lower } \\
\text { Bound }\end{array}$ & $\begin{array}{l}\text { Upper } \\
\text { Bound }\end{array}$ \\
\hline \multirow[t]{2}{*}{ Threshold } & {$[$ PET_A $=1]$} & -.753 & .777 & .939 & 1 & .333 & -2.277 & .770 \\
\hline & {$\left[\mathrm{PET} \_\mathrm{A}=2\right]$} & 2.223 & .782 & 8.084 & 1 & .004 & .691 & 3.755 \\
\hline \multirow[t]{5}{*}{ Location } & sightline distance & -.011 & .037 & .082 & 1 & .775 & -.084 & .063 \\
\hline & SDTL & -.003 & .037 & .009 & 1 & .925 & -.076 & .069 \\
\hline & Timeheadways & .062 & .045 & 1.937 & 1 & .164 & -.025 & .149 \\
\hline & channel & .393 & .171 & 5.288 & 1 & .021 & .058 & .728 \\
\hline & $\begin{array}{l}\text { Right_turning_sightline } \\
\text { _angle }\end{array}$ & .005 & .007 & .504 & 1 & .478 & -.008 & .018 \\
\hline
\end{tabular}




\section{All intersections- Remove sightline distance}

Goodness-of-Fit

\begin{tabular}{|lccc|}
\hline & Chi-Square & df & Sig. \\
\hline Pearson & 1604.469 & 1604 & .492 \\
Deviance & 1466.813 & 1604 & .993 \\
\hline
\end{tabular}

Link function: Logit.

Parameter Estimates

\begin{tabular}{|c|c|c|c|c|c|c|c|c|}
\hline & \multirow[b]{2}{*}{ Estimate } & \multirow[b]{2}{*}{ Std. Error } & \multirow[b]{2}{*}{ Wald } & \multirow[b]{2}{*}{ df } & \multirow[b]{2}{*}{ Sig. } & \multicolumn{2}{|c|}{$95 \%$ Confidence Interval } \\
\hline & & & & & & & $\begin{array}{l}\text { Lower } \\
\text { Bound }\end{array}$ & $\begin{array}{l}\text { Upper } \\
\text { Bound }\end{array}$ \\
\hline \multirow[t]{2}{*}{ Threshold } & [PET_A = 1] & -.573 & .447 & 1.646 & 1 & .199 & -1.448 & .302 \\
\hline & [PET_A = 2] & 2.402 & 456 & 27.699 & 1 & .000 & 1.508 & 3.297 \\
\hline \multirow[t]{4}{*}{ Location } & SDTL & -.014 & .006 & 4.619 & 1 & .032 & -.027 & -.001 \\
\hline & Timeheadways & .063 & .045 & 1.967 & 1 & .161 & -.025 & .150 \\
\hline & channel & .412 & .158 & 6.805 & 1 & .009 & .102 & .721 \\
\hline & $\begin{array}{l}\text { Right_turning_sightline } \\
\text { _angle }\end{array}$ & .006 & .005 & 1.327 & 1 & .249 & -.004 & .016 \\
\hline
\end{tabular}

Link function: Logit.

\section{All intersections-remove right turning sightline angle}

Goodness-of-Fit

\begin{tabular}{|lccc|}
\hline & Chi-Square & df & Sig. \\
\hline Pearson & 1593.627 & 1599 & .533 \\
Deviance & 1462.581 & 1599 & .993 \\
\hline
\end{tabular}

Link function: Logit.

Parameter Estimates

\begin{tabular}{|c|c|c|c|c|c|c|c|c|}
\hline & \multirow[b]{2}{*}{ Estimate } & \multirow[b]{2}{*}{ Std. Error } & \multirow[b]{2}{*}{ Wald } & \multirow[b]{2}{*}{$\mathrm{df}$} & \multirow[b]{2}{*}{ Sig. } & \multicolumn{2}{|c|}{$95 \%$ Confidence Interval } \\
\hline & & & & & & & $\begin{array}{l}\text { Lower } \\
\text { Bound }\end{array}$ & $\begin{array}{l}\text { Upper } \\
\text { Bound }\end{array}$ \\
\hline \multirow[t]{2}{*}{ Threshold } & {$\left[\mathrm{PET} \_\mathrm{A}=1\right]$} & -.941 & .317 & 8.834 & 1 & .003 & -1.561 & -.320 \\
\hline & [PET_A = 2] & 2.032 & .326 & 38.953 & 1 & .000 & 1.394 & 2.670 \\
\hline \multirow[t]{3}{*}{ Location } & SDTL & -.009 & .005 & 3.441 & 1 & .064 & -.020 & .001 \\
\hline & Timeheadways & .071 & .044 & 2.607 & 1 & 106 & -.015 & .157 \\
\hline & channel & .378 & .155 & 5.944 & 1 & .015 & .074 & .682 \\
\hline
\end{tabular}

Link function: Logit. 


\section{All intersections-remove time headway}

Goodness-of-Fit

\begin{tabular}{|lccc|}
\hline & Chi-Square & df & Sig. \\
\hline Pearson & 1101.792 & 1110 & .564 \\
Deviance & 1076.646 & 1110 & .758 \\
\hline
\end{tabular}

Link function: Logit.

Parameter Estimates

\begin{tabular}{|c|c|c|c|c|c|c|c|c|}
\hline & \multirow[b]{2}{*}{ Estimate } & \multirow[b]{2}{*}{ Std. Error } & \multirow[b]{2}{*}{ Wald } & \multirow[b]{2}{*}{ df } & \multirow[b]{2}{*}{ Sig. } & \multicolumn{2}{|c|}{$95 \%$ Confidence Interva } \\
\hline & & & & & & & $\begin{array}{l}\text { Lower } \\
\text { Bound }\end{array}$ & $\begin{array}{l}\text { Upper } \\
\text { Bound }\end{array}$ \\
\hline \multirow[t]{2}{*}{ Threshold } & {$[$ PET_A $=1]$} & -1.207 & .272 & 19.684 & 1 & .000 & -1.740 & -.674 \\
\hline & [PET_A = 2] & 1.758 & 278 & 40.096 & 1 & .000 & 1.214 & 2.303 \\
\hline \multirow[t]{2}{*}{ Location } & SDTL & -.005 & .004 & 1.498 & 1 & .221 & -.014 & .003 \\
\hline & channel & .306 & 148 & 4.253 & 1 & .039 & .015 & .596 \\
\hline
\end{tabular}

Link function: Logit.

\section{Exclude channel location 8- all variables present}

Goodness-of-Fit

\begin{tabular}{|lccc|}
\hline & Chi-Square & df & Sig. \\
\hline Pearson & 1516.429 & 1515 & .485 \\
Deviance & 1386.489 & 1515 & .992 \\
\hline
\end{tabular}

Link function: Logit.

Parameter Estimates

\begin{tabular}{|c|c|c|c|c|c|c|c|c|}
\hline & \multirow[b]{2}{*}{ Estimate } & \multirow[b]{2}{*}{ Std. Error } & \multirow[b]{2}{*}{ Wald } & \multirow[b]{2}{*}{ df } & \multirow[b]{2}{*}{ Sig. } & \multicolumn{2}{|c|}{$95 \%$ Confidence Interval } \\
\hline & & & & & & & $\begin{array}{l}\text { Lower } \\
\text { Bound }\end{array}$ & $\begin{array}{l}\text { Upper } \\
\text { Bound }\end{array}$ \\
\hline \multirow[t]{2}{*}{ Threshold } & [PET_A = 1] & -.240 & .795 & .091 & 1 & .763 & -1.797 & 1.318 \\
\hline & [PET_A = 2] & 2.735 & .802 & 11.613 & 1 & .001 & 1.162 & 4.307 \\
\hline \multirow[t]{5}{*}{ Location } & channel & .532 & .177 & 8.997 & 1 & .003 & .184 & .879 \\
\hline & Timeheadways & .061 & .046 & 1.800 & 1 & .180 & -.028 & .151 \\
\hline & SDTL & -.025 & .038 & .439 & 1 & .508 & -.100 & .050 \\
\hline & sightline distance & .010 & .039 & .061 & 1 & .805 & -.066 & .085 \\
\hline & $\begin{array}{l}\text { Right_turning_sightline } \\
\text { angle }\end{array}$ & .010 & .007 & 1.935 & 1 & .164 & -.004 & .023 \\
\hline
\end{tabular}

Link function: Logit. 


\section{Excluded channel location 8- remove sightline distance}

Goodness-of-Fit

\begin{tabular}{|lccc|}
\hline & Chi-Square & df & Sig. \\
\hline Pearson & 1516.719 & 1516 & .490 \\
Deviance & 1386.553 & 1516 & .992 \\
\hline
\end{tabular}

Link function: Logit.

Parameter Estimates

\begin{tabular}{|c|c|c|c|c|c|c|c|c|}
\hline & & \multirow[b]{2}{*}{ Estimate } & \multirow[b]{2}{*}{ Std. Error } & \multirow[b]{2}{*}{ Wald } & \multirow[b]{2}{*}{ df } & \multirow[b]{2}{*}{ Sig. } & \multicolumn{2}{|c|}{$95 \%$ Confidence Interval } \\
\hline & & & & & & & $\begin{array}{l}\text { Lower } \\
\text { Bound }\end{array}$ & $\begin{array}{l}\text { Upper } \\
\text { Bound }\end{array}$ \\
\hline \multirow[t]{2}{*}{ Threshold } & {$\left[\mathrm{PET} \_\mathrm{A}=1\right]$} & -.398 & .459 & .752 & 1 & .386 & -1.298 & .502 \\
\hline & [PET_A = 2] & 2.576 & .471 & 29.905 & 1 & .000 & 1.653 & 3.499 \\
\hline \multirow[t]{4}{*}{ Location } & channel & .514 & .162 & 10.012 & 1 & .002 & .196 & .832 \\
\hline & Timeheadways & .061 & .046 & 1.777 & 1 & .183 & -.029 & .150 \\
\hline & SDTL & -.016 & .007 & 5.846 & 1 & .016 & -.029 & -.003 \\
\hline & $\begin{array}{l}\text { Right_turning_sightline } \\
\text { _angle }\end{array}$ & .009 & .005 & 2.558 & 1 & .110 & -.002 & .019 \\
\hline
\end{tabular}

Link function: Logit.

\section{Excluded channel location 8- remove time headway}

Goodness-of-Fit

\begin{tabular}{|lccc|}
\hline & Chi-Square & df & Sig. \\
\hline Pearson & 1520.418 & 1515 & .456 \\
Deviance & 1388.369 & 1515 & .991 \\
\hline
\end{tabular}

Link function: Logit.

Parameter Estimates

\begin{tabular}{|c|c|c|c|c|c|c|c|c|}
\hline & \multirow[b]{2}{*}{ Estimate } & \multirow[b]{2}{*}{ Std. Error } & \multirow[b]{2}{*}{ Wald } & \multirow[b]{2}{*}{ df } & \multirow[b]{2}{*}{ Sig. } & \multicolumn{2}{|c|}{$95 \%$ Confidence Interval } \\
\hline & & & & & & & $\begin{array}{l}\text { Lower } \\
\text { Bound }\end{array}$ & $\begin{array}{l}\text { Upper } \\
\text { Bound }\end{array}$ \\
\hline \multirow[t]{2}{*}{ Threshold } & [PET_A = 1] & -.539 & .446 & 1.463 & 1 & .226 & -1.413 & .334 \\
\hline & [PET_A = 2] & 2.429 & 456 & 28.323 & 1 & .000 & 1.535 & 3.324 \\
\hline \multirow[t]{3}{*}{ Location } & channel & .463 & .158 & 8.610 & 1 & .003 & .154 & .772 \\
\hline & SDTL & -.013 & .006 & 4.623 & 1 & .032 & -.026 & -.001 \\
\hline & $\begin{array}{l}\text { Right_turning_sightline } \\
\text { _angle }\end{array}$ & .010 & .005 & 3.495 & 1 & .062 & .000 & .020 \\
\hline
\end{tabular}

Link function: Logit. 


\section{Excluded channel location 8- remove right turning sightline angle}

Goodness-of-Fit

\begin{tabular}{|lccc|}
\hline & Chi-Square & df & Sig. \\
\hline Pearson & 1068.402 & 1080 & .593 \\
Deviance & 1036.446 & 1080 & .825 \\
\hline
\end{tabular}

Link function: Logit.

Parameter Estimates

\begin{tabular}{|c|c|c|c|c|c|c|c|c|}
\hline & \multirow[b]{2}{*}{ Estimate } & \multirow[b]{2}{*}{ Std. Error } & \multirow[b]{2}{*}{ Wald } & \multirow[b]{2}{*}{ df } & \multirow[b]{2}{*}{ Sig. } & \multicolumn{2}{|c|}{$95 \%$ Confidence Interval } \\
\hline & & & & & & & $\begin{array}{l}\text { Lower } \\
\text { Bound }\end{array}$ & $\begin{array}{l}\text { Upper } \\
\text { Bound }\end{array}$ \\
\hline Threshold & {$\left[\mathrm{PET} \_\mathrm{A}=1\right]$} & -1.209 & .273 & 19.563 & 1 & .000 & -1.745 & -.673 \\
\hline & [PET_A = 2] & 1.750 & .279 & 39.255 & 1 & .000 & 1.202 & 2.297 \\
\hline Location & channel & .389 & .152 & 6.531 & 1 & .011 & .091 & .687 \\
\hline & SDTL & -.006 & .004 & 1.524 & 1 & .217 & -.014 & .003 \\
\hline
\end{tabular}

Link function: Logit.

\section{Excluded channel location 8- remove SDTL}

Goodness-of-Fit

\begin{tabular}{|lccc|}
\hline & Chi-Square & $\mathrm{df}$ & Sig. \\
\hline Pearson & .064 & 1 & .800 \\
Deviance & .064 & 1 & .800 \\
\hline
\end{tabular}

Link function: Logit.

Parameter Estimates

\begin{tabular}{|c|c|c|c|c|c|c|c|c|}
\hline & \multirow[b]{2}{*}{ Estimate } & \multirow[b]{2}{*}{ Std. Error } & \multirow[b]{2}{*}{ Wald } & \multirow[b]{2}{*}{ df } & \multirow[b]{2}{*}{ Sig. } & \multicolumn{2}{|c|}{$95 \%$ Confidence Interval } \\
\hline & & & & & & & $\begin{array}{l}\text { Lower } \\
\text { Bound }\end{array}$ & $\begin{array}{l}\text { Upper } \\
\text { Bound }\end{array}$ \\
\hline Threshold & {$\left[\mathrm{PET} \_\mathrm{A}=1\right]$} & -.899 & .109 & 68.442 & 1 & .000 & -1.112 & -.686 \\
\hline & [PET_A = 2] & 2.055 & .134 & 233.906 & 1 & .000 & 1.792 & 2.319 \\
\hline Location & channel & .443 & .146 & 9.164 & 1 & .002 & .156 & .730 \\
\hline
\end{tabular}

Link function: Logit. 


\section{Excluded channel location 7- all variables present}

Goodness-of-Fit
\begin{tabular}{|lccc|}
\hline & Chi-Square & df & Sig. \\
\hline Pearson & 1568.481 & 1565 & .470 \\
Deviance & 1425.596 & 1565 & .995 \\
\hline
\end{tabular}

Link function: Logit.

Parameter Estimates

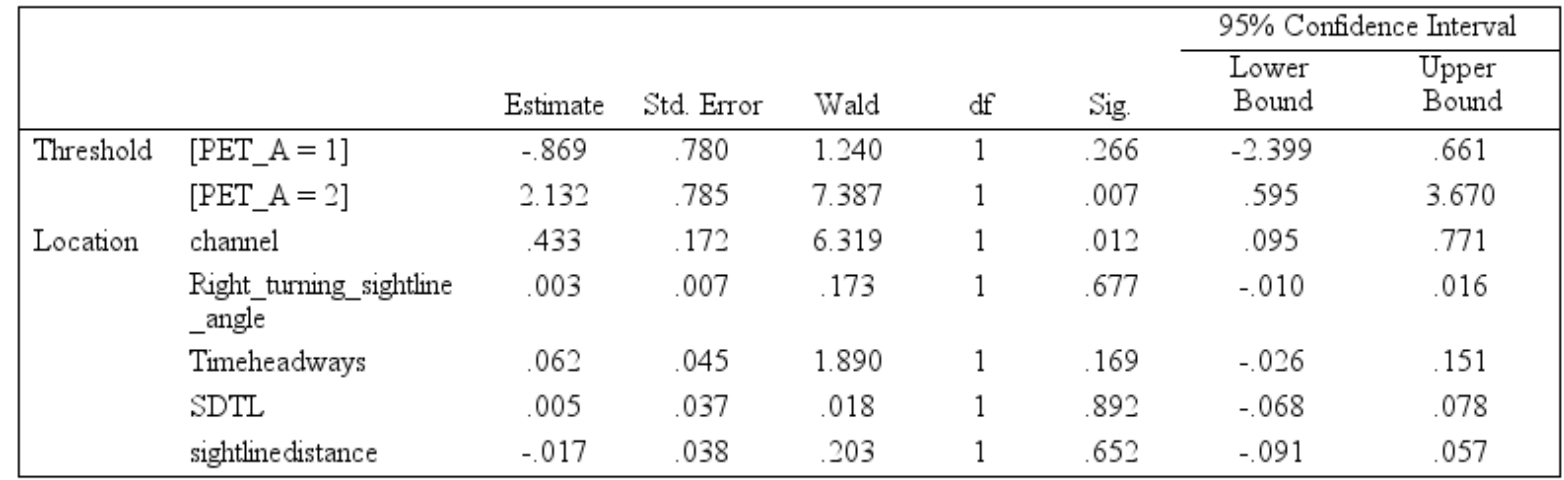

Link function: Logit.

Excluded channel location 7- remove sightline distance

Goodness-of-Fit

\begin{tabular}{|lccc|}
\hline & Chi-Square & df & Sig. \\
\hline Pearson & 1568.595 & 1566 & .477 \\
Deviance & 1425.805 & 1566 & .995 \\
\hline
\end{tabular}

Link function: Logit. 
Parameter Estimates

\begin{tabular}{|c|c|c|c|c|c|c|c|c|}
\hline & \multirow[b]{2}{*}{ Estimate } & \multirow[b]{2}{*}{ Std. Error } & \multirow[b]{2}{*}{ Wald } & \multirow[b]{2}{*}{ df } & \multirow[b]{2}{*}{ Sig. } & \multicolumn{2}{|c|}{$95 \%$ Confidence Interval } \\
\hline & & & & & & & $\begin{array}{l}\text { Lower } \\
\text { Bound }\end{array}$ & $\begin{array}{l}\text { Upper } \\
\text { Bound }\end{array}$ \\
\hline \multirow[t]{2}{*}{ Threshold } & {$\left[\mathrm{PET} \_\mathrm{A}=1\right]$} & -.584 & .449 & 1.690 & 1 & .194 & -1.464 & .296 \\
\hline & [PET_A = 2] & 2.417 & .459 & 27.679 & 1 & .000 & 1.516 & 3.317 \\
\hline \multirow[t]{4}{*}{ Location } & channel & .463 & .160 & 8.385 & 1 & .004 & .150 & .776 \\
\hline & $\begin{array}{l}\text { Right_turning_sightline } \\
\text { _angle }\end{array}$ & .005 & .005 & .817 & 1 & .366 & -.005 & .015 \\
\hline & Timeheadways & .063 & .045 & 1.938 & 1 & .164 & -.026 & .151 \\
\hline & SDTL & -.011 & .007 & 3.075 & 1 & .079 & -.024 & .001 \\
\hline
\end{tabular}

Link function: Logit.

\section{Excluded channel location 7- remove right turning sightline angle}

Goodness-of-Fit

\begin{tabular}{|lccc|}
\hline & Chi-Square & df & Sig. \\
\hline Pearson & 1557.985 & 1561 & .517 \\
Deviance & 1421.063 & 1561 & .995 \\
\hline
\end{tabular}

Link function: Logit.

Parameter Estimates

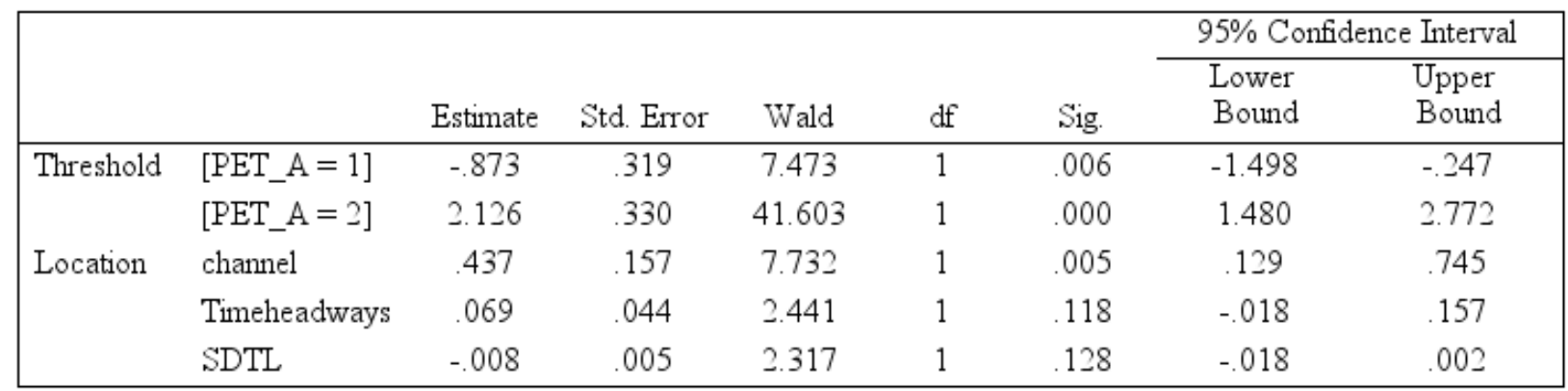

Link function: Logit.

\section{Excluded channel location 7- remove time headway}

Goodness-of-Fit

\begin{tabular}{|lccc|}
\hline & Chi-Square & df & Sig. \\
\hline Pearson & 1076.905 & 1090 & .605 \\
Deviance & 1044.995 & 1090 & .832 \\
\hline
\end{tabular}

Link function: Logit. 
Parameter Estimates

\begin{tabular}{|c|c|c|c|c|c|c|c|c|}
\hline & \multirow[b]{2}{*}{ Estimate } & \multirow[b]{2}{*}{ Std. Error } & \multirow[b]{2}{*}{ Wald } & \multirow[b]{2}{*}{ df } & \multirow[b]{2}{*}{ Sig. } & \multicolumn{2}{|c|}{$95 \%$ Confidence Interva } \\
\hline & & & & & & & $\begin{array}{l}\text { Lower } \\
\text { Bound }\end{array}$ & $\begin{array}{l}\text { Upper } \\
\text { Bound }\end{array}$ \\
\hline \multirow[t]{2}{*}{ Threshold } & {$\left[\mathrm{PET} \_\mathrm{A}=1\right]$} & -1.127 & .276 & 16.705 & 1 & .000 & -1.668 & -.587 \\
\hline & {$[$ PET_A $=2]$} & 1.864 & .283 & 43.285 & 1 & .000 & 1.309 & 2.419 \\
\hline \multirow[t]{2}{*}{ Location } & channel & .370 & .151 & 6.013 & 1 & .014 & .074 & .666 \\
\hline & SDTL & -.004 & .005 & .739 & 1 & .390 & -.013 & .005 \\
\hline
\end{tabular}

Link function: Logit. 